\title{
WestVirginiaUniversity
}

THE RESEARCH REPOSITORY @ WVU

Graduate Theses, Dissertations, and Problem Reports

2005

\section{Reservoir characterization using intelligent seismic inversion}

\author{
F. Emre Artun \\ West Virginia University
}

Follow this and additional works at: https://researchrepository.wvu.edu/etd

\section{Recommended Citation}

Artun, F. Emre, "Reservoir characterization using intelligent seismic inversion" (2005). Graduate Theses, Dissertations, and Problem Reports. 1620.

https://researchrepository.wvu.edu/etd/1620

This Thesis is protected by copyright and/or related rights. It has been brought to you by the The Research Repository @ WVU with permission from the rights-holder(s). You are free to use this Thesis in any way that is permitted by the copyright and related rights legislation that applies to your use. For other uses you must obtain permission from the rights-holder(s) directly, unless additional rights are indicated by a Creative Commons license in the record and/ or on the work itself. This Thesis has been accepted for inclusion in WVU Graduate Theses, Dissertations, and Problem Reports collection by an authorized administrator of The Research Repository @ WVU. For more information, please contact researchrepository@mail.wvu.edu. 


\title{
RESERVOIR CHARACTERIZATION USING INTELLIGENT SEISMIC INVERSION
}

\author{
F. Emre Artun \\ Thesis submitted to the \\ College of Engineering and Mineral Resources \\ at West Virginia University \\ in partial fulfillment of the requirements \\ for the degree of \\ MASTER OF SCIENCE \\ IN \\ PETROLEUM AND NATURAL GAS ENGINEERING
}

Shahab Mohaghegh, Ph.D., Chair

Sam Ameri, M.S.

Razi Gaskari, Ph.D.

Grant Bromhal, Ph.D.

Morgantown, West Virginia

2005

Keywords: Artificial neural networks, Buffalo Valley Field, intelligent systems, reservoir characterization, seismic inversion, synthetic seismic modeling, vertical seismic profile, well logs. 


\title{
Abstract \\ RESERVOIR CHARACTERIZATION USING INTELLIGENT SEISMIC INVERSION
}

\author{
F. Emre Artun
}

Integrating different types of data having different scales is the major challenge in reservoir characterization studies. Seismic data is among those different types of data, which is usually used by geoscientists for structural mapping of the subsurface and making interpretations of the reservoir's facies distribution. Yet, it has been a common aim of geoscientists to incorporate seismic data in high-resolution reservoir description through a process called seismic inversion. Using geostatistical models in this kind of studies becomes insufficient in dealing with the uncertainty and the non-linearity, because of the stationarity assumption of variogram models. As an alternate, soft computing has been widely used in reservoir characterization, as a method which is tolerant of uncertainty, imprecision, and partial truth.

In this study, a new intelligent seismic inversion methodology is presented to achieve a desirable correlation between relatively low-frequency seismic signals, and the much higher frequency wireline-log data. Vertical seismic profile (VSP) is used as an intermediate step between the well logs and the surface seismic. A synthetic seismic model is developed by using real data and seismic interpretation. This model represents the Atoka and Morrow formations, and the overlying Pennsylvanian sequence of the Buffalo Valley Field in New Mexico. Generalized regression neural network (GRNN) is used to build two independent correlation models between; 1) Surface seismic and VSP, 2) VSP and well logs. After generating virtual VSP's from the surface seismic, well logs are predicted by using the correlation between VSP and well logs. The values of the density log, which is a surrogate for reservoir porosity, are predicted for each seismic trace through the seismic line with a classification approach, having a correlation coefficient of 0.81 . The same methodology is then applied to real data taken from the Buffalo Valley Field, to predict interwell gamma ray logs and neutron porosity logs through the seismic line of interest. The same procedure can be applied to a complete 3D seismic block to obtain 3D distributions of reservoir properties with less uncertainty than the geostatistical estimation methods, which would hopefully help to increase the success of drilling new wells during field development. 
To my mother, Nilgün; my father, Bilsel; and my sister, Selin. 


\section{Acknowledgements}

First of all, I would like to express my sincere gratitude and appreciation to my advisor, Prof. Shahab Mohaghegh, for his endless support and guidance during my studies. He has not been only a great advisor, but also a mentor and a friend to me, and wherever I go through out my future career, I will carry on the fundamentals and professionalism that he taught me.

I would like to extend my appreciation to Prof. Jaime Toro, Prof. Tom Wilson, and Alejandro Sanchez, for their cooperation to make this multidisciplinary work achieve its goals. I am also so grateful to my committee members; Prof. Sam Ameri, Dr. Razi Gaskari, and Dr. Grant Bromhal, for their support and valuable suggestions. I would also like to thank Prof. Ilkin Bilgesu, for his friendship and support during my stay in Morgantown. Mrs. Ruth Long, Prof. Erdogan Gunel, and Mrs. Janis Gunel were like a second family to me, and I am thankful for that.

I feel very lucky that I have such wonderful friends around me. I have shared many great moments that will always be remembered with my colleagues and office mates; Jalal Jalali, Nikola Maricic, Miguel Tovar, Luisa Rolon, Erich Schlitt, Janaina Pereira, Chris Zinn, and Kazim Malik. I am thankful to Cem Ersahin, and Dr. Ibrahim Yavuz, who were always there whenever I needed someone to talk with, or to ask for some help for either technical or non-technical issues. An old friend, Hakan Gürgenli, was with me during the second year of my studies, and I am thankful for his friendship. I would like to thank Sinan Yaykin, for his great friendship, and for bringing Besiktas to Morgantown live, and uncut. And, of course, I am thankful to the members of legendary TED-Mania: Mehmet Tarman, Umut Gökcesu, Omer Izgeç, and Burak Kaynak, for being great friends, even though they are all around the world.

Finally, I would like to thank my family, who had full support and belief in me in every stage of my life. 


\section{Contents}

Abstract

Acknowledgements $\quad$ iv

1 Introduction and Motivation 1

1.1 Statement of the Problem . . . . . . . . . . . . . . . . . . 1

1.2 Literature Review . . . . . . . . . . . . . . . . 2

1.2.1 Intelligent Reservoir Characterization . . . . . . . . . . . 2

1.2 .2 Seismic Inversion . . . . . . . . . . . . . . . . . 5

1.3 Structure of the Thesis . . . . . . . . . . . . . . . . 7

2 Theoretical Background 9

2.1 Seismic Surveys . . . . . . . . . . . . . . . . . . . 9

2.1 .1 The Seismic Method . . . . . . . . . . . . . 9

2.1.2 Seismic Principles . . . . . . . . . . . . . . . . . 11

2.1.3 Vertical Seismic Profiling (VSP) . . . . . . . . . . . . . 13

2.1.4 Seismic Attributes . . . . . . . . . . . . . . . . 16

2.1.5 Synthetic Seismic Modeling . . . . . . . . . . . . . . 18

2.2 Artificial Neural Networks . . . . . . . . . . . . . . . . . . . . . . . . 18

2.2.1 Biological Neural Networks . . . . . . . . . . . . . . . 18

2.2.2 Introduction to Artificial Neural Networks . . . . . . . . . . . . . . . 21

2.2.3 Generalized Regression Neural Network (GRNN) . . . . . . . . . . 23

2.3 Correlation Statistics . . . . . . . . . . . . . . . . . . 24

3 Synthetic Model Study 26

3.1 Model Development . . . . . . . . . . . . . . . . . . . 26 
3.2 Model Description . . . . . . . . . . . . . . . . . . 27

3.3 Model Output. . . . . . . . . . . . . . . . . . . . 28

3.4 Methodology . . . . . . . . . . . . . . . . . . 30

3.4.1 Step 1: Correlation of Surface Seismic with VSP . . . . . . . . . 30

3.4.2 Step 2: Correlation of VSP with Well Logs . . . . . . . . . . . . . . 32

4 Real Case Study: The Buffalo Valley Field 36

4.1 Location and Geological Setting . . . . . . . . . . . . . . . . . 36

4.2 Atoka and Morrow Formations . . . . . . . . . . . . . . . . 38

4.3 Available Data . . . . . . . . . . . . . . . . . . 40

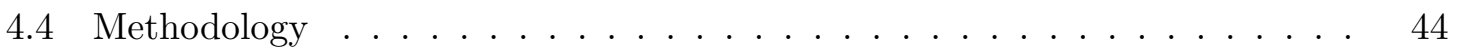

4.4.1 Step 1: Correlation of Surface Seismic with VSP . . . . . . . . . 45

4.4.2 Step 2: Correlation of VSP with Well Logs . . . . . . . . . . . . . . 46

5 Results and Discussions $\quad 50$

5.1 Synthetic Model Study . . . . . . . . . . . . . . . . . 50

5.1.1 Step 1: Correlation of Surface Seismic with VSP . . . . . . . . . 50

5.1.2 Step 2: Correlation of VSP with Well Logs . . . . . . . . . . . . . 50

5.2 Real Case Study: The Buffalo Valley Field, NM . . . . . . . . . . . . . . . 52

5.2.1 Step 1: Correlation of Surface Seismic with VSP . . . . . . . . . 52

5.2 .2 Step 2: Correlation of VSP with Well $\operatorname{Logs} \ldots \ldots$. . . . . . . . . 52

6 Concluding Remarks $\quad 77$

6.1 Conclusions . . . . . . . . . . . . . . . . . . . 77

6.2 Future Work . . . . . . . . . . . . . . . . . 78 


\section{List of Tables}

1.1 Data fusion and data mining techniques $[1] \ldots \ldots \ldots$

1.2 Comparison of geostatistical and intelligent algorithms [1] . . . . . . . . 5

2.1 Instantaneous attributes with their descriptions and applicability [16]. . . . 20

3.1 Layers and corresponding density and velocity ranges in the synthetic model. 27

3.2 Properties of wavelets used to compute seismic responses. . . . . . . . . . 28

3.3 Rearranging the data. Introducing classes, where 0: false and 1: true. . . . 35

4.1 Characteristics of Atoka and Morrow formations. . . . . . . . . . . . . . 42

4.2 Information about the wells on the selected seismic line including name, available logs with the time interval (sec.), and locations in terms of the trace number. . . . . . . . . . . . . . . . . . . . . . . . 44

4.3 Seismic attributes used for the field study. . . . . . . . . . . . . . . . 47

4.4 Ranking of the seismic attributes based on their influence on each type of log, determined by Key Performance Indicator (KPI) studies. . . . . . . . . 49

5.1 Correlation statistics for seven VSP attributes, for the first correlation step of the synthetic model study. . . . . . . . . . . . . . . . . . . . 51

5.2 Correlation statistics for density and velocity, for the second correlation step of the synthetic model study. . . . . . . . . . . . . . . . 51

5.3 Correlation statistics for eleven VSP attributes, for the first correlation step of the real case study. . . . . . . . . . . . . . . . . . . . . . . 57

5.4 Correlation statistics for the pattern, training, and calibration sets of the training model. VSP attributes were used as inputs to predict the gamma ray $\log . \ldots \ldots \ldots \ldots \ldots \ldots \ldots$ 
5.5 Correlation statistics for the pattern, training, and calibration sets of the training model. Surface seismic attributes were used as inputs to predict the

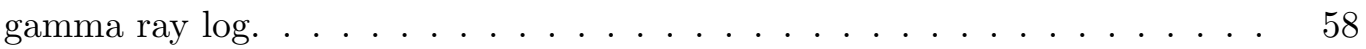

5.6 Correlation statistics for the pattern, training, and calibration sets of the training model. VSP attributes were used as inputs to predict the neutron porosity log. . . . . . . . . . . . . . . . . . . .

5.7 Correlation statistics for the pattern, training, and calibration sets of the training model. Surface seismic attributes were used as inputs to predict the neutron porosity log. . . . . . . . . . . . . . . .

5.8 Optimum smoothing factors for GRNN prediction models for the VSP attributes and $\operatorname{logs}$ for the synthetic model study. . . . . . . . . . . . . . .

5.9 Optimum smoothing factors for GRNN prediction models for the VSP attributes and $\operatorname{logs}$ for the real case study. . . . . . . . . . . . . . . 


\section{List of Figures}

1-1 Seismic inversion process. Modeling high-frequency well logs from low-frequency

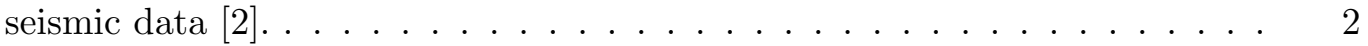

1-2 Reservoir data mining $[1] \ldots \ldots \ldots \ldots \ldots \ldots$

1-3 Basic flow chart of seismic pattern recognition (multi-attribute analysis) [9]. 6

1-4 Proposed correlation map. Two major steps of correlation: 1) Surface seismic

- VSP, 2) VSP - well logs. . . . . . . . . . . . . . . . . . . 7

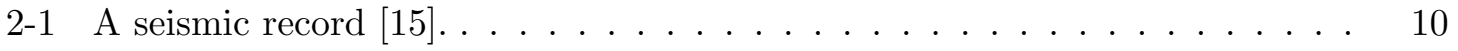

$2-2 \quad$ A seismic section $[15] \ldots \ldots \ldots \ldots \ldots \ldots \ldots$

2-3 Snell's Law. . . . . . . . . . . . . . . . . . . . . . . . . 13

2-4 Schematic view of a typical VSP survey. . . . . . . . . . . . . . . . 14

2-5 Timeline of seismic attribute analysis from 1950 to the present [9]. . . . . . 19

$2-6$ Schematic view of a bi-polar neuron $[20] \ldots \ldots \ldots \ldots \ldots \ldots \ldots$

2-7 Schematic diagram of an artificial neuron or a processing element [20]. . . . 23

3-1 Computed seismic responses (seismic sections). Top: Surface seismic responses - lower resolution, bottom: VSP responses - higher resolution. . . . 29

3-2 Cross-sectional density distribution of the synthetic model. . . . . . . . . . 31

3-3 Cross-sectional Envelope distribution which was used to determine special features that can be useful in the network training. Finally, traces 32 and 57 were decided to be used in training. . . . . . . . . . . . . . . . . . 32

3-4 Network structures used for training. Data of traces 32 and 57 have been used, to predict a VSP attribute from time and surface seismic attributes. .

3-5 Density log of trace - 50. Proposed classification: Three classes at density values $1.9,2.3$, and $2.65 \ldots \ldots \ldots \ldots \ldots$ 
3-6 Network structures used for training. Data of t-50 have been used, to predict one of the density classes from time and VSP attributes. . . . . . . . . . .

4-1 Geographical location of the Buffalo Valley Field (Pointed with a star.). . .

4-2 Southeast New Mexico and west Texas. Pennsylvanian paleography of Permian Basin. In blue dash line an approximate outline of the paleo Tobosa Basin [24] . . . . . . . . . . . . . . . . . . . . .

4-3 Generalized stratigraphic section of the Northwest Shelf areas in the Permian Basin, with the cumulative gas and oil production from the major reservoirs of Pennsylvanian plays [24]. . . . . . . . . . . . . . . . .

4-4 Regional stratigraphic cross section of the Upper Mississippian, Lower Pennsylvanian, and Lower Permian Sequence in the Buffalo Valley Field [24]. . . 41

4-5 An illustration of logs having good and bad qualities. . . . . . . . . . . . . 43

4-6 Map of wells available logs within the seismic survey area of the Buffalo Valley Field. The seismic line chosen to work with, and the five wells on that line are highlighted. . . . . . . . . . . . . . . .

4-7 Amplitude distribution of the seismic line. Red dashed lines are the five wells that the line is passing through. Well-1 is the well with the VSP survey. . .

4-8 Network structures used for training. Data of well-1 have been used, to predict a VSP attribute from time and surface seismic attributes. . . . . . .

4-9 Network structures used for training. Data of all wells have been used, to predict gamma ray and neutron porosity logs from time and VSP attributes.

5-1 Actual vs. network results for each attribute after training the network for surface seismic - VSP correlation. Results for training, calibration, and verification sets are included with different symbols. . . . . . . . . . . . . .

5-2 Actual (left) and network-predicted (right) distributions for VSP attributes: amplitude, average energy, and envelope. . . . . . . . . . . . . 55

5-3 Actual (left) and network-predicted (right) distributions for VSP attributes: frequency, Hilbert transform, and paraphase. . . . . . . . . . 56

5-4 Actual (left) and network-predicted (right) distributions for VSP attribute

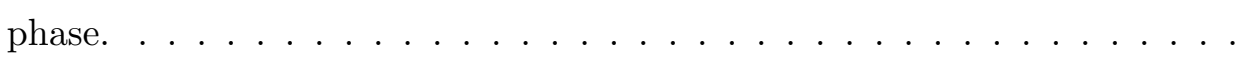


5-5 Defining density classes, and the corresponding training results. a) Three classes $(1.9,2.3,2.65)$. Training $r^{2}=0.82$, b) Four classes $(1.9,2.09,2.3$, 2.65). Training $r^{2}=0.94 \ldots \ldots \ldots \ldots \ldots$

5-6 Actual (top), and network-predicted (bottom) distributions of density values $(\mathrm{r}=0.81)$. In terms of classes; $87 \%$ of the data points have been predicted

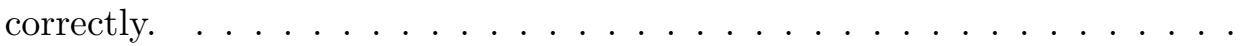

5-7 Actual (left), and network-predicted (right) distributions of velocity (top), and acoustic impedance (bottom) . . . . . . . . . . . . . . .

5-8 Actual vs. network plots for frequency and signed frequency shown as logs. Although having relatively low correlation coefficient values, visual plots show

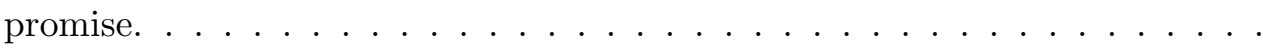

5-9 Actual vs. network plots for phase and paraphase shown as logs. Although having relatively low correlation coefficient values, visual plots show promise.

5-10 Actual vs. network plots for seven of the attributes, that had satisfactory correlation statistics. Training, calibration, and verification sets are included with different symbols and colors. . . . . . . . . . . . . . . .

5-11 Actual and network-predicted gamma ray $\operatorname{logs}$ for wells 1 , 2, and 3. Values for training, and calibration sets are included. VSP attributes were used as inputs. . . . . . . . . . . . . . . . . .

5-12 Actual and network-predicted gamma ray logs for wells 4, and 5. Values for training, and calibration sets are included. VSP attributes were used as inputs. 66

5-13 Network-predicted gamma ray distribution through the seismic line of interest. Actual log lines are also shown for five wells on the line. VSP attributes were used as inputs. . . . . . . . . . . . . . . . . .

5-14 Actual and network-predicted gamma ray logs for wells 1, 2, and 3. Values for training, and calibration sets are included. Surface seismic attributes were used as inputs. . . . . . . . . . . . . . . . . .

5-15 Actual and network-predicted gamma ray logs for wells 4, and 5. Values for training, and calibration sets are included. Surface seismic attributes were used as inputs. . . . . . . . . . . . . . . . . . . .

5-16 Network-predicted gamma ray distribution through the seismic line of interest. Actual log lines are also shown for five wells on the line. Surface seismic attributes were used as inputs. . . . . . . . . . . . . . 
5-17 Actual and network-predicted neutron porosity logs for wells 1, and 2. Values for training, and calibration sets are included. VSP attributes were used as inputs. . . . . . . . . . . . . . . . . . .

5-18 Actual and network-predicted neutron porosity logs for wells 1, and 2. Values for training, and calibration sets are included. Surface seismic attributes were used as inputs. . . . . . . . . . . . . . . . . . .

5-19 Network-predicted gamma ray distribution through the seismic line of interest. Actual log lines are also shown for two wells on the line. VSP attributes were used as inputs. . . . . . . . . . . . . . . . . .

5-20 Network-predicted gamma ray distribution through the seismic line of interest. Actual log lines are also shown for two wells on the line. Surface seismic attributes were used as inputs. . . . . . . . . . . . . . . . 


\section{Chapter 1}

\section{Introduction and Motivation}

\subsection{Statement of the Problem}

Reservoir characterization is the study of building a spatial numerical model of the reservoir by using available appropriate data gathered from previous studies. This numerical model is then used in flow simulators, which are used to predict the reservoir performance. Field development plans are mainly based on these predictions. That is why an accurate and reliable reservoir characterization study is indispensable in reservoir management. Due to many different types of data available; the major challenge in reservoir characterization is to integrate all different kinds of data in one accurate and high-resolution reservoir model.

The concept of data analysis forms the basis of reservoir characterization. In data analysis, many issues about the data such as the uncertainty, unreliability, and large variety of scales due to different origins of source must be taken into consideration. Together with the immense size of data to deal with, these issues bring complex problems, which are hard to address with conventional tools. That is why unconventional computation tools have gained much interest in data analysis in recent years. Among those modern tools, the use of intelligent systems is an example, which mimics the mechanism of the human mind

and, by which it is possible to deal with imprecision and partial truth [1]. Since the same issues also apply to data that is used in reservoir characterization, it should not surprise us that using intelligent systems in reservoir characterization studies has become a widely-used method in the petroleum engineering literature.

Let's consider different types of data used in reservoir characterization: core samples provide very high resolution information about the reservoir (fraction of inches), while seismic data have a resolution in tens of feet, and well logs have in one of inches. Because 
of its low resolution, seismic data is routinely used only to attain a structural view of the reservoir. On the other hand, unlike core samples or well logs, which are only available at isolated localities of a reservoir, seismic data frequently provides $3 \mathrm{D}$ coverage over a large area. Because of this areal coverage, researchers have always aimed to use seismic data in reservoir description.

Inverse modeling of reservoir properties from the seismic data is known as seismic inversion in the literature. The process presented in this study includes modeling of the well logs from seismic data, which is also an inverse modeling process (Figure 1-1). This approach attracts a lot of interest and is very important because of the necessary shift from exploration to development of existing fields [2].

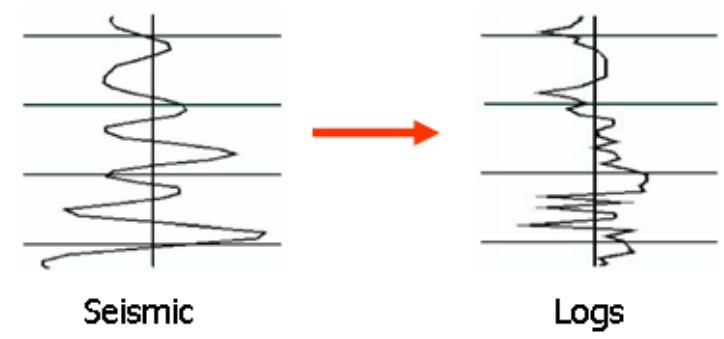

FiguRE 1-1: Seismic inversion process. Modeling high-frequency well logs from lowfrequency seismic data [2].

\subsection{Literature Review}

\subsubsection{Intelligent Reservoir Characterization}

Reservoir characterization is a data-driven business. The common aim is to develop an accurate reservoir model by making the best use of the available data. Issues like uncertainty, size of the data to deal with, unreliability, and the data coming from different sources bring the need of using unconventional tools such as soft computing. Some statistics basically show how applying these new technologies can improve success of petroleum engineering applications. The rate of success in exploration has risen to $40 \%$ in 1990 from $30 \%$ in the 1980s. Oil and gas well drilling success has risen to an average of 47\% in 1996 from 3-30\% in the early 1990s. The U.S. gas production is expected to increase 2 trillion cubic feet 
(Tcf)/yr, and the U.S. oil production is expected to increase 100 million bbls/yr by using these new techniques in data acquisition. In general; these techniques can be useful in reducing costs and risks of exploration, and having more efficient production of remaining oil and gas to increase the producing life of reservoirs [1].

As the problems in reservoir characterization get more complex with the multi-dimensional, chaotic and imprecise data; they get harder to solve with the scope of human ability and understanding. The classical data processing tools are becoming insufficient to deal with such kinds of problems. Nikravesh and Aminzadeh [1] have made a list of data fusion and data mining techniques, which are being replaced with the conventional tools (Table 1.1).

TABle 1.1: Data fusion and data mining techniques [1].

Data mining techniques Data fusion techniques

Deductive database client Deterministic:

Trasform-based, functional evaluation-based,

Inductive learning correlation-based, optimization-based, ...

Clustering Non-deterministic:

Hypothesis testing, statistical estimation, discrimination

Case-based learning function, neural network, fuzzy logic, ...

Visualization Hybrid:

Statistical package

Genetic algorithms, Bayesian network, ...

They have defined the reservoir data mining concept with the chart shown in Figure 1-2, which shows the main components of an integrated reservoir characterization study. They have classified the algorithms as rockphysical, geostatistical, and intelligent, which can be used to obtain the reservoir properties from other sources of data such as seismic. They have given examples for intelligent algorithms as; using supervised and unsupervised training of artificial neural networks, clustering, genetic algorithms (GA), and simulated annealing (SA). A comparison of geostatistical and intelligent algorithms is made in Table 1.2 .

Intelligent algorithms have been used by many researchers in reservoir characterization. One of the common applications is generating synthetic logs for undrilled locations by using available log data gathered from existing wells. In other words, this process is logging a well 
prior to drilling, which may help to make decisions on locations of the development wells.

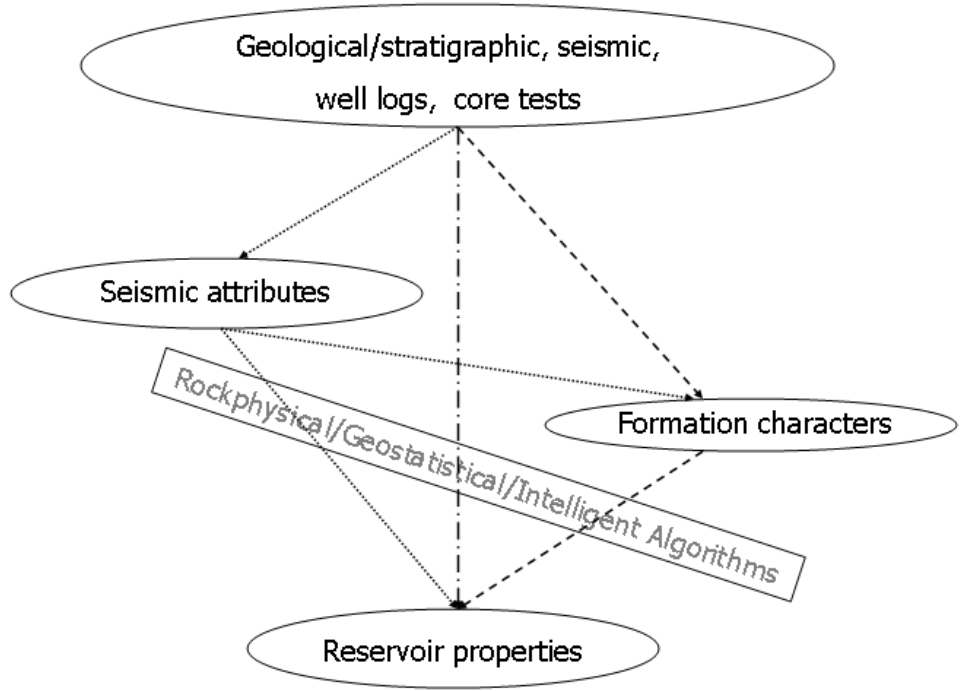

FiguRE 1-2: Reservoir data mining [1].

Mohaghegh et al. [3; 4] generated virtual magnetic resonance imaging (MRI) logs which are useful in determining the critical parameters for reserve estimations such as; water saturation, porosity and permeability. They have used available conventional logs such as gamma ray, spontaneous potential (SP), caliper, density and resistivity. The neural network is trained with the data of wells having all of these logs including the MRI logs. The obtained neural network model is then applied to other wells in the field to generate virtual MRI logs. In a similar study, among gamma ray, resistivity, density and neutron logs, Rolon [5] generated synthetic density, resistivity and neutron logs separately by using other three types of logs.

Another common application is estimating permeability by using logs and cores for network training. Mohaghegh et al. [6] developed a back-propagation neural network model with the permeability gathered from core samples as output, and gamma ray, density and deep induction logs as inputs. The model has successfully predicted the permeability values for the locations, which were not included in the training data of the neural network. In another study, Arpat et al. [7] estimated permability using porosity, water saturation, depth, 
TABLE 1.2: Comparison of geostatistical and intelligent algorithms [1].

\begin{tabular}{lll} 
& Geostatistical & Intelligent \\
\hline Data: & $\begin{array}{l}\text { Data assumption: a certain } \\
\text { probability distribution }\end{array}$ & $\begin{array}{l}\text { Data automatic clustering and } \\
\text { expert-guided segmentation } \\
\text { classification of relationship } \\
\text { between data and targets }\end{array}$ \\
Model: & $\begin{array}{l}\text { Weight functions come from } \\
\text { variogram trend, stratigraphic } \\
\text { facies, and probability constraints }\end{array}$ & $\begin{array}{l}\text { Weight functions come from } \\
\text { supervised training based on } \\
\text { geological and stratigraphic information }\end{array}$ \\
& Stochastic, not optimized & Optimized by GA, SA, ANN, and BN. \\
\hline
\end{tabular}

and percentages of shale, dolomite and limestone as inputs. They have also used backpropagation algorithm for training, and they have introduced a neighborhood approach, which uses upper and lower neighbor data points as well in the input layer. As a different type of application, Weiss et al. [8] estimated bulk volume oil and oil production rate for the first year in the Lower Brushy Canyon, by using LLD, LLS, density porosity, and neutron porosity as inputs. They have selected those types of logs after applying fuzzy ranking to all available logs.

Using intelligent systems in reservoir characterization is getting more common each day, as the oil industry realizes the power of such kinds of tools, and their applicability in petroleum engineering. Many applications other than the ones presented here can be found in the petroleum engineering literature.

\subsubsection{Seismic Inversion}

Incorporating seismic data in reservoir description studies has attracted a lot of interest through out the years. Barnes [9] recently summarized the modern seismic pattern recognition process, which includes feeding a set of seismic attributes together with other types of data such as logs to obtain information about the reservoir facies distribution, lithology and other reservoir properties. The flow chart of this process includes using a black-box algorithm such as neural networks as a prediction or classification tool (Figure 1-3). 


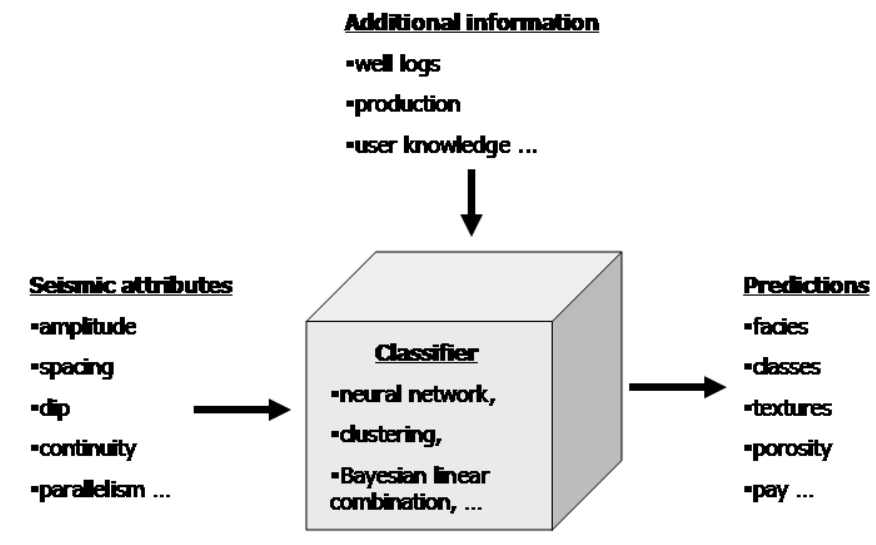

FiguRE 1-3: Basic flow chart of seismic pattern recognition (multi-attribute analysis) [9].

Seismic inversion has been applied by several authors with different approaches. Hampson et al. [2] and Leiphart and Hart [10] have compared different techniques such as multiple linear regression, backpropagation and probabilistic neural networks. They have predicted porosity logs from seismic attributes and both have suggested probabilistic neural networks to use in this type of problems considering its mathematical simplicity and success.

Balch et al. [11] have used fuzzy ranking to see which type of seismic attribute is related to the target reservoir property. They have modeled correlations between those selected attributes and porosity, water saturation and net pay thickness by using a backpropagation neural network. Chawathe et al. [12] used neural networks to predict gamma ray log from seismic attributes; amplitude, phase, frequency, reflection strength, and quadrature. However, they have used higher-resolution crosswell seismic data instead of surface seismic as a new approach. Soto and Holditch [13] have used the same types of attributes from surface seismic to predict the gamma ray log with neural networks.

Reeves et al. [14] introduced a new methodology, which divides the whole seismic inversion problem into two parts. They have considered cross-well tomography as an intermediate step in their procedure, after finding a correlation between surface seismic and cross-well seismic. They have suggested producing virtual cross-well seismic data, before dealing with logs. Giving Chawathe et al.'s [12] work as an example, they stated that, well logs can 
easily be predicted from virtual cross-well seismic data. According to the authors, using crosswell seismic as an intermediate scale data can provide improved vertical resolution, increase constraints and reduce the uncertainty of reservoir description.

In this study, a similar methodology is followed. Instead of cross-well seismic which is rather hard to obtain, vertical seismic profile (VSP) is incorporated into the study as the intermediate scale data (Figure 1-4). This is due to the fact that VSP is available more frequently, and is less expensive to obtain than cross-well tomography. It is a common type of data that can be found in many fields.

Together with integrating a third type of data, another unique feature of this study was developing a synthetic model and its integration in the research, before dealing with real data. Having a synthetic seismic model that we had the full control of, gave the opportunity to develop and test the proposed methodology better before applying it to real data. This model represents the gas producing Atoka and Morrow formations with the overlying Pennsylvanian sequence of the Buffalo Valley Field in New Mexico. Surface seismic and VSP responses of this model are computed. Artificial neural networks are used to develop two independent correlation models between; 1) Surface seismic and VSP, 2) VSP and well logs. Density log has been selected as the target log, and is predicted from the seismic line. In the second case, field data have been used and gamma ray and neutron porosity distributions are produced through a seismic section.

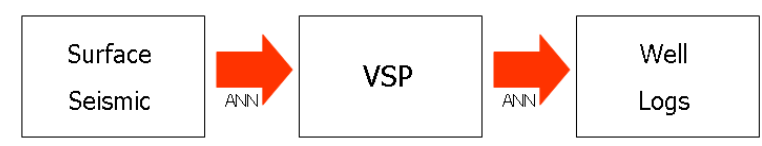

Figure 1-4: Proposed correlation map. Two major steps of correlation: 1) Surface seismic - VSP, 2) VSP - well logs.

\subsection{Structure of the Thesis}

This thesis includes 6 chapters:

- Chapter 1 is the current introduction chapter, which includes the statement of the problem, literature review, and the structure of the thesis. 
- Chapter 2 is named as 'Theoretical Background' and it includes explanation of concepts; seismic surveys, artificial neural networks, and basic correlation statistics based on the methodology followed in this study.

- Chapter 3 and Chapter 4 are the chapters, which contain detailed analysis of the synthetic model study, and the field study, respectively. Background information, available data, and methodologies are explained in these chapters.

- Chapter 5 is the 'Results and Discussions' chapter, and it includes all results obtained from two studies explained in Chapters 3 and 4, as well as their discussions.

- Chapter 6: 'Concluding Remarks' is the last chapter. The major conclusions of this study, and potential future work is explained in that chapter. 


\section{Chapter 2}

\section{Theoretical Background}

\section{$2.1 \quad$ Seismic Surveys}

\subsubsection{The Seismic Method}

The seismic method is the most widely used tool in the exploration of hydrocarbon reservoirs. It is a common method to obtain a structural view of the subsurface geology. The basic theory of the seismic method is based on the movements of signals through the subsurface. Seismic surveys are usually done by two types of methods [15]:

1. Refraction Method: is useful in identifying rock units with acoustic velocity. It can be used in detailing rock structure of deep, high-velocity carbonate and evaporite sediments.

2. Reflection Method: is used relatively more than the refraction method, and it is useful in identifying formation tops.

Before understanding the theory of the seismic method, some key terms should be understood clearly. A seismic trace is the response of a single seismic detector to the earth's movement due to seismic energy. If these traces are displayed side-by-side, then it is a seismic record (Figure 2-1). A processing stage comes after obtaining a seismic record, to enhance the signal, to minimize noise and increase the resolution. These processed images are then put together to produce the final output of the seismic survey: a seismic section (Figure 2-2) [15]. 


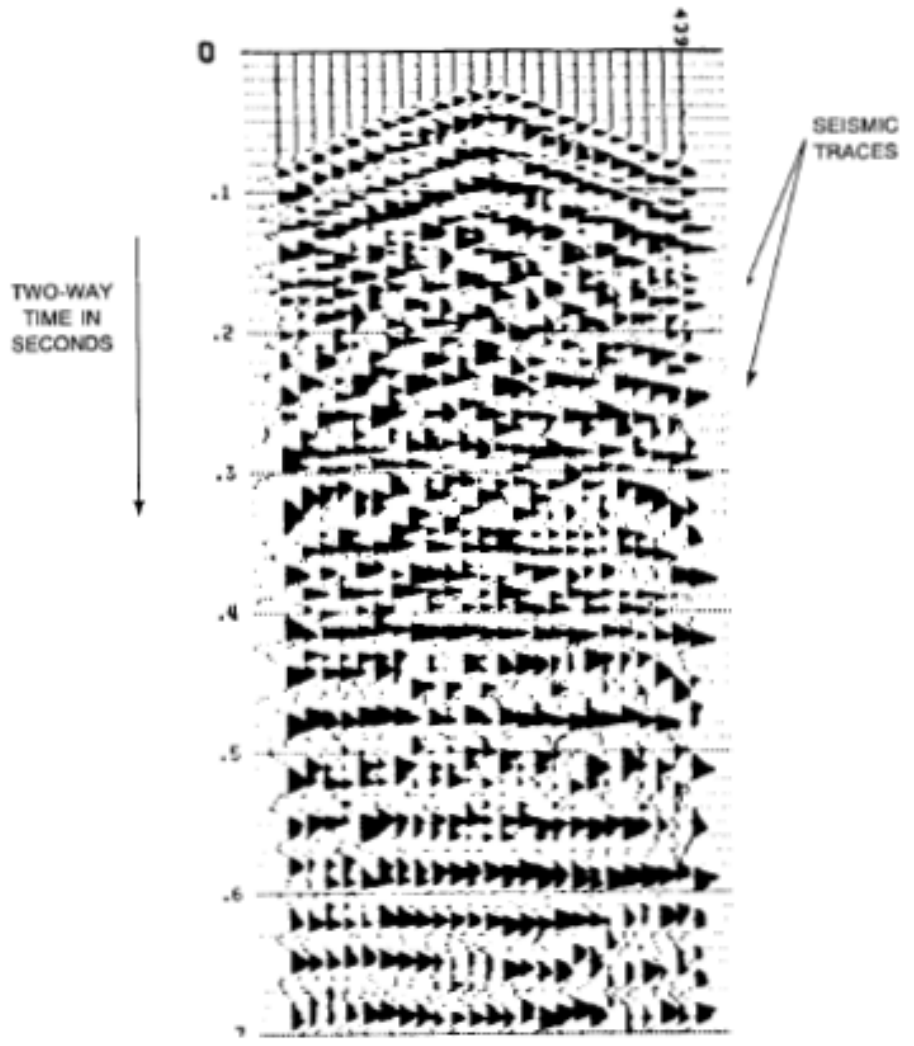

Figure 2-1: A seismic record [15]. 


\subsubsection{Seismic Principles}

When a pebble is dropped into the water, one can observe waves propagated away from the center, creating definite circles, which get larger and larger in diameter. The same process can be observed in the vertical plane, which shows that wave propagation is a three-dimensional phenomenon. Seismic wave propagation works out in the same way. Once the seismic energy is induced to the ground by a vibrating or explosive source, energy propagates through the layers of the earth. Considering the waves moving away from the center, the leading wave is called the wave front [15].

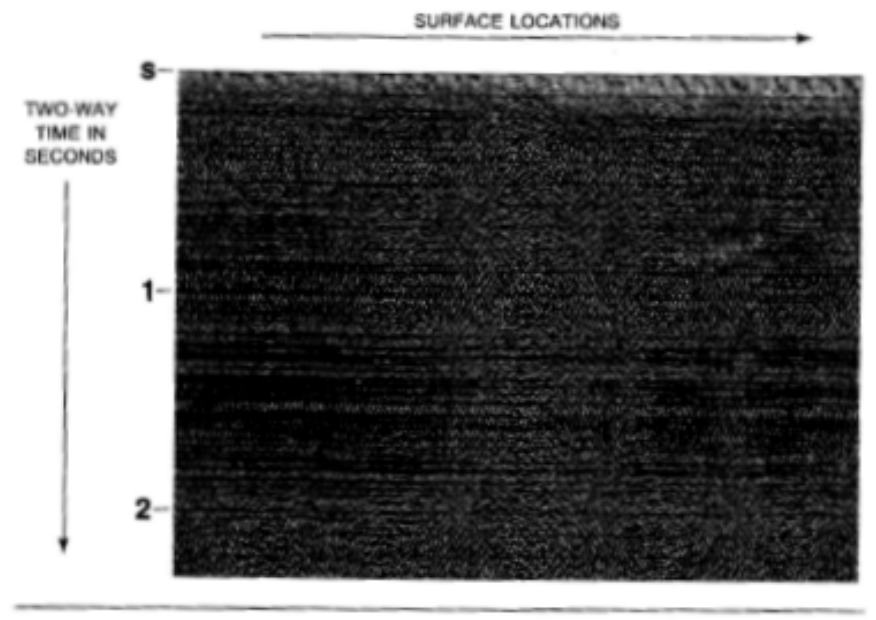

FIGURE 2-2: A seismic section [15].

If the propagating wave strikes a boundary between two media having different velocities, part of the energy is reflected from the boundary, and the remainder is transmitted into the next layer. This way, the energy is divided into various components. These relative portions of the energy transmitted and reflected are determined by the contrast in the acoustic impedances of the rock layers on each side. Acoustic impedance, $Z$, is the product of the density, $\rho$, and the velocity, $v$, of the rock, and it is usually higher when the rock is harder.

If we consider a ray of amplitude $A_{0}$ which is normally incident on an interface between two media differing in velocities and densities, a transmitted ray (having amplitude $A_{1}$ ) would travel through the interface in the same direction, and the reflected ray of amplitude 
$A_{2}$ would return to the source. The reflection coefficient, $R$ is defined as the ratio of the amplitude $A_{1}$ of the reflected ray, to the amplitude $A_{0}$ of the incident ray. In terms of acoustic impedances, for a normally incident ray, Zeoppritz's equation states that:

$$
R=\frac{Z_{2}-Z_{1}}{Z_{2}+Z_{1}}
$$

where; $Z_{1}$ and $Z_{2}$ are the acoustic impedances of the first and second layers respectively. This equation can also be written in terms of the velocity and density as;

$$
R=\frac{\left(\rho_{2} v_{2}-\rho_{1} v_{1}\right)}{\left(\rho_{2} v_{2}+\rho_{1} v_{1}\right)}
$$

Another term is the transmission coefficient, which is the ratio of the amplitude transmitted to the incident amplitude:

$$
T=\frac{A_{2}}{A_{0}}
$$

\section{Snell's Law}

Snell's Law describes the relationship between the velocities and the angles which the rays make before being reflected and after being transmitted through the next layer. After a portion of the ray is reflected from the boundary, remaining portion is transmitted to the next layer by changing its direction and is called the refracted ray. Snell's Law states that; the ratio of the angle, $\theta$, to the velocity is constant:

$$
\sin \theta_{1} / V_{1}=\sin \theta_{2} / V_{2}
$$

or;

$$
\sin \theta_{1} / \sin \theta_{2}=V_{1} / V_{2}
$$

Snell's Law is illustrated in Figure 2-3. 


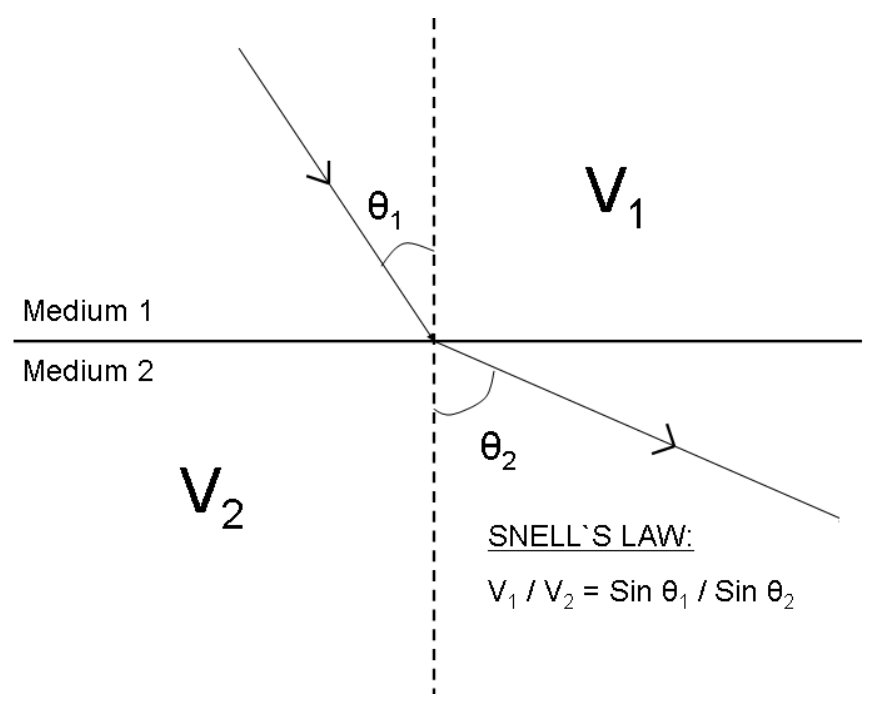

FiguRE 2-3: Snell's Law.

\subsubsection{Vertical Seismic Profiling (VSP)}

Vertical seismic profiling differs from conventional seismic surveys with the location of signal receivers. In VSP surveys, the receivers are located in the borehole instead of surface. By this way, signals moving towards up or down can be both received. This is the theory behind higher resolution of data (approximately 2 times larger) gathered with VSP comparing to data gathered with surface seismic. Figure 2-4 is schematic view of how VSP surveys are conducted. VSP surveys are very similar to velocity surveys in terms of where the sources and receivers are located. However, they differ from each other with two issues [15]:

1. The distance between geophone recording depths (smaller in VSP, every 15-40 meters)

2. Collection of information (Only first break times are collected in velocity surveys. In VSP, upgoing and downgoing events are also collected.)

The basic components required for a VSP survey are; 1) a borehole, 2) an energy source, 3) a downhole geophone, and 4) a recording system. For each of these components, the required conditions must be met to conduct a VSP survey.

\section{Borehole}

In a vertical well, interpreting the results of a VSP survey is much easier. If the well is deviated, then an accurate deviation survey should be conducted before the survey. A 
survey in a deviated well has some advantages, such as better lateral resolution of the subsurface beneath the borehole.

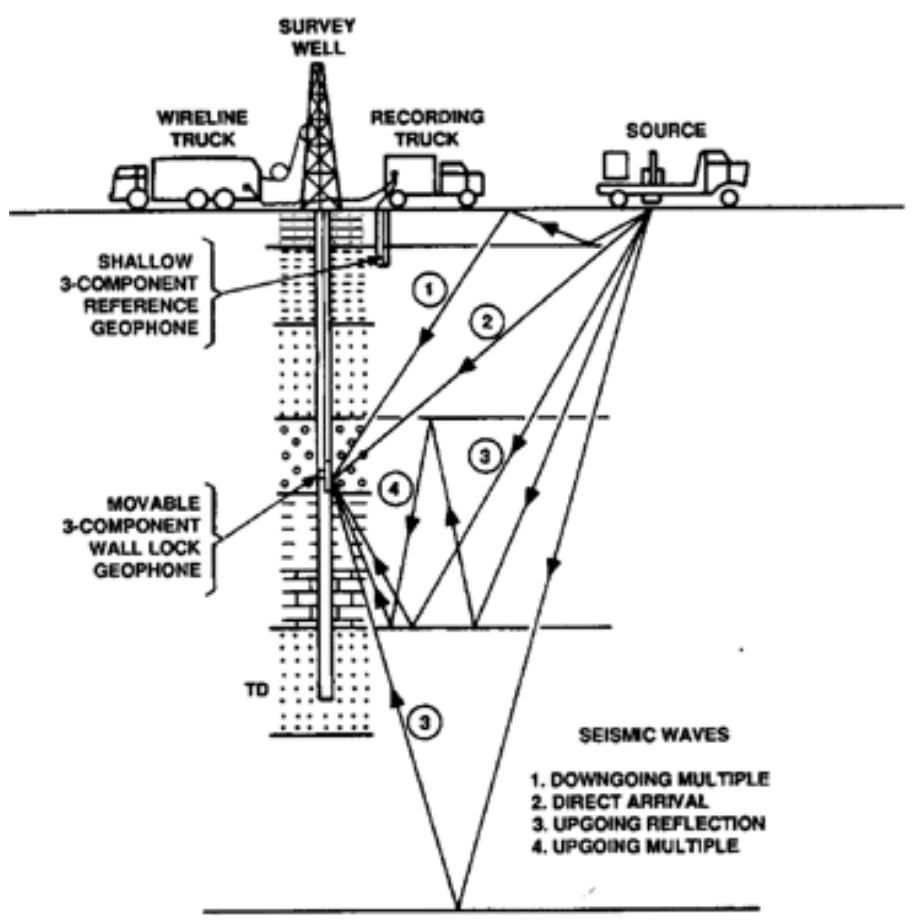

FiguRE 2-4: Schematic view of a typical VSP survey.

In terms of casing and cementing, the important issue is to make sure that seismic waves are transmitted across the borehole/formation interface to the downhole geophone with minimum waveform character distortion. A cased hole is ideal for that purpose in the case that it is cemented as cement is a good transmitter of the seismic energy. In the case of an uncased hole, it is recommended to determine the recording depths after analyzing the caliper log. In the order of preference; four common borehole environments can be listed as;

1. Single casing, cemented.

2. Uncased.

3. Single casing, uncemented, old enough for mud and cuttings in annulus to have solidified. 
4. Recently cased, uncemented.

In terms of data, a well having different types of logs, core samples, and drill cuttings should be preferred for a VSP survey to a well having less amount of data.

\section{Energy Source}

VSP is usually used to be correlated with the surface seismic. Therefore, they should have the same wavelet and high-frequency content. In general, this correlation happens after the data processing stage.

The energy source must generate a consistent and repeatable shot wavelet. Its output level should be carefully selected for optimum response. In all VSP surveys, the downgoing events are stronger than the upgoing ones. If the output strength us increased, more downgoing events would be created. The increase in the number and amplitude of the downgoing events must be greater than the gain of the amplitude of the upgoing events.

The most common surface energy sources for VSP surveys are dynamites, mechanical impulse sources, vibrators, and air guns.

\section{The Downhole Geophone}

The downhole geophone is very different than the geophones designed for surface. They are carried within a massive housing, which makes the geophone resistant to high pressure, and high temperature.

\section{The Recording System}

Resolution, dynamic gain, and recording format are the important issues that need to meet the standards for a VSP survey. The responses should be recorded with enough resolution to be able to capture high-resolution wavelets.

By Gadallah [15], common applications of VSP surveys are listed as;

1. Exploration applications

- Determining reflection coefficients.

- Identification of seismic reflectors.

- Comparison of VSP with synthetic seismogram. 
- Fresnel zone and VSP horizontal resolution.

- Seismic amplitude studies.

- Determining physical properties of the rocks.

- Seismic wave attenuation.

- Thin bed stratigraphy.

2. Reservoir engineering and drilling applications

- Predicting depths of seismic reflectors.

- Predicting rock conditions ahead of the bit.

- Defining reservoir boundaries.

- Locating faults.

- Monitoring secondary recovery processes.

- Seismic tomography and reservoir description.

- Predicting high-pressure zones ahead of the bit.

- Detection of man-made fractures.

\subsubsection{Seismic Attributes}

According to Chen [16]; seismic attributes are specific measurements of geometric, kinematic, dynamic, or statistical features derived from seismic data. Similarly, they can be defined as all the information obtained from seismic data, either by direct measurements or by logical or experience-based reasoning. Since their introduction in the early 1970's, complex seismic trace attributes have gained considerable popularity, first as a convenient display form, and later, as they were incorporated with other seismically-derived measurements, they became a valid analytical tool for reservoir characterization. The study and interpretation of seismic attributes provide us with some qualitative information of the geometry and the physical parameters of the subsurface [17]. Many different methods have been used to invent and compute hundreds of seismic attributes. These methods include complex trace analysis, interval statistics, correlation measures, Fourier analysis, time-frequency analysis, wavelet transforms, principal components, and various empirical

methods [9]. Detailed explanations of instantaneous attributes are shown in Table 2.1. The attributes which are used in this study can be defined as; 
Trace amplitude: The instantaneous amplitude is the measure of the strength of the reflected signal. Indicates changes in physical properties of various lithological entities. It can sometimes be used to detect gas presence [12]. There are two important features of instantaneous amplitude:

1. Instantaneous amplitude is not simply the magnitude of the real seismic trace, which is a popular concept for measuring the amplitude of seismic data.

2. The maximum of the instantaneous amplitude function does not necessarily occur at the maximum amplitude of the real seismic trace.

Instantaneous phase: Phase angles range from -180 degrees to +180 degrees. Envelope and phase are combined as polar components of a trace signal [18].

Instantaneous frequency: This attribute describes how long it takes the phase to complete 360 degrees of rotation [18].

Trace envelope: Represents the reflection strength. The envelope is independent of the phase and it relates directly to the acoustic impedance [18].

Hilbert transform: This amounts to a 90-degree phase rotation. Amplitude and Hilbert transform are combined as Cartesian components of a trace signal [18].

Paraphase: This attribute is the instantaneous phase with the predictable trend removed. As such, it assists visualizing the structural picture because phase tracks geologic boundaries [18].

Average energy: This attribute integrates the envelope between paraphase events. It highlights stratigraphic detail through energy fluctuations across traces. Values are in degrees [18].

Signed frequency: This attribute allows removal of the clip against non-positive values $[18]$.

Barnes [9] made a timeline diagram, which shows the development of seismic attribute analysis since 1950 which included the introduction of using neural networks in seismic pattern recognition in early 1990s (Figure 2-5). Key attributes are shown italicized, and representative papers are shown in diagonals in the figure. 


\subsubsection{Synthetic Seismic Modeling}

Synthetic seismic modeling is a forward modeling process. A seismic wavelet gathered from real data can be convolved with a reflection coefficient in order to simulate the seismic response. Reflection coefficient $(\mathrm{R})$ is defined above with the equation (2.1). As a result of this process, a synthetic seismic trace can be obtained. During the modeling process, the tuning thickness can be determined after the vertical resolution has been calculated with the relationship [24];

$$
V R=\frac{v}{4 f}
$$

where; $V R$ is the vertical resolution in $f t /(\sec \times H z), v$ is the interval velocity in $\mathrm{ft} / \mathrm{sec}$ and $f$ is the dominant frequency in $\mathrm{Hz}$.

\subsection{Artificial Neural Networks}

\subsubsection{Biological Neural Networks}

Artificial Neural Networks (ANN) draw much of their inspiration from the biological nervous system. It is therefore very useful to have some knowledge of the way this system is organized.

Most living creatures, which have the ability to adapt to a changing environment, need a controlling unit, which is able to learn. Higher developed animals and humans use very complex networks of highly specialized neurons to perform this task. The control unit - or brain - can be divided in different anatomic and functional sub-units, each having certain tasks like vision, hearing, motor and sensor control. The brain is connected by nerves to the sensors and actors in the rest of the body. The human brain consists of a very large number of neurons, about $10^{11}$ in average. These can be seen as the basic building bricks for the central nervous system (CNS). The neurons are interconnected at points called synapses. The complexity of the brain is due to the massive number of highly interconnected simple units working in parallel, with an individual neuron receiving input from up to 10,000 others.

The neuron contains all structures of an animal cell. The complexity of the structure and of the processes in a simple cell is enormous. Even the most sophisticated neuron 

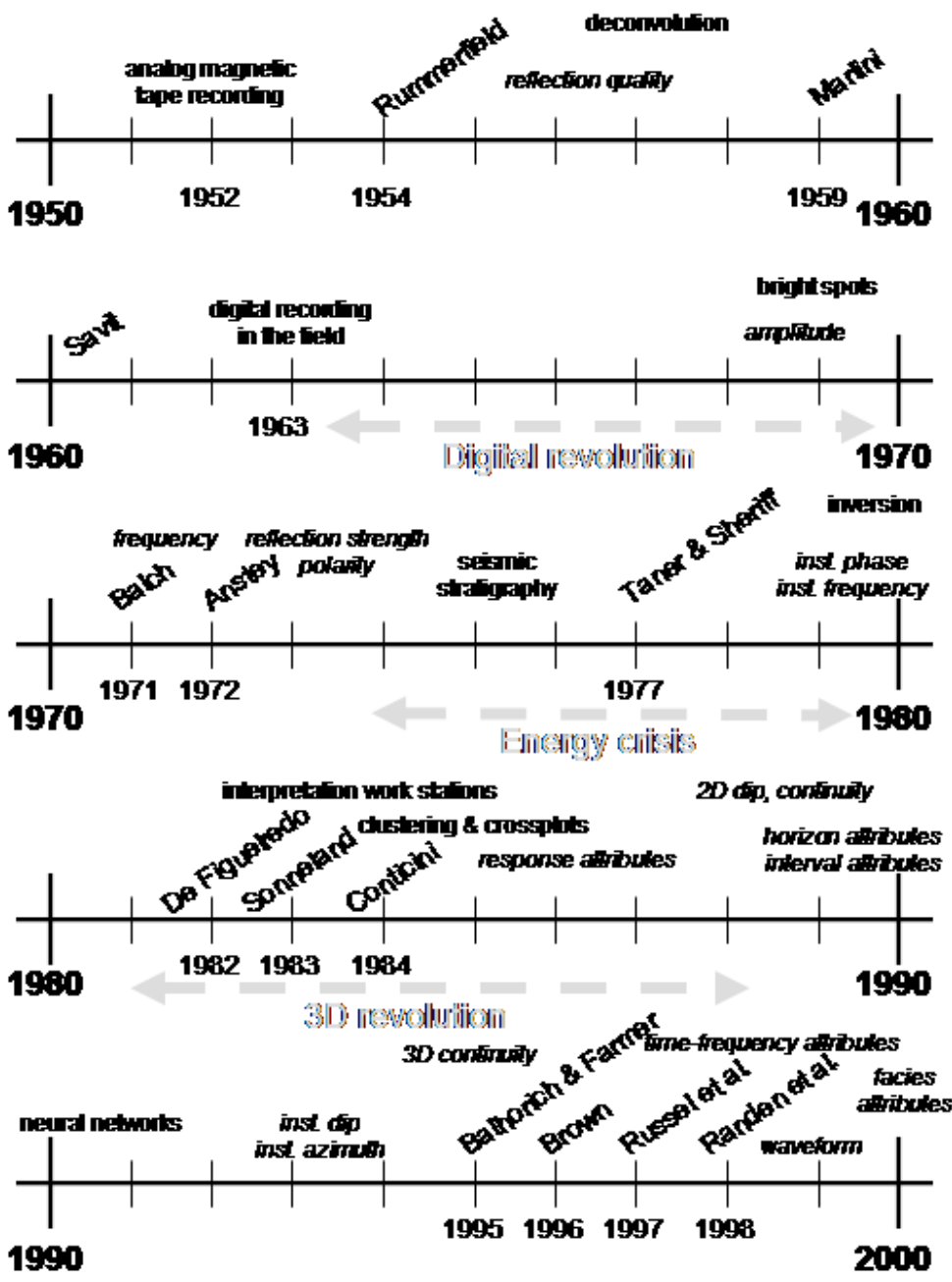

FiguRE 2-5: Timeline of seismic attribute analysis from 1950 to the present [9]. 
TABLE 2.1: Instantaneous attributes with their descriptions and applicability [16].

\begin{tabular}{|c|c|c|}
\hline Name & Description & Applicability \\
\hline $\begin{array}{l}\text { Instantaneous real amplitude } \\
\mathrm{f}(\mathrm{t})\end{array}$ & $\begin{array}{l}\text { The time-domain vibration amplitude of traces } \\
\text { at the selected sample. It is the default } \\
\text { expression of most seismic trace data. }\end{array}$ & $\begin{array}{l}\text { Traditionally widely used in structural and stratigraphic interpretations. } \\
\text { Often used as the base with other amplitude attributes to isolate high } \\
\text { or low amplitude areas such as bright spots and dim spots. }\end{array}$ \\
\hline $\begin{array}{l}\text { Instantaneous quadrature } \\
\text { amplitude } q(t)\end{array}$ & $\begin{array}{l}\text { Stemmed from the complex seismic trace } \\
\text { analysis, being the time-domain vibration } \\
\text { amplitude whose phase delay is } 90^{\circ} \text { from the } \\
\text { instantaneous real amplitude. }\end{array}$ & $\begin{array}{l}\text { The phase-delay feature is useful in quality control of the vertical } \\
\text { variation of instantaneous phase, also useful in id entifying someAVO } \\
\text { anomalies from thin-layer reservoirs since they may only be observable } \\
\text { at specific phases. }\end{array}$ \\
\hline Instantaneous phase $\gamma(t)$ & $\begin{array}{l}\text { Defined as the angle whose tangent is } \\
(q(t) f(t)) \text {,the phase (modulation) of traces at } \\
\text { the selected sample, in degrees or radians. }\end{array}$ & $\begin{array}{l}\text { Tends to enhance weak intra-reservoir events, but also enhance noise. } \\
\text { Color scale on final map should take into account circular nature of results } \\
\left.\text { (i.e. } \gamma_{-180}=\gamma_{190}\right) \text {. Since hydrocarbons often cause local phasing,this attribute } \\
\text { is often used with others as one of the hydrocarbon indicators. }\end{array}$ \\
\hline $\begin{array}{l}\text { Cosine of instantaneous } \\
\text { phase } \cos (\gamma(t))\end{array}$ & $\begin{array}{l}\text { An attribute derived from instantaneous } \\
\text { phase. }\end{array}$ & $\begin{array}{l}\text { Since its fixed bounds }(-1 \text { to }+1) \text { are easier to understand, it is often } \\
\text { used with instantaneous phase for better displaying its variation. }\end{array}$ \\
\hline $\begin{array}{l}\text { Product of inst. real } \\
\text { amplitude and cosine of inst. } \\
\text { phase } f(t) \cos (\gamma(t))\end{array}$ & $\begin{array}{l}\text { This composite attribute is designed to } \\
\text { enhance peak/trough amplitudes, especially } \\
\text { for zero-phase seismic data. }\end{array}$ & $\begin{array}{l}\text { This attribute enhances peak and trough amplitudes and turns all } \\
\text { trough amplitudes as pseu do peak amplitudes for better structural } \\
\text { interpretation. }\end{array}$ \\
\hline $\begin{array}{l}\text { Instantaneous frequency } \\
\psi(\varpi)\end{array}$ & $\begin{array}{l}\text { Defined as the derivative of instantaneous } \\
\text { phase with time, dy (t)/dt,in degrees/ms or } \\
\text { radians/ms. }\end{array}$ & $\begin{array}{l}\text { Often used to estimate seismic attenuation. Oil and gas reservoirs usually } \\
\text { cause drop-off of high frequency components.lt helps to measure cyclic- } \\
\text { ity of geological intervals. Tends to be unstable in the presence of noise. }\end{array}$ \\
\hline $\begin{array}{l}\text { Amplitude weighted } \\
\text { instantaneous frequency }\end{array}$ & $\begin{array}{l}\text { Instantaneous frequency weighted by } \\
\text { instantaneous amplitude formulated as } \\
\Sigma\left(\mathrm{f}(\mathrm{t})^{2} \mathrm{~d} \gamma(\mathrm{t}) / \mathrm{dt}\right) / \Sigma\left(\mathrm{f}(\mathrm{t})^{2}\right) \text {. }\end{array}$ & $\begin{array}{l}\text { Provides a more robust/smoothed estimate of instantaneous frequency } \\
\text { and is less prone to noise. }\end{array}$ \\
\hline $\begin{array}{l}\text { Energy weighted } \\
\text { instantaneous frequency }\end{array}$ & $\begin{array}{l}\text { Instantaneous frequency weighted by } \\
\text { theinstantaneous energy } \mathrm{A}(\mathrm{t}) \text { as } \\
\Sigma\left(\mathrm{A}(\mathrm{t})^{2} \mathrm{~d} \gamma(\mathrm{t}) / \mathrm{dt}\right) / \Sigma\left(\mathrm{A}(\mathrm{t})^{2}\right)\end{array}$ & $\begin{array}{l}\text { Provides the most robust estimate of instantaneous frequency. But } \\
\text { such a smoothing can also suppress anomaly information in the trace. }\end{array}$ \\
\hline $\begin{array}{l}\text { Slope of instantaneous } \\
\text { frequency }\end{array}$ & $\begin{array}{l}\text { Defined as the rate of inst. frequency change, } \\
\mathrm{d}(\mathrm{d} \gamma(\mathrm{t}) / \mathrm{dt}) / \mathrm{dt} \text {. }\end{array}$ & $\begin{array}{l}\text { Often used to indicate rate of attenuation and absorption. Since gas, } \\
\text { oil,and water/brine saturation cause different attenuations, this } \\
\text { attribute,for high-resolution data, can indicate those fluid boundaries, } \\
\text { useful in time lapse 3-D. }\end{array}$ \\
\hline Reflection strength $A(t)$ & $\begin{array}{l}\text { Defined as }\left(f(t)^{2}+q(t)^{2}\right)^{12} \text {. Alternative names } \\
\text { are "Instantaneous amplitude," "Amplitude } \\
\text { envelope." }\end{array}$ & $\begin{array}{l}\text { Useful in identifying bright/dim/flat spots. Often used to determine lateral } \\
\text { fluid,lithologic,and stratigraphic variations in reservoirs.As the absolute } \\
\text { value of the complex trace magnitude, it loses some vertical resolution. }\end{array}$ \\
\hline dB-based reflection strength & $\begin{array}{l}\text { Decibel scale of reflection strength, or } 20 \\
\text { times the common logarithm of reflection } \\
\text { strength. }\end{array}$ & $\begin{array}{l}\text { The decibel scale is often used in frequency domain to display the power } \\
\text { spectrum. Here this attribute is used to examine the variation or anomaly of } \\
\text { reflection strength in decibel scale.Fractal analysis of this attribute, that is, a } \\
\text { model-based description of seismic waveforms can yield some fractal } \\
\text { index to stratigraphic sequence and possible hydrocarbon anomaly. }\end{array}$ \\
\hline $\begin{array}{l}\text { Med-filtered energy of } \\
\text { reflection strength }\end{array}$ & $\begin{array}{l}\text { Defined as the time-domain median-filtered } \\
\text { energy of reflection strength. }\end{array}$ & $\begin{array}{l}\text { This median-filtered energy attribute enhances the peak anomalies of } \\
\text { reflection strength,similar to the role played by another attribute } \\
\text { perigram, a filtered reflection strength. }\end{array}$ \\
\hline $\begin{array}{l}\text { dB-based energy of } \\
\text { reflection strength }\end{array}$ & $\begin{array}{l}\text { Decibel scale of time-domain energy of } \\
\text { reflection strength. }\end{array}$ & $\begin{array}{l}\text { Often used with } \mathrm{dB} \text {-based reflection strength to examine the time } \\
\text { domain energy anomaly in decibel scale. }\end{array}$ \\
\hline Slope of reflection strength & $\begin{array}{l}\text { The rate of reflection strength change over } \\
\text { time. }\end{array}$ & $\begin{array}{l}\text { Very useful in characterizing vertical stratigraphic sequences and } \\
\text { vertical variation in reservoir fluid content such as in time lapse 3-D. }\end{array}$ \\
\hline $\begin{array}{l}\text { Product of filtered reflection } \\
\text { strength \& cosine of inst. } \\
\text { phase }\end{array}$ & $\begin{array}{l}\text { Filtered reflection strength or perigram is } \\
\text { obtained by subtracting the dc/average } \\
\text { component from the reflection strength. }\end{array}$ & $\begin{array}{l}\text { Useful in analysis of amplitude anomalies by mapping enhanced high- } \\
\text { amplitude and continuous events. }\end{array}$ \\
\hline Apparent polarity & Defined as the polarity of reflection strength. & $\begin{array}{l}\text { Useful for checking the lateral variation of polarity along a reflection } \\
\text { layer. Often used in conjunction with reflection strength. }\end{array}$ \\
\hline Response phase & $\begin{array}{l}\text { Derived from the instantaneous phase around } \\
\text { the lobes of reflection strength. }\end{array}$ & $\begin{array}{l}\text { An alternative way to track the time and spatial-variant phase change } \\
\text { of the seismic wavelet. }\end{array}$ \\
\hline Response frequency & $\begin{array}{l}\text { Derived from the instantaneous frequency } \\
\text { around the lobes of reflection strength. }\end{array}$ & $\begin{array}{l}\text { An alternative way to track the time and sp atial variant dominant } \\
\text { frequency change of the seismic wavelet. }\end{array}$ \\
\hline
\end{tabular}


models in artificial neural networks seem comparatively toy-like.

Structurally the neuron can be divided in three major parts: the cell body (soma), the dendrites, and the axon, see Figure 2-6 for an illustration. The dendrites receive the signals from other neurons. The signals are electrical impulses, and transmitted with a chemical process. Chemical transmitters modify the incoming signal, which is similar to what weights do in artificial neural networks. The received signals are then summed up in the soma. If sufficient input is received, the cell fires (i.e. transmits the signal to over its axon, to other cells.). This process occurs as a result of concentrations of different types of ions such as; potassium, sodium, and chloride.

In many ways, the mechanism of artificial neural networks have received their motivation from biological neural networks. One of the key features is the ability of being fault tolerant, which can be explained as being able to recognize many different input signals that we have not seen before, or being tolerant to damages in the neural system [19].

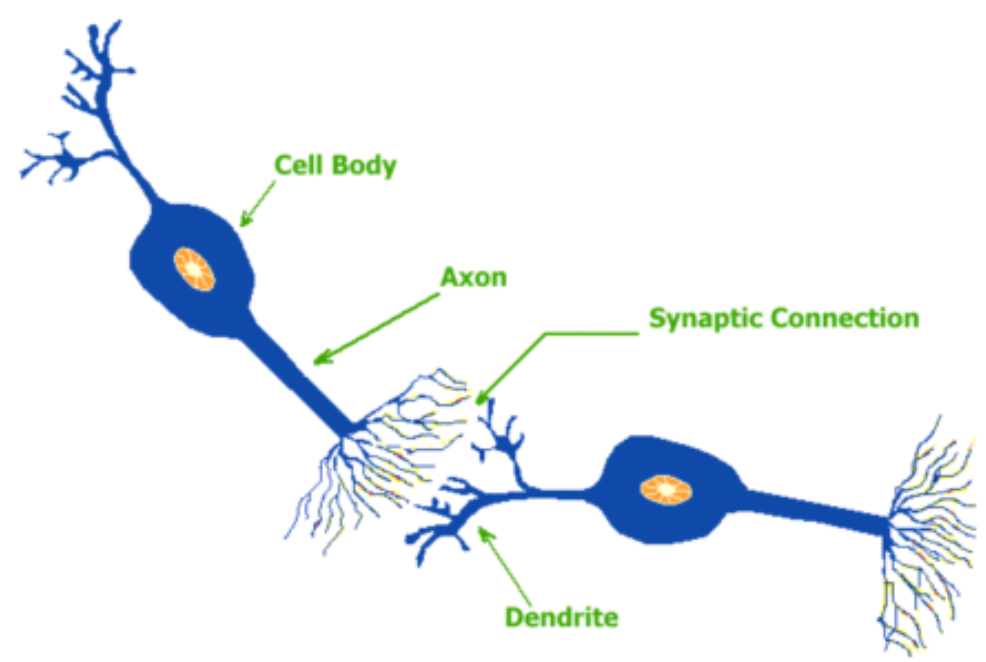

Figure 2-6: Schematic view of a bi-polar neuron [20].

\subsubsection{Introduction to Artificial Neural Networks}

Artificial neural networks (ANN) can be broadly defined as information-processing systems, which mimic the human mind as a mathematical model representation of the biological 
neural networks which is explained above. They have gained an increasing popularity in different fields of engineering in the past few decades, because of their capability of extracting complex and non-linear relationships.

The simplest unit of a neural network is the neuron (processing element). Figure 2-7 shows a typical neuron. The basic information processing occurs like the following; outputs $\left(I_{n}\right)$ coming from another neuron are multiplied by their corresponding weights $\left(W_{n}\right)$, and summed. An activation function is then applied to the summation, and the output of that neuron is now calculated and ready to be transferred to another neuron [20].

The internal state of a neuron after the activation function is applied, is called its activation. Thus, for the neuron shown in the figure, its activation, $y$, would be equal to $f\left(\sum I_{k} W_{k}\right)$; where $f(x)$ can be any activation function. A very common activation function is the sigmoid function (s-shaped curve) and it is defined as;

$$
f(x)=\frac{1}{1+\exp (-x)}
$$

The mechanism of artificial neural networks is based on the following assumptions [19]:

1. Information processing occurs in many simple elements that are called neurons (processing elements).

2. Signals are passed between neurons over connection links.

3. Each connection link has an associated weight, which, in a typical neural network, multiplies the signal being transmitted.

4. Each neuron applies an activation function (usually non-linear) to its net input to determine its output signal.

A neural network can be characterized by its pattern of connections between the neurons (i.e. its architecture), its method of determining the weights on the connection links (i.e. training algorithm), and its activation function.

In addition to petroleum engineering and many other engineering disciplines, artificial neural networks have been used in many different kinds of applications such as; signal processing, control, pattern recognition, medicine, speech recognition, speech production, and business [19]. 


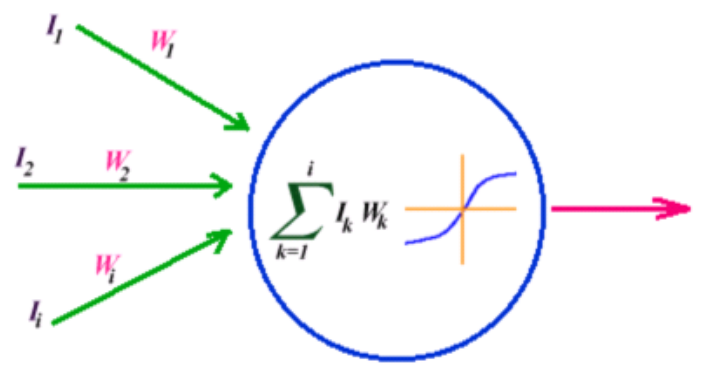

FiguRE 2-7: Schematic diagram of an artificial neuron or a processing element [20].

\subsubsection{Generalized Regression Neural Network (GRNN)}

GRNN is a modification to probabilistic neural network that has been suggested by authors, who have studied seismic inversion $[2 ; 10]$. GRNN has also been successfully used in geological pattern recognition applications such as; synthetic log generation [5] and total organic carbon content prediction from logs [25]. Besides, GRNN has been used in the closest application to this study, which is using cross-well seismic as the intermediate scale data [14; 26]. Huang et al. [25] described GRNN as an easy-to-implement tool, which has efficient training capabilities, and the ability to handle incomplete patterns.

Introduced by Specht [21] in 1991, GRNN is a one-pass learning algorithm with a highly parallel structure. It is a memory-based network, which provides estimates of continuous variables, and converges to the underlying regression surface. This approach is freed from the necessity of assuming a specific functional form. Instead, the appropriate form is expressed as a probability density function (pdf) which can be determined from the observed data. General regression uses $y$ (a scalar random variable), the $X$ (a particular measured value of a vector random variable $x)$, and the non-parametric estimator of the joint pdf $f(x$, y). After defining the scalar Euclidian distance function, $D_{i}^{2}$;

$$
D_{i}^{2}=\left(\mathbf{X}-\mathbf{X}^{i}\right)^{T}\left(\mathbf{X}-\mathbf{X}^{i}\right)
$$

performing the integrations results with the following:

$$
\hat{Y}(\mathbf{X})=\frac{\sum_{i=1}^{n} Y^{i} \exp \left(-\frac{D_{i}^{2}}{2 \sigma}\right)}{\sum_{i=1}^{n} \exp \left(-\frac{D_{i}^{2}}{2 \sigma}\right)}
$$

In order to define it in a simpler mathematical form; (2.4) is proposed instead of (2.2), 
since it has given similar results. Instead of the Euclidian distance, it uses the city block distance, $C_{i}$;

$$
\begin{gathered}
C_{i}=\sum_{i=1}^{p}\left|\left(\mathbf{X}_{j}-\mathbf{X}_{j}^{i}\right)\right| \\
\hat{Y}(\mathbf{X})=\frac{\sum_{i=1}^{n} Y^{i} \exp \left(-\frac{C_{i}}{\sigma}\right)}{\sum_{i=1}^{n} \exp \left(-\frac{C_{i}}{\sigma}\right)}
\end{gathered}
$$

The estimate $Y(X)$ is defined as a weighted average of the observed values, $Y_{i}$, where each observed value is weighted exponentially according to its Euclidian or city block distance [21]. $\sigma$ is the smoothing factor, and optimum smoothing factor is determined after several runs according to the mean-squared error of the estimate, which must be kept at minimum. The smoothing factor must be greater than 0 and can usually range from 0.01 to 1 with good results [22]. This process is named as the training of the network. If a number of iterations passes with no improvement in the mean-squared error, that smoothing factor is determined as the optimum one for that data set. In the production phase, that smoothing factor is applied to data sets that the network has not seen before. While applying the network to a new set of data, increasing the smoothing factor would result with decreasing the range output values.

GRNN is especially useful in approximating continuous functions. It may have multidimensional input, and it will fit multidimensional surfaces through data. It is a three-layer network. In the hidden layer, there must be one hidden neuron for each training pattern $[22]$.

\subsection{Correlation Statistics}

Through out the text, some correlation statistics are included to define the quality of the correlation models that have been developed. One of the major correlation statistics is the coefficient of determination, which is known as r-squared. Defining $Y$, the set of actual outputs, and $\hat{Y}$, the set of predicted outputs, and $n$, the number of samples; r-squared is equal to [23]:

$$
r^{2}=1-\frac{S S E}{S S T}
$$


where;

$$
\begin{gathered}
S S E=\sum\left(Y_{i}-\hat{Y}_{i}\right) \\
S S T=\left(\sum Y_{i}^{2}\right)-\frac{\left(\sum Y_{i}\right)^{2}}{n}
\end{gathered}
$$

Another term used is the correlation coefficient, $r$, which is basically the square root of r-squared. These terms can be between 0 and 1 , and values closer to 1 indicate better match. However, in the case of logs or any other geological patterns, r-squared might not always be representative of the quality of the match, since the trends followed are basically more important than the values. That is why visual analysis is considered more than the correlation statistics in those cases. 


\section{Chapter 3}

\section{Synthetic Model Study}

As one of the unique features of this study, a synthetic seismic model has been developed before dealing with real data. It was aimed to find out the most appropriate methodology to achieve the goals of this research.

This model has been built in a way that it is a representative model of the Pennsylvanian stratigraphy of the Buffalo Valley Field in New Mexico. Real data from this field is used in the real case study which is explained in Chapter 4. The geological structure of this field is also explained in that chapter. In this chapter, information about how the model has been built, the description of the model, the output of the model (i.e. available data for the neural network studies), and the methodology followed are explained.

\subsection{Model Development}

The model has been developed by using Struct which is a modeling package in the Geographix Discovery Suite of Landmark Graphics. It is a comparative example of the stratigraphic section of the Buffalo Valley Field, which includes Atoka and Morrow formations together with the overlying Pennsylvanian sequence. It is developed by using a forward modeling process, which has simulated straight rays traveling from the surface and avoiding diffraction at interfering events. The model has been defined with properties like thickness, geometry, lateral distribution, density and interval velocity of the rocks which were gathered from the actual data set [24]:

Horizontal dimension - $4.9 \mathrm{mi},(7.9 \mathrm{~km})$, equivalent to the dimension of the 3D survey. 
Vertical dimension - Real depth - approximately $7000 \mathrm{ft}$; and thickness of the sequence - $200 \mathrm{ft}$. This data was measured from well logs.

Geometry of the sand channels and sand/limestone layers - After considering the well log interpretation and seismic visualization, channels and layers were defined as having thicknesses between 10 and $80 \mathrm{ft}$.

Density and interval velocity of shales and sand bodies - The average density and velocity values were derived from well $\operatorname{logs}$ as shown in Table 3.1;

TABLE 3.1: Layers and corresponding density and velocity ranges in the synthetic model.

\begin{tabular}{lcc} 
Lithology & Density, g/cc & Velocity, ft/s \\
\hline Sandstone & $2.4-2.7$ & $12,500-16,000$ \\
Shale & $1.9-2.10$ & $9,000-11,000$ \\
Limestone & $2.5-2.7$ & $14,000-17,000$ \\
\hline
\end{tabular}

\section{Surface Seismic and VSP Derived Models}

Two separate models have been obtained by extracting wavelets from actual surface seismic and VSP for the time window of Atoka and Morrow formations. The synthetic surface seismic response (Figure 3-1) has been computed by using a wavelet derived from the zone of interest in line 1034 of the 3D surface seismic data, and the synthetic VSP response (Figure 3-1) has been computed by using a Butterworth wavelet derived from line 2064 of the 3D VSP with a larger bandwidth. The properties of the wavelets used for each case are shown in Table 3.2. Tuning thickness has been determined after the vertical resolution has been calculated with the equation (2.6).

\subsection{Model Description}

In the model, the geological complexity increases with depth. The positive amplitudes (blue in Figure 3-1) are produced at the top of the carbonates, reflecting the interface between an overlying weak acoustic impedance rock (shales, layers in white) and an underlying high acoustic impedance (carbonates). Negative amplitude (red) is produced due to the interface 
TABlE 3.2: Properties of wavelets used to compute seismic responses.

\begin{tabular}{lcc} 
Property & 3D Surface Seismic & VSP \\
\hline Bandwidth, Hz & $11-95$ & $20-110$ \\
Dominant Frequency, $\mathrm{Hz}$ & 45 & 65 \\
Dominant Period, sec & 0.022 & 0.0154 \\
Interval Velocity, $\mathrm{ft} / \mathrm{sec}$ & $15000-16000$ & $15000-16000$ \\
Tuning Thickness, $\mathrm{ft}$ & $83-88$ & $57-61$ \\
\hline
\end{tabular}

between the strong acoustic impedance carbonate, and the underlying weak impedance shale $[24]$.

If the thickness of the layer exceeds the resolvable thickness, amplitude becomes very low (white in Figure 3-1), since there is no reflectivity contrast in those regions. The reflection character is basically related to lateral stratigraphic changes. For Atoka and Morrow formations, there is a lateral variation due to a series of lenses and layers of sandstones and sands with carbonate content that are laterally and vertically stacked, and embedded in shale. This results with a discontinuous seismic character with faster lateral variations of the amplitude. Laterally, continuous marine sequences, such as the carbonate and interbedded shales of the Strawn, Canyon and Cisco formations, produce laterally continuous reflectors. On the other hand, laterally varying formations like Atoka and Morrow, produce discontinuous seismic reflectors, which brings up more visible amplitude variations. This character of Atoka and Morrow is mainly caused by lenses of sand channels, which are pinching out and stacked on top of each other [24].

\subsection{Model Output}

The model is basically a seismic line of 100 traces, which includes three wells at traces 20, 50 and 80 with the well at trace 50 having a VSP. These wells had well logs of density and velocity. The available data after developing the model were;

1. Surface seismic responses;

2. Vertical seismic profile responses;

3. Density and velocity distributions. 


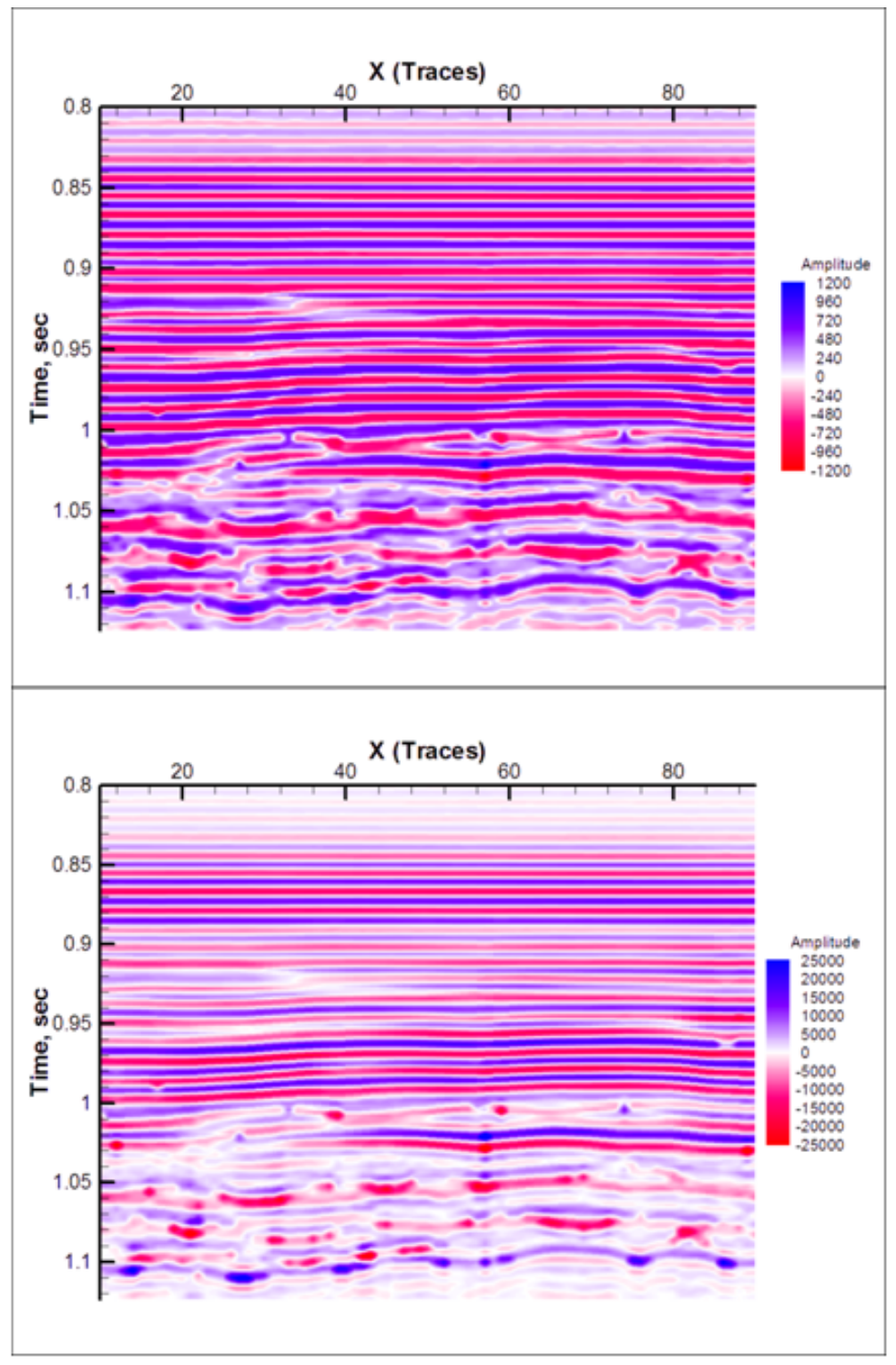

Figure 3-1: Computed seismic responses (seismic sections). Top: Surface seismic responses - lower resolution, bottom: VSP responses - higher resolution. 
Seismic responses have been computed as distributions of the following attributes:

- Trace Amplitude

- Trace Envelope

- Average Energy

- Hilbert Transform

- Instantaneous Phase

- Instantaneous Frequency

- Paraphase

\subsection{Methodology}

The methodology in this study includes two major steps of correlation as proposed (Figure 1-4); 1) Correlation of surface seismic with VSP; 2) Correlation of VSP with well logs. The available data which is mentioned above are used to find the best correlation models. Instead of using all of the data available, the data of interval 0.8-1.124 seconds are used, as only that interval was geologically rich in terms of information. This interval corresponded to $6,600-9,000 \mathrm{ft}$. Next, these two steps of correlation will be explained in details.

\subsubsection{Step 1: Correlation of Surface Seismic with VSP}

As the first step of the proposed correlation methodology, correlations between surface seismic attributes and VSP attributes have been looked for. First, the model has been visualized by plotting the cross-sectional distributions of density, velocity and seismic attributes for both surface seismic and VSP. The density distribution (Figure 3-2) clearly reflects the arrangement of the rock layers, where in the middle zone, sand channels can be seen. The model has a uniform distribution laterally. 


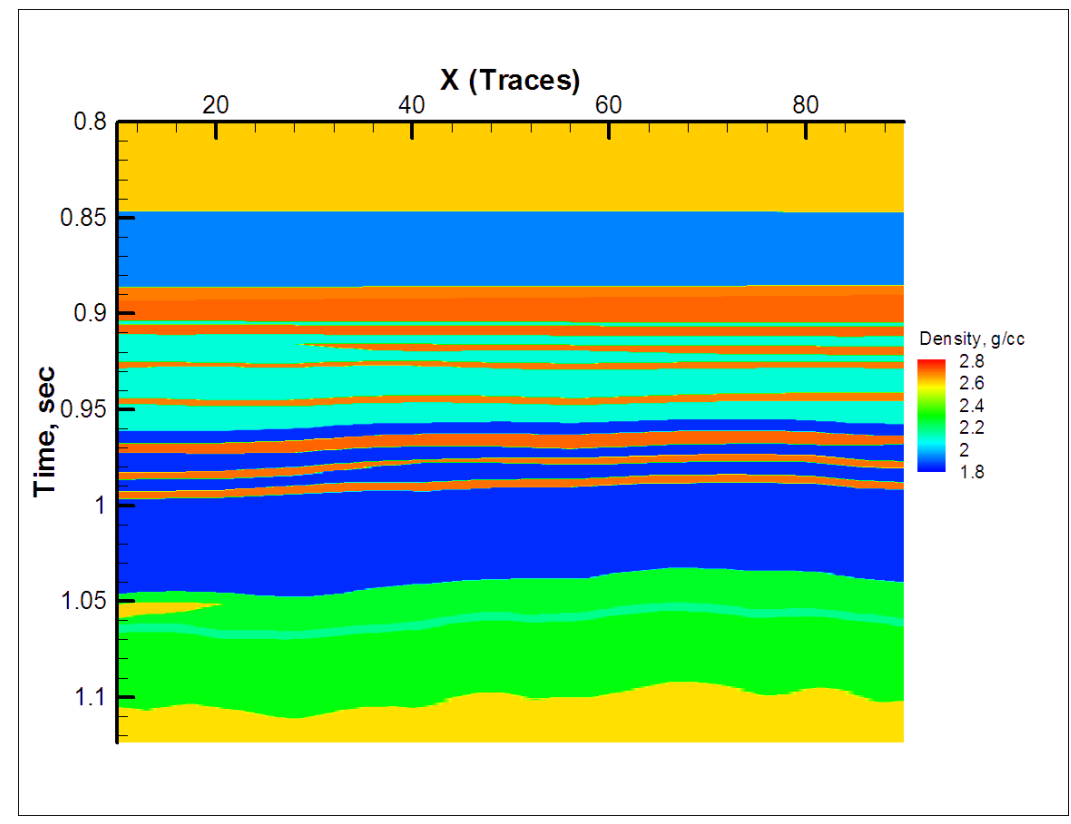

Figure 3-2: Cross-sectional density distribution of the synthetic model.

The main aim was to determine the most appropriate data that can be used in training before starting to train the network. The predictability of a neural network model highly depends on how and with what data it has been trained. Thus, the data should contain a lot of information regarding the model, to get the most successful results in the production phase. For this purpose, an effort has been made to identify special geological features that can be useful in training the neural network. These include; edges of sand channels, extreme value points, and unique geological structures. Although the model has a uniform distribution laterally in most of the regions, those kinds of features can be found mostly in the middle zone. In order to include those features in the training model, data of traces 32 and 57 have been decided upon to be used in training after several tests (Figure 3-3). Number of traces that is used has been kept at two, because of the limitation in optimum number of data rows. Two traces included 326 data rows.

The network structure used in training is shown in Figure 3-4. As shown, data of traces 32 and 57 have been used, to predict a VSP attribute from time and seven available surface seismic attributes. $70 \%$ of the data were selected randomly, specifically for training. Among the remaining 30\%; $20 \%$ were used for calibration, and $10 \%$ were used for verification. 
At the end, seven separate prediction models have been developed for seven attributes, which are based on data of t-32 and t-57. After having confidence with the prediction abilities of these models, they have been applied to the whole seismic line to obtain networkpredicted distributions of available attributes. These distributions were then plotted to be able to compare with the actual ones.

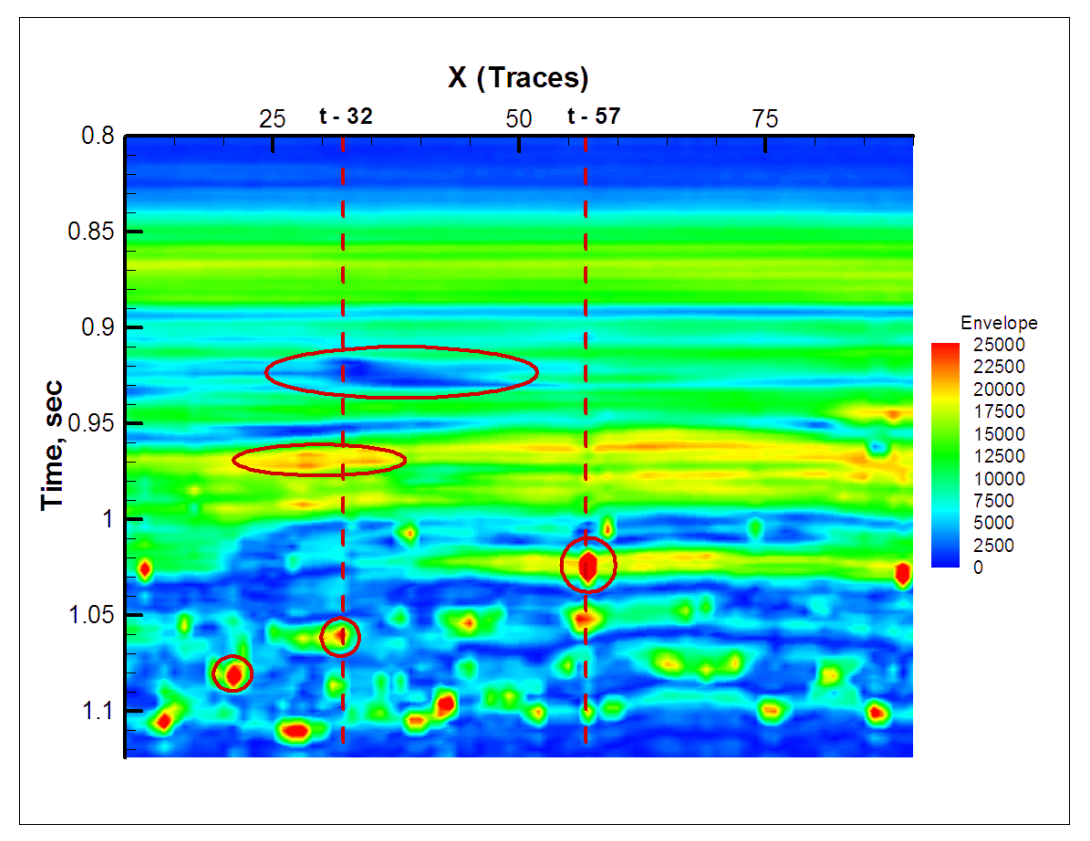

Figure 3-3: Cross-sectional Envelope distribution which was used to determine special features that can be useful in the network training. Finally, traces 32 and 57 were decided to be used in training.

\subsubsection{Step 2: Correlation of VSP with Well Logs}

The second step of the correlation studies is the main goal of this study, which is deriving logs from VSP data. Since t-50 is the trace which includes all of the data that are dealt with theoretically (i.e. surface seismic, VSP and well logs), this trace has been used to develop the model of this part of the correlation. Density log has been selected as the target log, as it was the only log together with the velocity log which has a very similar structure 

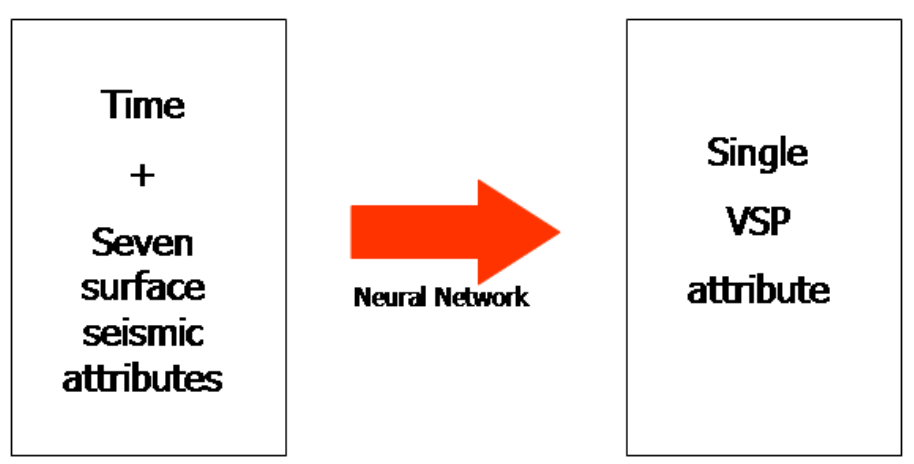

Figure 3-4: Network structures used for training. Data of traces 32 and 57 have been used, to predict a VSP attribute from time and surface seismic attributes.

with density. Methodology developed with the density log was then applied to velocity and acoustic impedance (the product of density and velocity.)

When one looks at the density log of t-50, one can clearly see that there are a few different averaged values of density (Figure 3-5), which have been later defined as classes. Each of these classes actually represents a different type of rock layer defined in the model. Finally, instead of using actual values of density, it was decided to use these classes as the target values. By doing this, we have changed the nature of the neural modeling to one of classification. Classification networks are sometimes simpler than networks that are built to predict continuous values. In the initial trial; classes were defined as (Figure 3-5);

- $\sigma \approx 1.9 \mathrm{~g} / \mathrm{cc} \rightarrow$ Class 1

- $\sigma \approx 2.3 \mathrm{~g} / \mathrm{cc} \rightarrow$ Class 2

- $\sigma \approx 2.65 \mathrm{~g} / \mathrm{cc} \rightarrow$ Class 3

The data set has been re-arranged in a way that the corresponding class of that row is equal to 1 and others are 0 (Table 3.3). Thus, the network structure was like the one in Figure 3-6. All of the VSP attributes with time were used as inputs to predict one of the density classes.

By using the generalized regression neural network algorithm, a reliable training model has been built to be used in density prediction. With that model, the cross-sectional density distribution has been produced through the seismic line, and that distribution has been compared with the actual distribution. Same procedure was applied to velocity and acoustic impedance. Results and discussions are included in Section 5.1. 


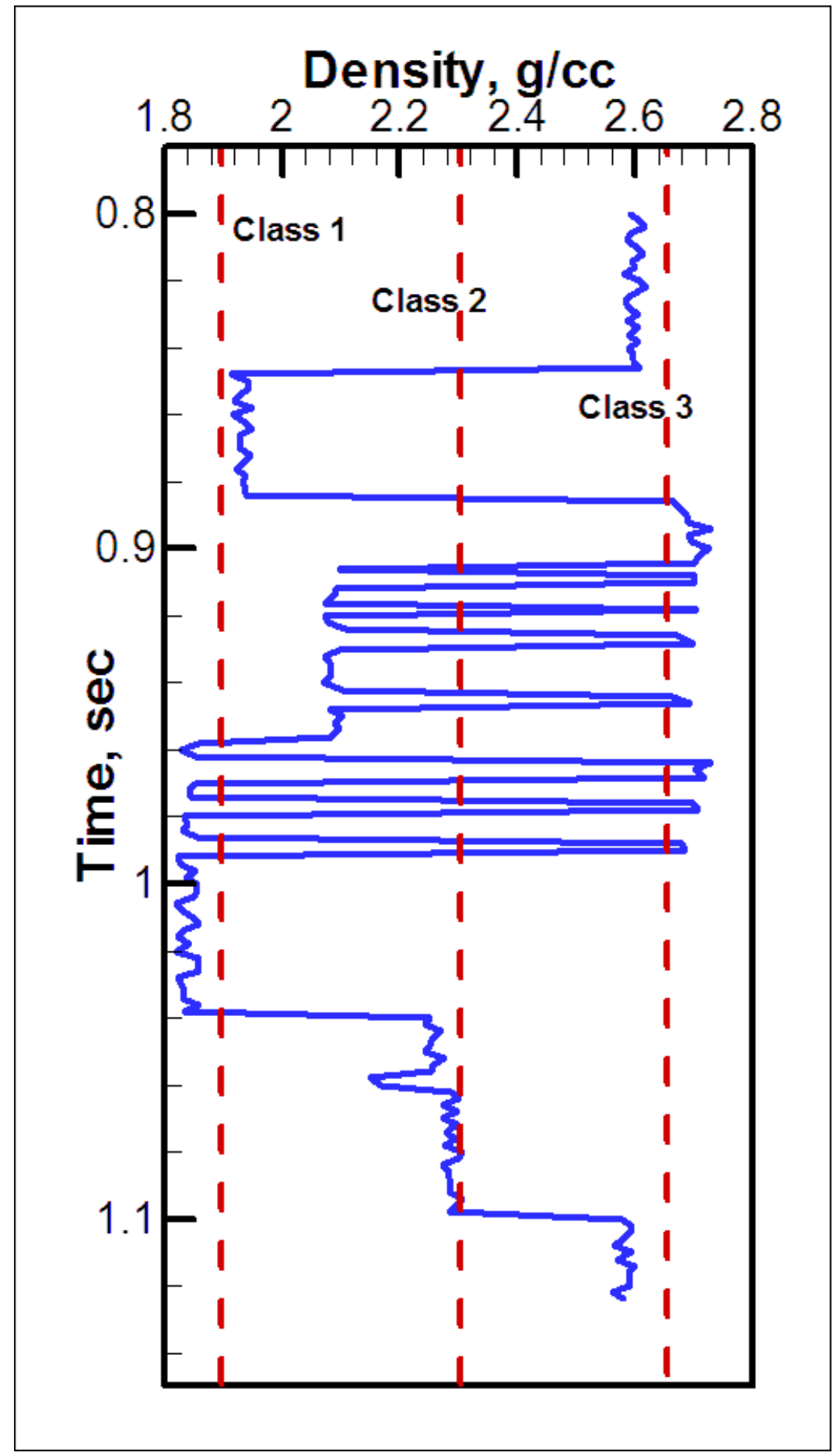

Figure 3-5: Density log of trace - 50. Proposed classification: Three classes at density values $1.9,2.3$, and 2.65 . 
TABLE 3.3: Rearranging the data. Introducing classes, where 0: false and 1: true.

\begin{tabular}{cccc} 
Density, g/cc & Class 1 & Class 2 & Class 3 \\
\hline 2.592 & 0 & 0 & 1 \\
2.599 & 0 & 0 & 1 \\
2.273 & 0 & 1 & 0 \\
1.923 & 1 & 0 & 0 \\
2.286 & 0 & 1 & 0 \\
$\vdots$ & $\vdots$ & $\vdots$ & $\vdots$ \\
\hline
\end{tabular}

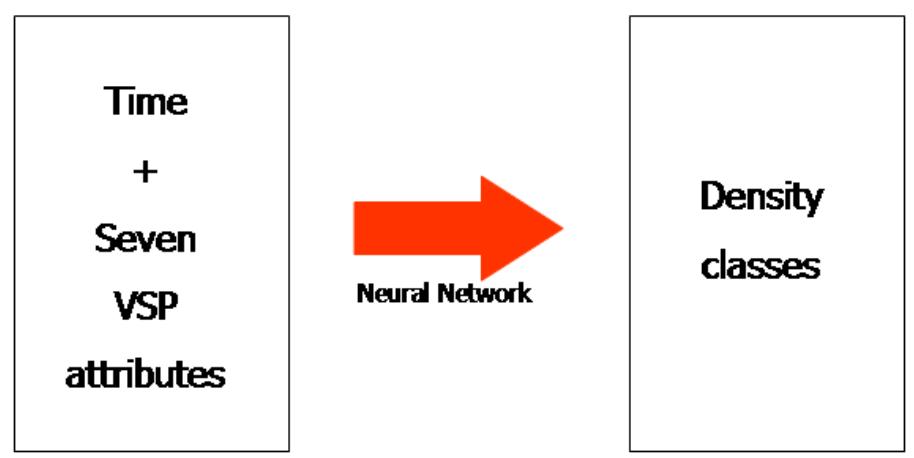

FiguRE 3-6: Network structures used for training. Data of t-50 have been used, to predict one of the density classes from time and VSP attributes. 


\section{Chapter 4}

\section{Real Case Study: The Buffalo Valley Field}

\subsection{Location and Geological Setting}

The Buffalo Valley Field is located in Chaves County, southeast of New Mexico, USA (Figure 4-1). Sanchez's [24] description of the geologic setting of the Buffalo Valley Field is as follows;

"Regionally, the area is situated in the Northwestern shelf of the Permian Basin, which is situated in west Texas and southeastern New Mexico. The Permian Basin also includes the Midland Basin, Central Basin Platform and Delaware Basin. The evolution of this basin began with Ordovician to Devonian sedimentation associated with extensional tectonics related to mid-continent rifting of its ancestor, the Tobosa Basin. Later, in the late Mississippian and early Pennsylvanian periods, a collision between the Gondwana and Laurasia plates triggered the Marathon-Ouachita Orogeny (Figure 4-2), causing the uplifting of the Central Basin platform and consequently the fragmentation of the Tobosa Basin, which created the Delaware Basin to the west, and the Midland Basin to the east.

Within the Delaware Basin, the stratigraphic sequence from middle Mississippian to Permian reflects both paleotectonic activity and relative changes in sea level. In general, through the middle to upper Mississippian, marine carbonate deposition is replaced by black organic shales. During this time, the Delaware Basin experienced differential subsidence with tilting to the east and vertical movements along Proterozoic weakness zones. Deformation affected both the uplifted areas and the basin. A generalized stratigraphic column of the Northwestern shelf is shown in Figure 4-3, along with a production summary of the Pennsylvanian plays in the Permian Basin. 


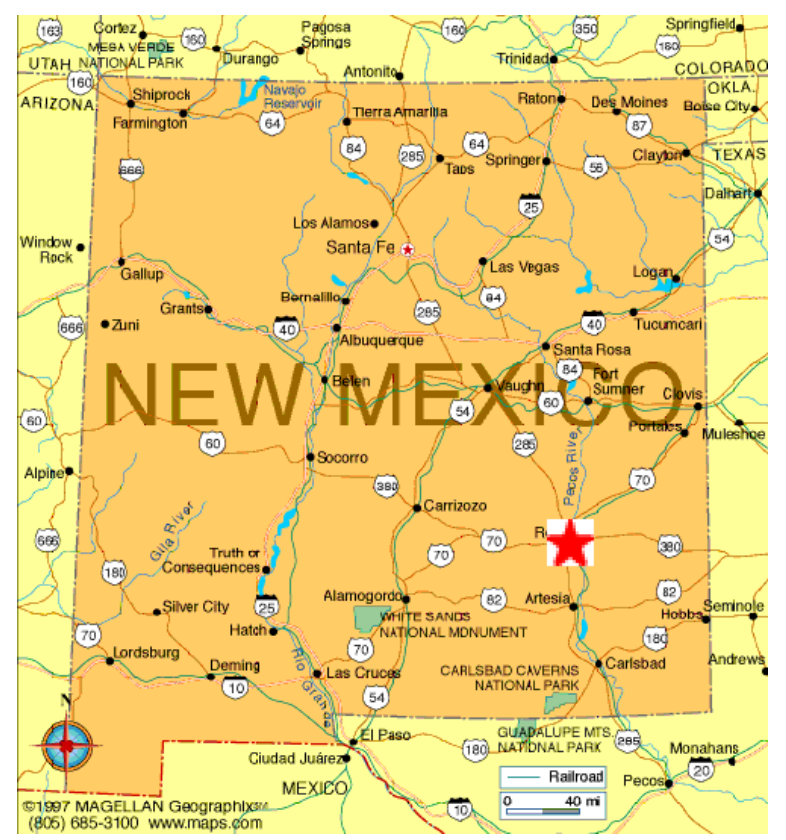

Figure 4-1: Geographical location of the Buffalo Valley Field (Pointed with a star.).

During the early Pennsylvanian, with the beginnings of the Marathon Ouachita Orogeny, activation of the Pedernal and Central Basin uplifts took place. These positive topographic structures served as sediment sources for the depositional systems that filled the Delaware Basin. The resultant alluvial, fluvio-deltaic, and basinal marine sequences pro-graded S-SW from the Northwestern Shelf into the Delaware Basin (Figure 4-2). In the Buffalo Valley Field, the Atoka and Morrow Formations recorded these conditions with the deposition of sands, interbedded with shales and limestones. Based on the stratigraphic observations in the Buffalo Valley Field, the Morrow Formation seems to have eroded the underlying Mississippian shales and is unconformable to the Chester Formation. The stratigraphic relationship between the Morrow and Atoka is conformable within the study area in most of the southern areas of New Mexico.

Tectonic effects of the Marathon Ouachita Orogeny continued during the middle and late Pennsylvanian. The result was a regional increase in the compressional regime, resulting in faulting and folding primarily to the south of the Delaware Basin in the Marathon fold belt, but, in some instances extending into the northern part of the basin. Simultaneously, extensive carbonate shelves started to develop along the margin of the Delaware Basin. 
For example, the Atoka Formation records carbonate bank development and deposition of shallow marine limestones to shallow marine sandstones. These conditions prevailed with mostly carbonate sedimentation through the remainder of the Pennsylvanian, represented by the Strawn, Canyon and Cisco Formations."

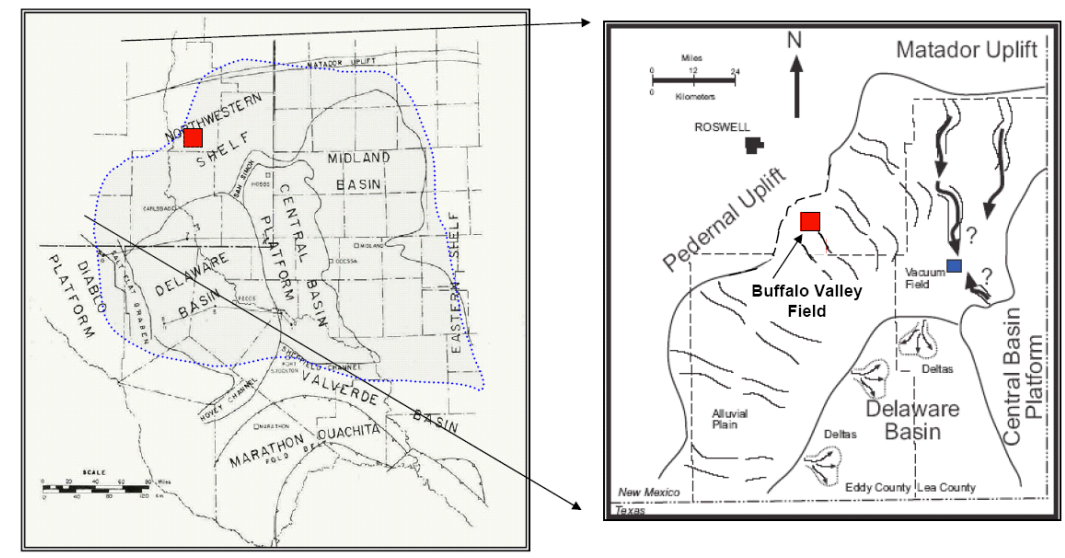

Figure 4-2: Southeast New Mexico and west Texas. Pennsylvanian paleography of Permian Basin. In blue dash line an approximate outline of the paleo Tobosa Basin [24].

\subsection{Atoka and Morrow Formations}

A comprehensive analysis of Atoka and Morrow Formations has been made by Sanchez [24]. Logs and well reports have been downloaded from the New Mexico Bureau of Geology and Mineral Resources website. These files have been used to correlate formation tops and thicknesses through cross-sectional analyses. Gamma ray log has been used as the main indicator. Density, sonic and resistivity logs have also been used. Cross-sections in northsouth, east-west, and northeast-southeast orientations were constructed to understand the behavior of the sequence (Figure 4-4). Since core samples were not available for this study, petrophysical properties were derived from well logs. Apparent total porosity was generally calculated using density, neutron porosity, and sonic logs. Well logs also reflected the reservoir variability in these formations.

An integrated seismic interpretation was carried out using the 3D seismic volume, post stack trace correlation seismic volume and well log response tied to the seismic data. The 
local character of the seismic traces on the well location reflect additional lateral information from a radius equal to the Fresnel zone (horizontal resolution). It has been calculated as approximately $1200 \mathrm{ft}$ and $1000 \mathrm{ft}$ for the 3D survey and the VSP respectively. The vertical seismic resolution for the Atoka and Morrow in the synthetic seismogram is of few feet, while for the 3D seismic survey and VSP volume yields to a tuning thickness between 83-88 $\mathrm{ft}$, and 57-61 ft respectively [24].

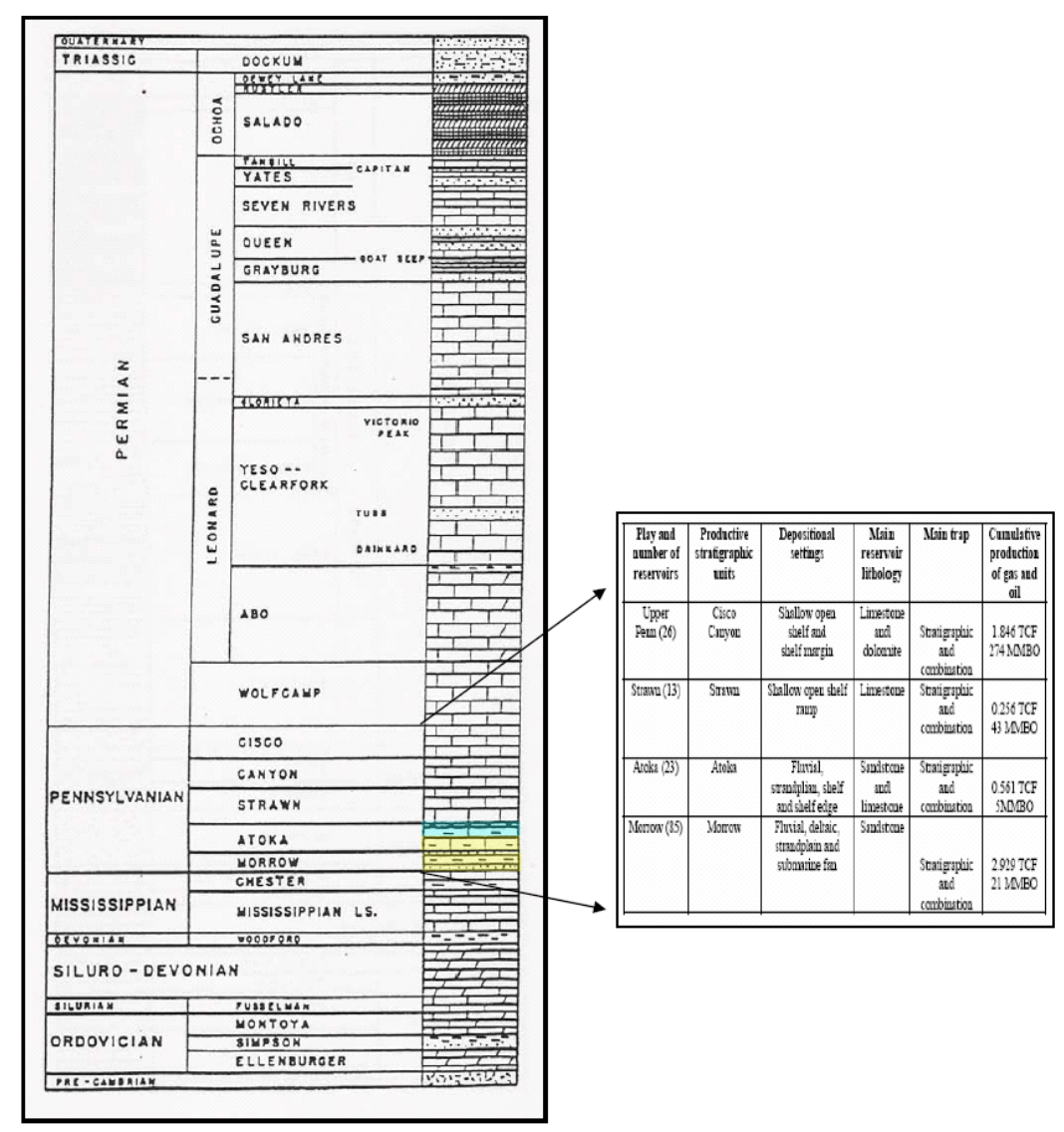

FiguRE 4-3: Generalized stratigraphic section of the Northwest Shelf areas in the Permian Basin, with the cumulative gas and oil production from the major reservoirs of Pennsylvanian plays [24].

The sediments of the Morrow formation are mostly interbedded sandstones and shales. Its thickness is very variable and ranges from $80 \mathrm{ft}$ to $200 \mathrm{ft}$. It is characterized by a high reservoir complexity having a high variability of porosity. It becomes deeper to the south 
east, having a subsea depth of 4,400-5,200 ft. It has a lower density and velocity, comparing with Atoka (sandstone with carbonate content) and Chester (carbonates) formations. In Sanchez's study [24], Morrow is divided into three as upper, middle, and lower Morrow. Middle Morrow is more homogeneous than upper and lower Morrow which are laterally discontinuous. Matrix of these formations have been identified as quartz. Lower and middle Morrow seemed to be located near the gas direction field, while upper Morrow seemed to be having carbonate content.

Atoka formation has been reported to have a composition of sands, limestones, and interbedded shales. The carbonate content of Atoka is higher than Morrow, and that is why it has a higher density. It has a thickness between 70-150 ft at a subsea depth of 4400-5200 ft. Atoka formation is conformable with the underlying shales and sandstones of the Upper Morrow. In Sanchez's study [24], Atoka is divided into tow as upper and lower Atoka. Lower Atoka has a lower density and higher porosity than the upper Atoka. They are seperated from each other by a variable shale layer of 10-15 ft. Shale/sand ratio is higher in lower Atoka. Lower Atoka also has a higher carbonate content with a matrix of quartz. Upper Atoka has a matrix of calcite and quartz.

Specific characteristics of these formations are listed in Table 4.1.

\subsection{Available Data}

The database available from the Buffalo Valley Field can be classified in three sets of data $[24]$

1. A 3D seismic survey covering an area of $24 m i^{2}$ with a vibroseis source, sweep frequencies ranging from 8 to $98 \mathrm{~Hz}$, and a sweep length of 17 seconds. This data set has been loaned to the Department of Geology and Geography of West Virginia University by WesternGeco, Houston, Tx.

2. A vertical seismic profile volume, with a two-LRS-315 vibrators source, covering an area of approximately $3.5 m i^{2}$ in the southeast corner of the area.

3. Logs from around 40 wells, either paper or electronic copies. Available types of logs included gamma ray, neutron, density, sonic, spontaneous potential, and resistivity. Paper copies have been scanned, and then digitized together with other available 
electronic copies. Average total depth of those wells were ranging from 8,000 to 9,000 $\mathrm{ft}$, intersecting the Atoka and Morrow formations.

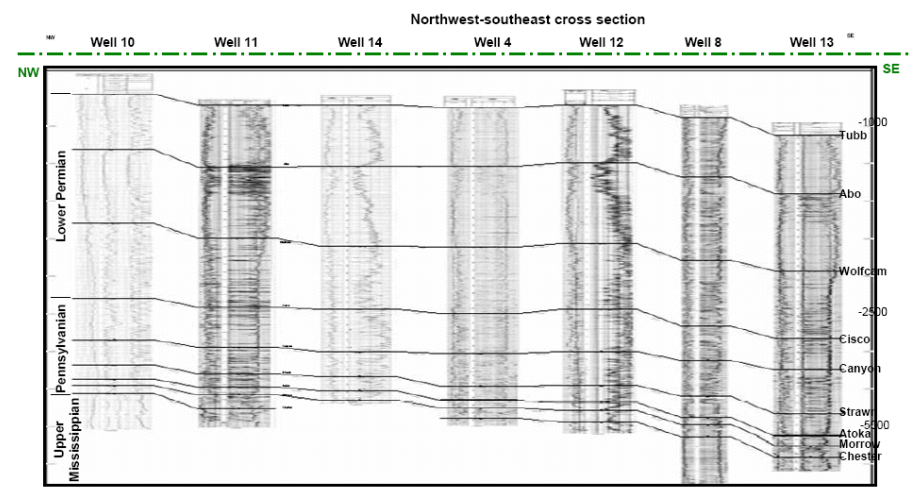

Figure 4-4: Regional stratigraphic cross section of the Upper Mississippian, Lower Pennsylvanian, and Lower Permian Sequence in the Buffalo Valley Field [24].

In addition to these, well drilling reports, headers, and production data were incorporated in the interpretation and analysis. Those files were available on the official web sites of New Mexico Bureau of Geology and Mineral Resources [27], New Mexico Energy, Mineral and Natural Resources Department Oil Conservation Division [28], and the New Mexico Tech Go-Tech [29].

A map showing the locations of the wells with the available types of logs is shown in Figure 4-5. The well with the VSP survey is highlighted in the south-east part of the survey area. Throughout the text, that well will be called Well \#1.

Unfortunately, not all of the available well logs had a high visual quality. That made them hard to be digitized accurately. An illustration for good quality logs and bad quality logs are shown in Figure 4-6. It is a proven fact that; quality of the data has an important role in building reliable neural network models. Reasonable amount of noise in the data is acceptable, and even useful for a more realistic model. However, it is impossible to rely on a model, which has been built with unreliable data. Rolon's study [5] clearly states this fact, by comparing two similar studies with well log data having different levels of quality. After considering these, it has been decided to conduct a quality check of the digitized log files. It was aimed to use data having an acceptable quality not to face with the problem of building poor prediction models. 
TABLE 4.1: Characteristics of Atoka and Morrow formations.

\begin{tabular}{|c|c|c|c|c|c|}
\hline $\begin{array}{l}\text { Name of the } \\
\text { formation }\end{array}$ & Composition & $\begin{array}{l}\text { Thickness, } \\
f t\end{array}$ & $\begin{array}{c}\text { Thickness of } \\
\text { sand channels, } f t\end{array}$ & $\begin{array}{l}\text { Porosity } \\
\text { range, \% }\end{array}$ & $\begin{array}{c}\text { Average } \\
\text { porosity, \% }\end{array}$ \\
\hline \multicolumn{6}{|l|}{ Atoka } \\
\hline Upper Atoka & $\begin{array}{c}\text { Sands, } \\
\text { carbonates, } \\
\text { interbedded shales }\end{array}$ & $60-120$ & $3-20$ & $1-14$ & $4-6$ \\
\hline Lower Atoka & $\begin{array}{l}\text { Sands with } \\
\text { some carbonate } \\
\text { content }\end{array}$ & $30-40$ & 10 & $4-14$ & $8-9$ \\
\hline \multicolumn{6}{|l|}{ Morrow } \\
\hline Upper Morrow & $\begin{array}{c}\text { Sands with } \\
\text { carbonate content } \\
\text { interbedded with shales }\end{array}$ & 30 & $5-15$ & $4-14$ & $6-7$ \\
\hline Middle Morrow & $\begin{array}{c}\text { Stacked sands } \\
\text { with interbedded } \\
\text { shales }\end{array}$ & $50-70$ & $5-25$ & $2-14$ & $5-8$ \\
\hline Lower Morrow & $\begin{array}{l}\text { Interbedded } \\
\text { sandstones } \\
\text { with shale }\end{array}$ & $70-90$ & $5-30$ & $7-18$ & $8-10$ \\
\hline
\end{tabular}




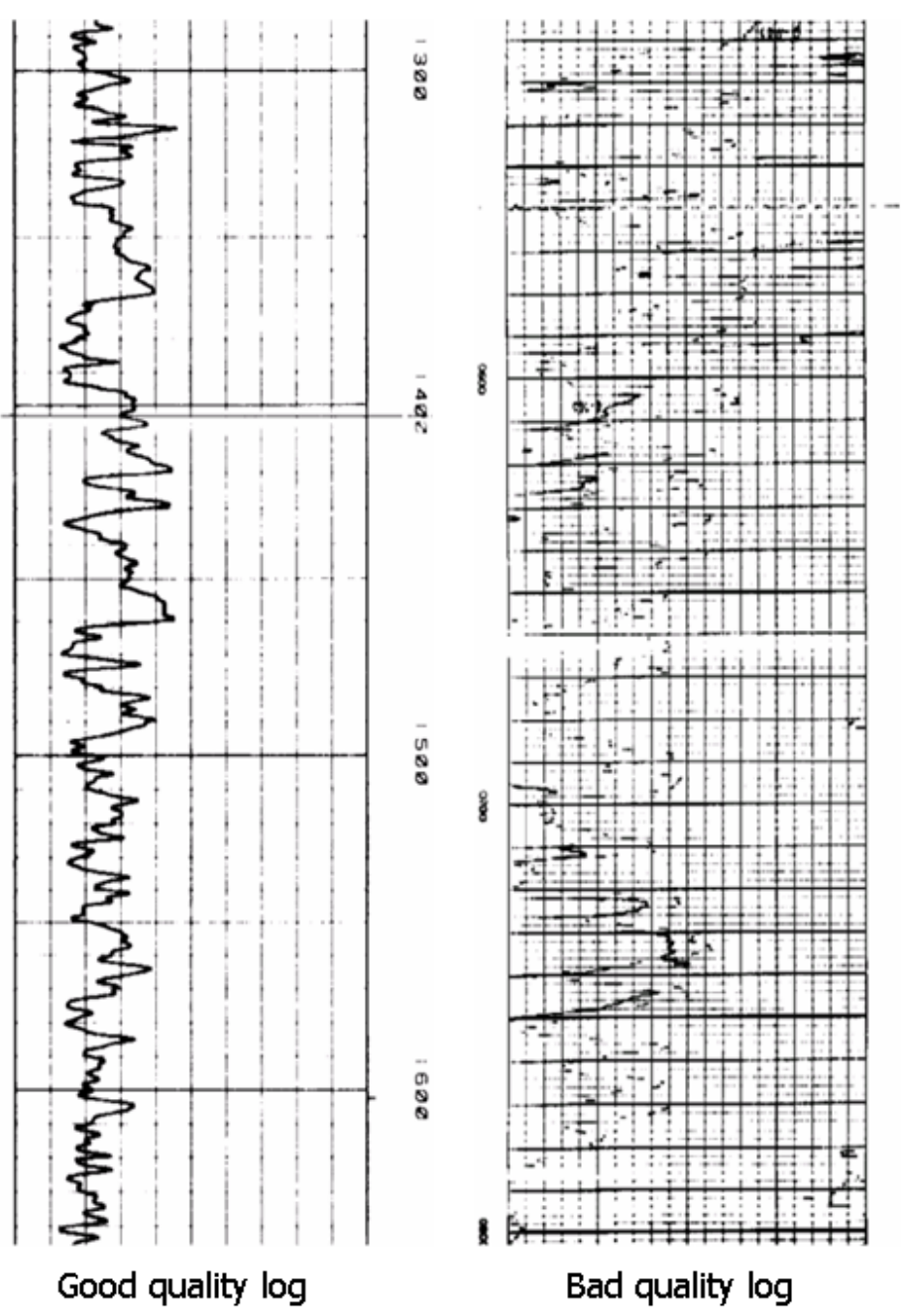

FigURE 4-5: An illustration of logs having good and bad qualities. 
Considering the qualities of the logs, and the location of the VSP well, a seismic line within the seismic survey area was determined to work on. It is a straight line in the SENW direction, and is passing through five wells including the VSP well. It is shown in the Figure 4-5 as a dashed line. The line included 173 seismic traces, with the VSP well, well-1, located on trace 16. Other wells are located on traces 55, 90, 123, and 153, respectively. The surface seismic amplitude distribution of the line is shown in Figure 4-7.

TABLE 4.2: Information about the wells on the selected seismic line including name, available logs with the time interval (sec.), and locations in terms of the trace number.

\begin{tabular}{cc|ccccc} 
& & \multicolumn{5}{|c}{ Well logs } \\
\hline Well & @ & & & & \\
name & Trace \# & Gamma ray & Neutron porosity & Sonic & Velocity & Neutrons \\
\hline Well - 1 & 16 & $0.92-1.092$ & $0.92-1.092$ & & $0.92-1.092$ & \\
Well - 2 & 55 & $0.92-1.089$ & $0.92-1.089$ & $0.92-1.019$ & & \\
Well - 3 & 90 & $0.92-1.07$ & & & $0.92-1.07$ \\
Well - 4 & 123 & $0.92-1.042$ & & & $0.92-1.042$ \\
Well - 5 & 153 & $0.92-1.0415$ & $0.92-1.055$ & & \\
\hline
\end{tabular}

In terms of the seismic data; VSP data were available only for Well-1. Surface seismic data were extracted through the seismic line of interest and were avaliable for an interval of $0.92-1.1$ seconds. A total of 27 attributes were available. 11 of them were provided by the Kingdom Suite, and other 16 attributes were calculated with theoretical relationships. Table 4.3 shows the list of the available attributes.

\subsection{Methodology}

The same methodology with the one followed in the synthetic case study, was applied to real field data. 


\subsubsection{Step 1: Correlation of Surface Seismic with VSP}

First, it was aimed to produce the VSP distributions through the seismic line just like the available surface seismic distributions. Since, there was only one available VSP survey, which was on Well-1, the required correlation models could have only been developed by using the data of that well.

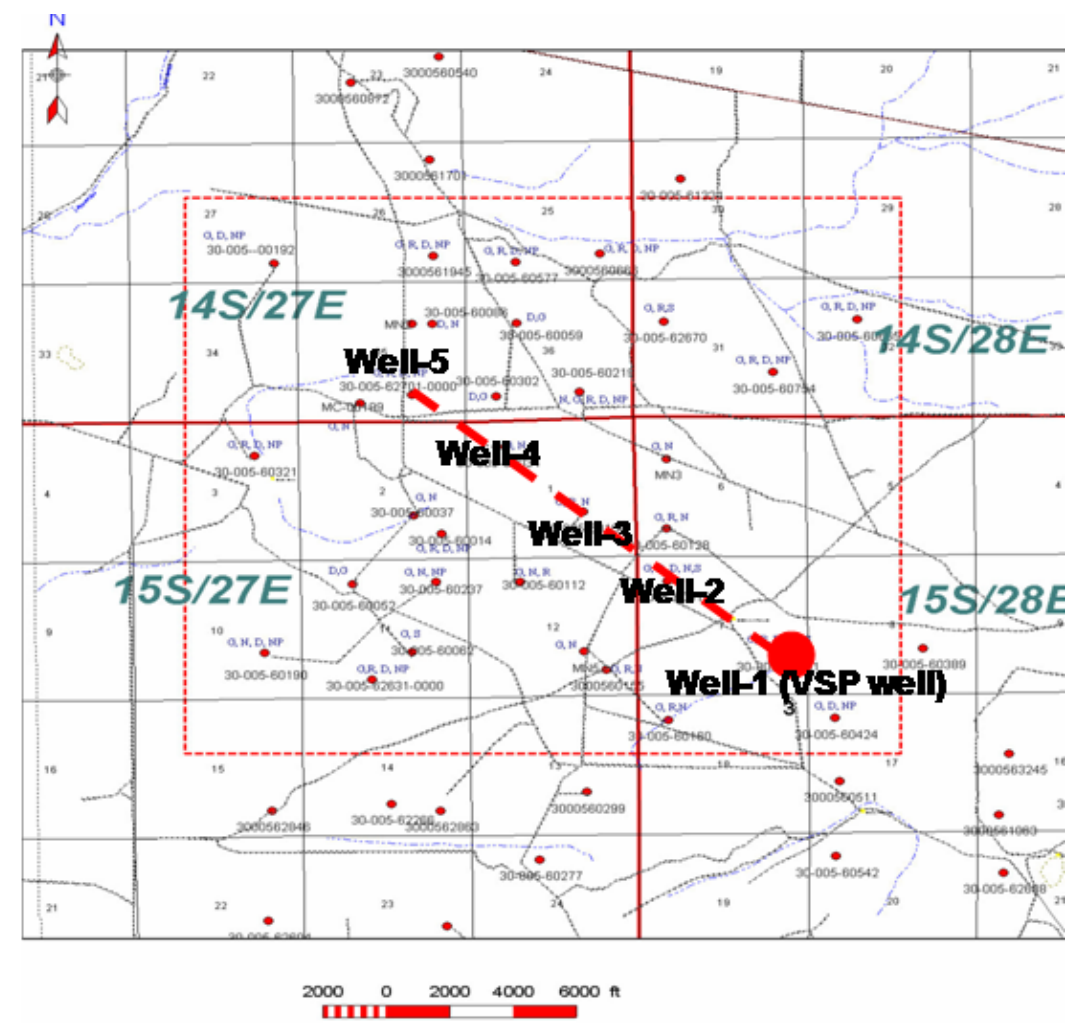

FiguRE 4-6: Map of wells available logs within the seismic survey area of the Buffalo Valley Field. The seismic line chosen to work with, and the five wells on that line are highlighted.

The eleven attributes which were obtained from Kingdom Suite, were used since other attributes were derivable from them. As in the synthetic model study, eleven surface seismic attributes were used together with time, as inputs, to predict the single VSP attribute. Thus, eleven neural network models were developed for eleven attributes. The network structure is shown in Figure 4-8. 
Results were similar to the results of the synthetic model study. They were assumed to be reliable to apply to other sections of the seismic line. Cross-sectional distributions of the eleven attributes were produced from these models for the interval: 0.92-1.1 seconds, passing through 173 traces.

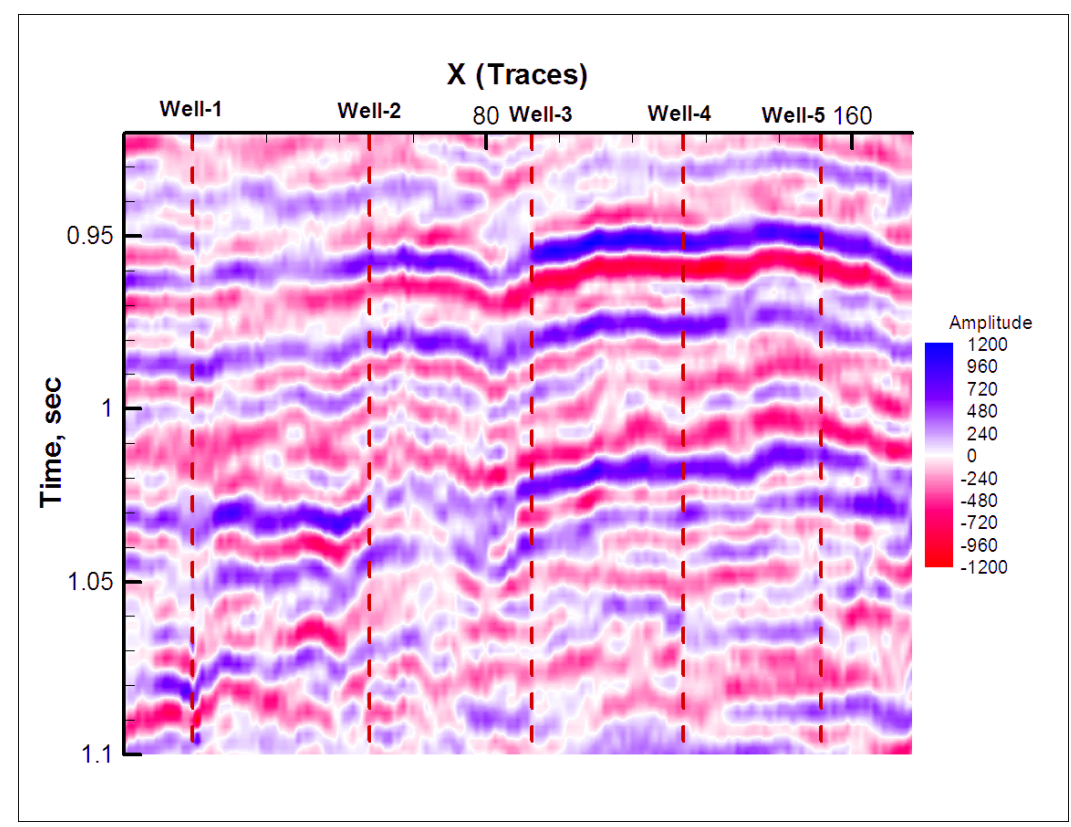

Figure 4-7: Amplitude distribution of the seismic line. Red dashed lines are the five wells that the line is passing through. Well-1 is the well with the VSP survey.

\subsubsection{Step 2: Correlation of VSP with Well Logs}

The approach carried out in this part was to use all the available well data for training, and to apply the model to other parts of the seismic line to obtain the distributions. The main idea is to have a more reliable training model by using all the available data.

In this case, $90 \%$ of the total of 871 rows of data from five wells was used for training, while $10 \%$ was used for calibration during training. Two types of logs; gamma ray and neutron porosity were selected as target logs. Because of the large number of available attributes a Key Performance Indicator (KPI) [30] study was carried out, to determine the most influential attributes. As a result of this study each attribute had a coefficient between 
TABLE 4.3: Seismic attributes used for the field study.

\begin{tabular}{ll} 
From Kingdom Suite & Deriven \\
\hline Amplitude & $1^{\text {st }}$ derivative of amplitude \\
Average Energy & $2^{\text {nd }}$ derivative of amplitude \\
Envelope & $1^{\text {st }}$ derivative of envelope \\
Finite difference & $2^{\text {nd }}$ derivative of envelope \\
Frequency & Instantaneous energy \\
Hilbert transform & Instantaneous power \\
Paraphase & Instantaneous acceleration \\
Peak-to-Trough Ratio & Decay rate \\
Phase & Instantaneous Q, quality factor \\
Signed Frequency & Amplitude weighted phase \\
Seismic inversion & Average frequency \\
& Residual envelope \\
& Integrated residual amplitude \\
& Smoothed envelope \\
& Integrated absolute amplitude \\
& Smoothed inversion \\
\hline
\end{tabular}

0 and 1 , which basically shows the influence of that attribute on the selected output (i.e. logs). The attributes (including the time) were ranked based on their KPI coefficients, and the ones having a coefficient larger than 0.5 were used as inputs. Those rankings for gamma ray and neutron porosity are shown in Table 4.4. The best thirteen attributes for the gamma ray, and the best eight attributes for the neutron porosity had coefficients higher than 0.5, and they were used as the input attributes. The network structure for this part is shown in Figure 4-9.

Training results were analyzed for each well separately, and upon applying those models to the other traces on the seismic line, distributions of gamma ray logs and neutron porosity logs were produced. 

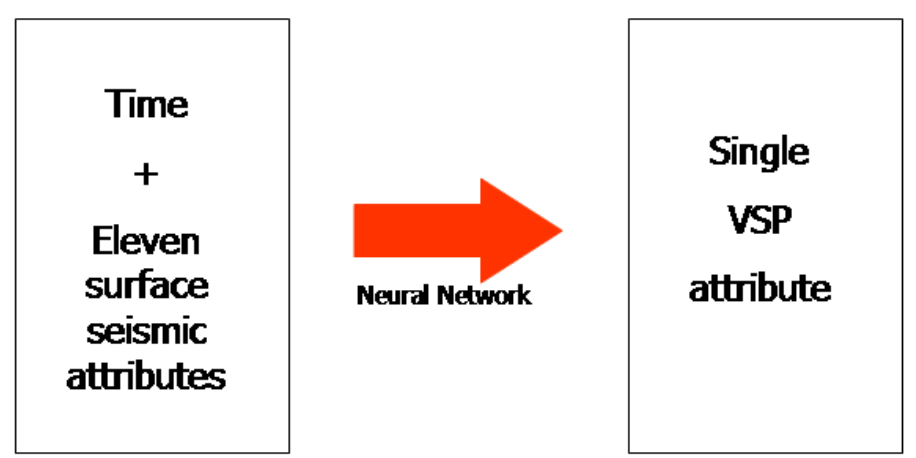

Figure 4-8: Network structures used for training. Data of well-1 have been used, to predict a VSP attribute from time and surface seismic attributes.
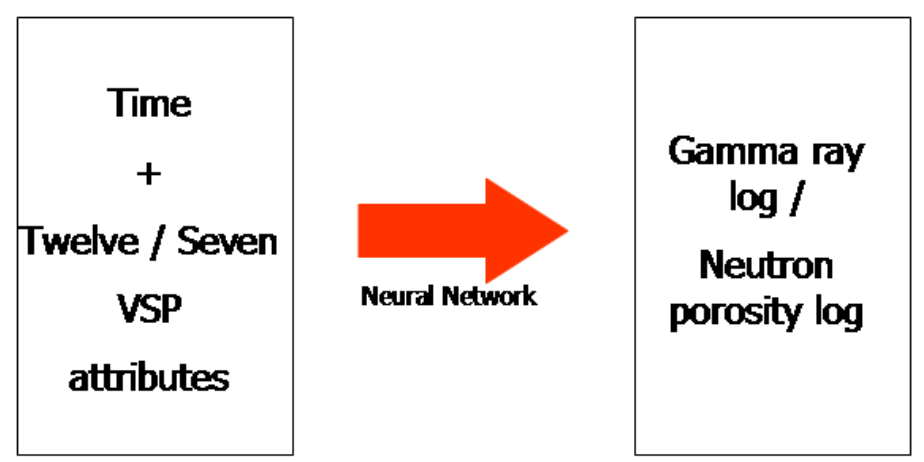

Figure 4-9: Network structures used for training. Data of all wells have been used, to predict gamma ray and neutron porosity logs from time and VSP attributes. 
TABLE 4.4: Ranking of the seismic attributes based on their influence on each type of log, determined by Key Performance Indicator (KPI) studies.

\begin{tabular}{ccc} 
Rank & Gamma Ray & Neutron Porosity \\
\hline 1 & Peak-to-Trough & Amp. weighted phase \\
2 & Smoothed Envelope & Time \\
3 & Finite Difference & Peak-to-Trough \\
4 & Average Frequency & Instant Energy \\
5 & Instant Energy & Smoothed Envelope \\
6 & Envelope & Envelope \\
7 & Time & Amplitude \\
8 & Amp. weighted phase & HF Inversion \\
9 & Amplitude & Finite Difference \\
10 & Phase & Average Energy \\
11 & Hilbert & Average Frequency \\
12 & Smoothed Inversion & Paraphase \\
13 & HF Inversion & Hilbert \\
14 & $1^{\text {st }}$ der. of amplitude & Smoothed Inversion \\
15 & Average Energy & Decay rate \\
16 & Inst. acceleration & Phase \\
17 & Inst. Q factor & Signed frequency \\
18 & Decay rate & Frequency \\
19 & $2^{n d}$ der. of amplitude & $1^{\text {st }}$ der. of amplitude \\
20 & Residual envelope & Inst. residual envelope \\
21 & Frequency & Inst. abs. amplitude \\
22 & Inst. abs. amplitude & Inst. Q factor \\
23 & Inst. residual envelope & $1^{\text {st }}$ der. of envelope \\
24 & $1^{\text {st }}$ der. of envelope & Residual envelope \\
25 & Inst. power & Inst. acceleration \\
26 & Signed frequency & $2^{\text {nd }}$ der. of amplitude \\
27 & Paraphase & $2^{\text {nd }}$ der. of envelope \\
28 & $2^{\text {nd }}$ der. of envelope & Inst. power \\
\hline & &
\end{tabular}




\section{Chapter 5}

\section{Results and Discussions}

\subsection{Synthetic Model Study}

\subsubsection{Step 1: Correlation of Surface Seismic with VSP}

Table 5.1 shows the correlation statistics of the training models developed for this step of the study. Correlation coefficient, r, and r-squared values are included as accuracy indicators of the match. Results for pattern (overall), training, calibration, and verification sets are included.

Figure 5-1 shows the results of the training as actual vs. network-predicted plots for training, calibration, and verification sets of seven attributes. Each set of data is shown with a different symbol and color.

Statistical and visual results indicate that reliable models have been developed. These models have been applied to the whole line (i.e. other traces of the synthetic model). The seismic attribute distributions have been re-produced. They have been re-plotted to be able to compare with the actual distributions. Figures 5-2, 5-3, and 5-4 show the comparison plots for each attribute, after applying the models for these attributes to the entire line. These plots also include the actual log lines of each attribute at traces 20, 35, 50, 65, and, 80 , which makes it easier to assess the quality of the produced distributions.

\subsubsection{Step 2: Correlation of VSP with Well Logs}

For the second step where the density has been predicted; actual vs. network plot of the model is shown in Figure 5-3a. Although the network seemed to be successful in most parts, it has missed some points in the middle-valued region $(0.9-0.96 \mathrm{sec})$, which was assumed to 
TABLE 5.1: Correlation statistics for seven VSP attributes, for the first correlation step of the synthetic model study.

\begin{tabular}{l|cc|cc|cc|cc} 
& \multicolumn{2}{|c|}{ Amplitude } & \multicolumn{2}{|c|}{ Average Energy } & \multicolumn{2}{|c|}{ Envelope } & \multicolumn{2}{c}{ Frequency } \\
\hline & $r^{2}$ & $r$ & $r^{2}$ & $r$ & $r^{2}$ & $r$ & $r^{2}$ & $r$ \\
\hline Pattern & 1.00 & 1.00 & 0.83 & 0.91 & 0.97 & 0.98 & 0.76 & 0.87 \\
Training & 1.00 & 1.00 & 0.84 & 0.92 & 0.98 & 0.99 & 0.76 & 0.87 \\
Calibration & 1.00 & 1.00 & 0.79 & 0.89 & 0.90 & 0.95 & 0.81 & 0.90 \\
Verification & 1.00 & 1.00 & 0.75 & 0.86 & 0.91 & 0.95 & 0.73 & 0.86 \\
\hline
\end{tabular}

\begin{tabular}{l|cc|cc|cc} 
& \multicolumn{2}{|c|}{ Hilbert Transform } & \multicolumn{2}{c|}{ Paraphase } & \multicolumn{2}{c}{ Phase } \\
\hline & $r^{2}$ & $r$ & $r^{2}$ & $r$ & $r^{2}$ & $r$ \\
\hline Pattern & 0.92 & 0.96 & 0.88 & 0.94 & 0.93 & 0.96 \\
Training & 0.93 & 0.96 & 0.89 & 0.94 & 0.97 & 0.99 \\
Calibration & 0.90 & 0.95 & 0.85 & 0.92 & 1.00 & 1.00 \\
Verification & 0.96 & 0.98 & 0.85 & 0.92 & 0.52 & 0.72 \\
\hline
\end{tabular}

belong to Class 2: $2.3 \mathrm{~g} / \mathrm{cc}$. To overcome this problem, it has been decided to introduce another class to our model. Class 4 was assigned to density values around $2.09 \mathrm{~g} / \mathrm{cc}$ (Figure $5-3 \mathrm{~b}$ ). That has helped the network to be successful in that region, too (Figure 5-3b), and this network model has been decided upon to be used in further studies. The correlation statistics of this model are shown in Table 5.2 together with the results for the velocity log.

TABLE 5.2: Correlation statistics for density and velocity, for the second correlation step of the synthetic model study.

\begin{tabular}{l|cc|cc} 
& \multicolumn{2}{|c|}{ Density } & \multicolumn{2}{c}{ Velocity } \\
\hline & $r^{2}$ & $r$ & $r^{2}$ & $r$ \\
\hline Pattern & 0.82 & 0.91 & 0.90 & 0.95 \\
Training & 0.94 & 0.97 & 0.93 & 0.96 \\
Calibration & 0.54 & 0.73 & 0.97 & 0.99 \\
Verification & 0.54 & 0.73 & 0.49 & 0.70 \\
\hline
\end{tabular}

Actual VSP attributes were applied to this model, and density has been predicted along the seismic line with a correlation coefficient of 0.82 . This has been repeated with the predicted VSP attributes coming from the first step of the correlation studies. Density has 
again been predicted through the seismic line with a correlation coefficient value of 0.81 . $87 \%$ of the data points have been predicted correctly in terms of the proposed classes.

Figure 5-6 shows the final actual vs. network-predicted density distributions. It is seen that, the lithological units as well as the sand channels have been successfully predicted by the neural network. With this final result, the goal of predicting density log through the two-step intelligent seismic inversion methodology has been accomplished. The same procedure has also been applied to velocity and acoustic impedance, and their comparisons are shown in Figure 5-7.

\subsection{Real Case Study: The Buffalo Valley Field, NM}

\subsubsection{Step 1: Correlation of Surface Seismic with VSP}

As in the synthetic case, surface seismic - VSP correlation models have been developed, by using time and eleven surface seismic attributes to predict the single VSP attribute. The study was done by using the attributes, which were obtained from the Kingdom Suite as the other attributes can be derived by using those ones.

Table 5.3 shows the correlation statistics for these models for each attribute. Results for pattern, training, calibration, and verification sets are included. Verification results for phase, paraphase, frequency, and signed frequency seemed to be low. However, when plotted it seemed that they were not as bad as they sound with their correlation coefficients. Their actual vs. network graphs are shown in Figures 5-8 and 5-9. Actual vs. network plots for other attributes are shown in Figure 5-10.

These models were then applied to other traces on the seismic line, with the available surface seismic data. VSP distributions were produced through the entire seismic line.

\subsubsection{Step 2: Correlation of VSP with Well Logs}

Gamma ray and neutron porosity were selected as the target logs. The results for these two types of logs are presented below separately.

\section{Gamma Ray Log}

Correlation statistics are shown in Table 5.4 for pattern, training, and calibration sets, respectively. Results are showing both overall statistics, and separate well statistics. Graphs 
that show actual and network-predicted log lines are shown in Figures 5-11 and 5-12 for all wells. Figure 5-13 shows the predicted gamma ray distribution of the seismic line using these models. Actual log lines of five wells are also shown in the plot which may give a chance to compare with the predicted one.

The same methodology has been applied by using surface seismic attributes. Table 5.5 shows the correlation statistics. Figures 5-14 and 5-15 show the actual log lines and network-predicted log results of the training models for five wells. Figure 5-16 shows the predicted distribution.

\section{Neutron Porosity Log}

Neutron porosity log was available in only two wells; well-1 and well-2. Thus, these two wells were used in training. Correlation statistics of these models are shown in Table 5.6 and Table 5.7, for the models with inputs of VSP attributes and surface seismic attributes, respectively. Figure 5-17 show the actual and network-predicted logs for two wells for the model with VSP attributes. Figure 5-18 shows the logs for the model in which surface seismic attributes were used as inputs. Predicted distributions of neutron porosity are shown in Figures 5-19 and 5-20 for two models.

Finally, the most optimum smoothing factors found for each of the network models are shown in Table 5.8 and Table 5.9 for synthetic model study, and real case study, respectively. 


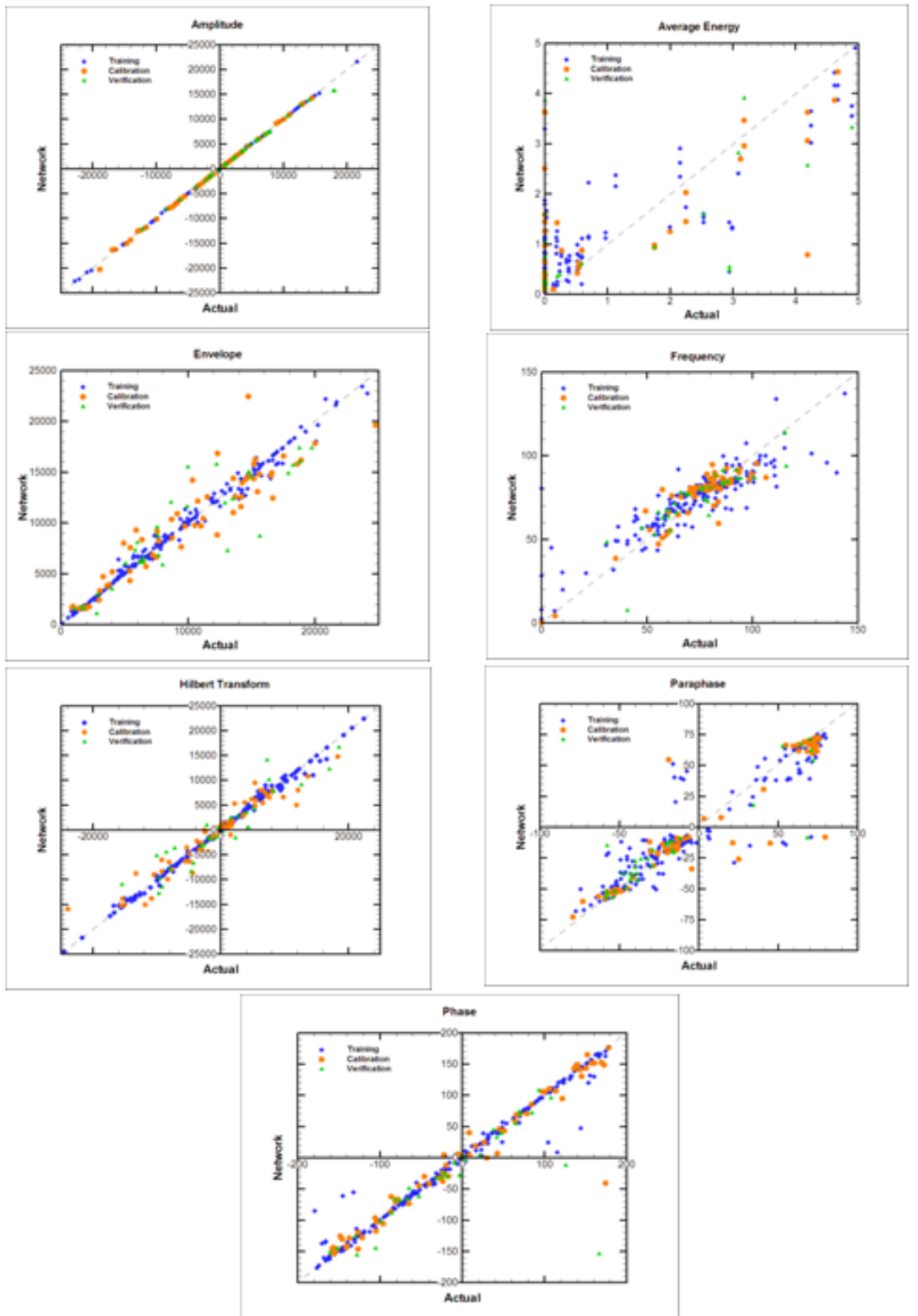

Figure 5-1: Actual vs. network results for each attribute after training the network for surface seismic - VSP correlation. Results for training, calibration, and verification sets are included with different symbols. 


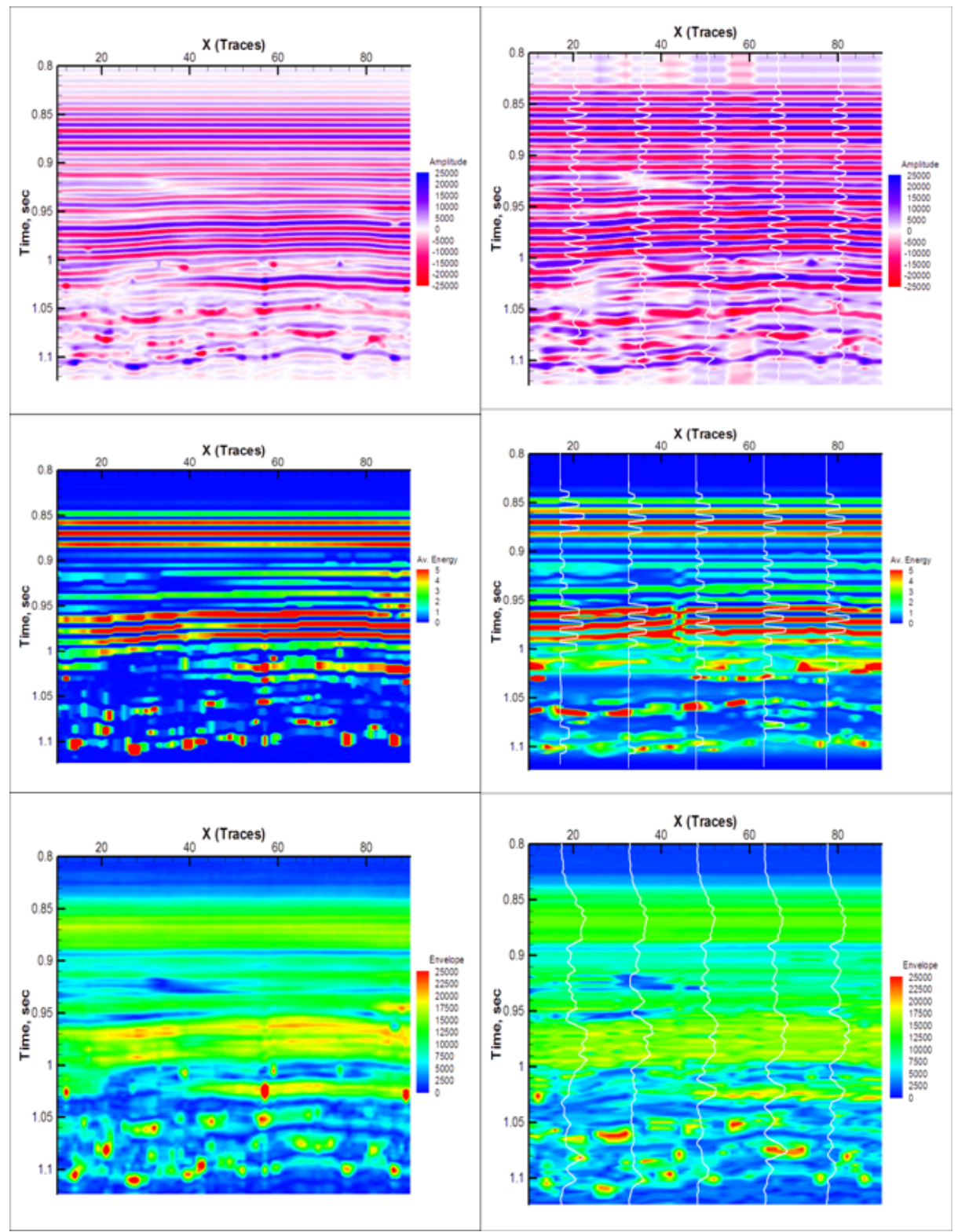

FIGURE 5-2: Actual (left) and network-predicted (right) distributions for VSP attributes: amplitude, average energy, and envelope. 


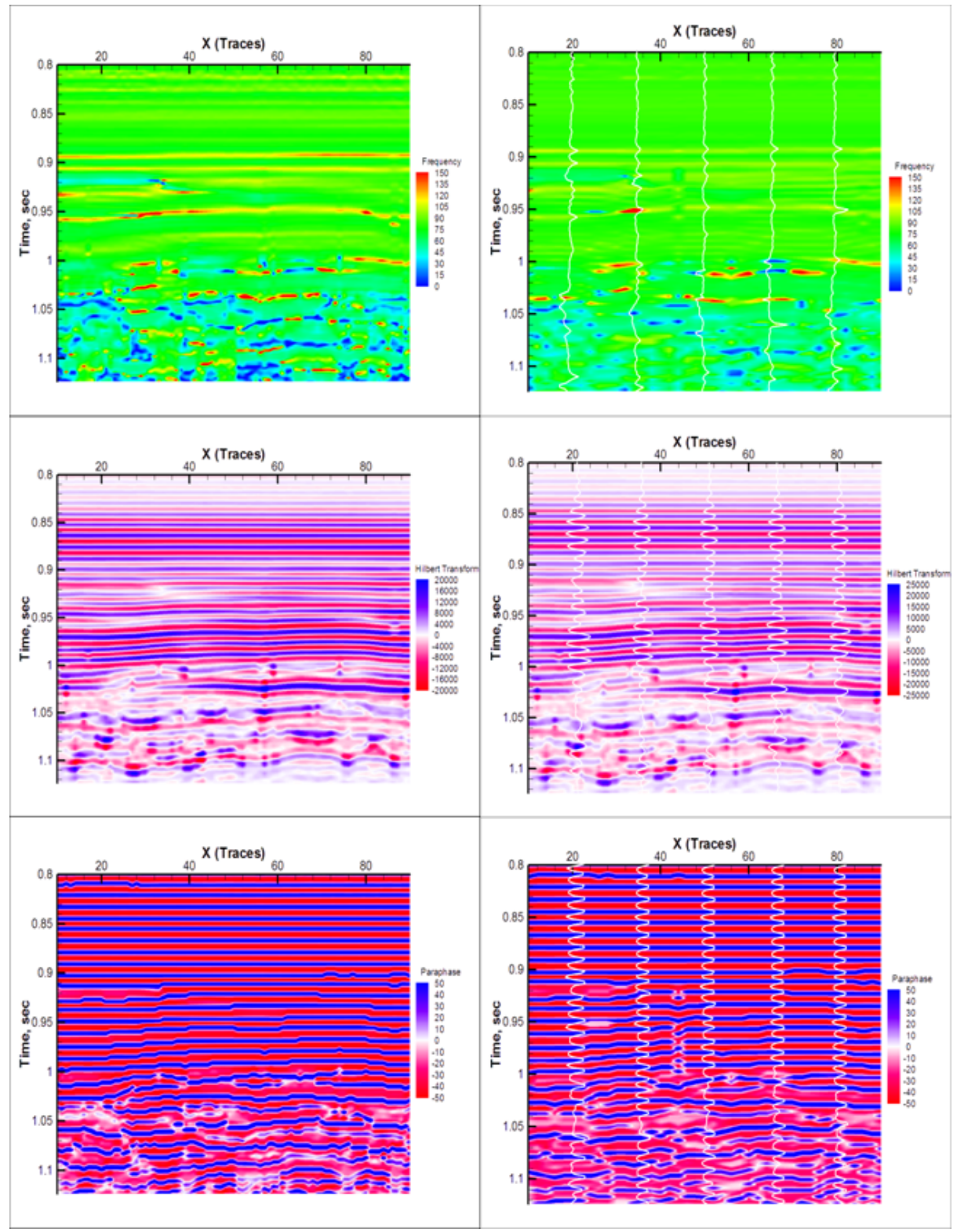

FIGURE 5-3: Actual (left) and network-predicted (right) distributions for VSP attributes: frequency, Hilbert transform, and paraphase. 
TABLE 5.3: Correlation statistics for eleven VSP attributes, for the first correlation step of the real case study.

\begin{tabular}{l|cc|cc|cc|cc} 
& \multicolumn{2}{|c|}{ Amplitude } & \multicolumn{2}{|c|}{ Average Energy } & \multicolumn{2}{|c|}{ Envelope } & \multicolumn{2}{|c}{ Frequency } \\
\hline & $r^{2}$ & $r$ & $r^{2}$ & $r$ & $r^{2}$ & $r$ & $r^{2}$ & $r$ \\
\hline Pattern & 0.97 & 0.98 & 0.96 & 0.98 & 0.98 & 0.99 & 0.34 & 0.58 \\
Training & 1.00 & 1.00 & 0.98 & 0.99 & 0.98 & 0.99 & 0.92 & 0.96 \\
Calibration & 0.91 & 0.95 & 0.98 & 0.99 & 0.98 & 0.99 & 0.83 & 0.91 \\
Verification & 0.90 & 0.95 & 0.85 & 0.92 & 0.85 & 0.92 & 0.21 & 0.46 \\
\hline
\end{tabular}

\begin{tabular}{l|cc|cc|cc|cc} 
& \multicolumn{2}{|c|}{ Finite Difference } & \multicolumn{2}{|c|}{ Hilbert Transform } & \multicolumn{2}{|c|}{ Phase } & \multicolumn{2}{c}{ Paraphase } \\
\hline & $r^{2}$ & $r$ & $r^{2}$ & $r$ & $r^{2}$ & $r$ & $r^{2}$ & $r$ \\
\hline Pattern & 0.92 & 0.96 & 0.98 & 0.99 & 0.64 & 0.80 & 0.79 & 0.89 \\
Training & 0.98 & 0.99 & 0.98 & 0.99 & 0.96 & 0.98 & 0.98 & 0.89 \\
Calibration & 0.98 & 0.99 & 0.98 & 0.99 & 0.74 & 0.86 & 0.90 & 0.95 \\
Verification & 0.83 & 0.91 & 0.92 & 0.96 & 0.41 & 0.64 & 0.29 & 0.54 \\
\hline
\end{tabular}

\begin{tabular}{l|cc|cc|cc} 
& \multicolumn{2}{|c|}{ Peak-to-Trough } & \multicolumn{2}{c|}{ Signed Frequency } & \multicolumn{2}{c}{ Inversion } \\
\hline & $r^{2}$ & $r$ & $r^{2}$ & $r$ & $r^{2}$ & $r$ \\
\hline Pattern & 0.93 & 0.96 & 0.46 & 0.68 & 0.98 & 0.99 \\
Training & 0.98 & 0.99 & 0.98 & 0.99 & 0.98 & 0.99 \\
Calibration & 0.90 & 0.95 & 0.86 & 0.93 & 0.98 & 0.99 \\
Verification & 0.79 & 0.89 & 0.09 & 0.30 & 0.98 & 0.99 \\
\hline
\end{tabular}

TABLE 5.4: Correlation statistics for the pattern, training, and calibration sets of the training model. VSP attributes were used as inputs to predict the gamma ray log.

\begin{tabular}{l|cc|cc|cc} 
& \multicolumn{2}{|c|}{ Pattern } & \multicolumn{2}{c|}{ Training } & \multicolumn{2}{c}{ Calibration } \\
\hline Well & $r^{2}$ & $r$ & $r^{2}$ & $r$ & $r^{2}$ & $r$ \\
\hline All & 0.77 & 0.88 & 0.79 & 0.89 & 0.60 & 0.77 \\
Well-1 & 0.58 & 0.76 & 0.57 & 0.75 & 0.73 & 0.85 \\
Well-2 & 0.75 & 0.86 & 0.76 & 0.87 & 0.67 & 0.82 \\
Well-3 & 0.66 & 0.81 & 0.72 & 0.85 & 0.27 & 0.52 \\
Well-4 & 0.76 & 0.90 & 0.77 & 0.88 & 0.27 & 0.52 \\
Well-5 & 0.81 & 0.90 & 0.82 & 0.91 & 0.69 & 0.83 \\
\hline
\end{tabular}




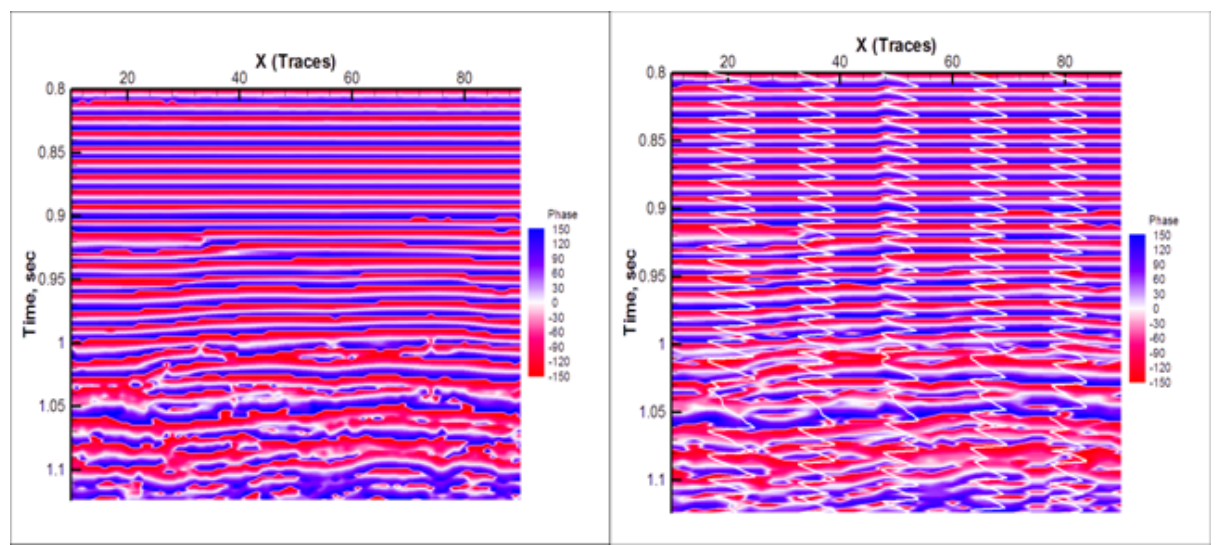

FigURE 5-4: Actual (left) and network-predicted (right) distributions for VSP attribute phase.

TABLE 5.5: Correlation statistics for the pattern, training, and calibration sets of the training model. Surface seismic attributes were used as inputs to predict the gamma ray $\log$.

\begin{tabular}{l|cc|cc|cc} 
& \multicolumn{2}{|c|}{ Pattern } & \multicolumn{2}{c|}{ Training } & \multicolumn{2}{c}{ Calibration } \\
\hline Well & $r^{2}$ & $r$ & $r^{2}$ & $r$ & $r^{2}$ & $r$ \\
\hline All & 0.94 & 0.97 & 0.69 & 0.83 & 0.82 & 0.91 \\
Well-1 & 0.96 & 0.98 & 0.98 & 0.99 & 0.82 & 0.91 \\
Well-2 & 0.93 & 0.96 & 0.95 & 0.97 & 0.77 & 0.88 \\
Well-3 & 0.95 & 0.98 & 0.98 & 0.99 & 0.63 & 0.79 \\
Well-4 & 0.91 & 0.99 & 0.92 & 0.96 & 0.80 & 0.90 \\
Well-5 & 0.97 & 0.98 & 0.97 & 0.99 & 0.86 & 0.92 \\
\hline
\end{tabular}



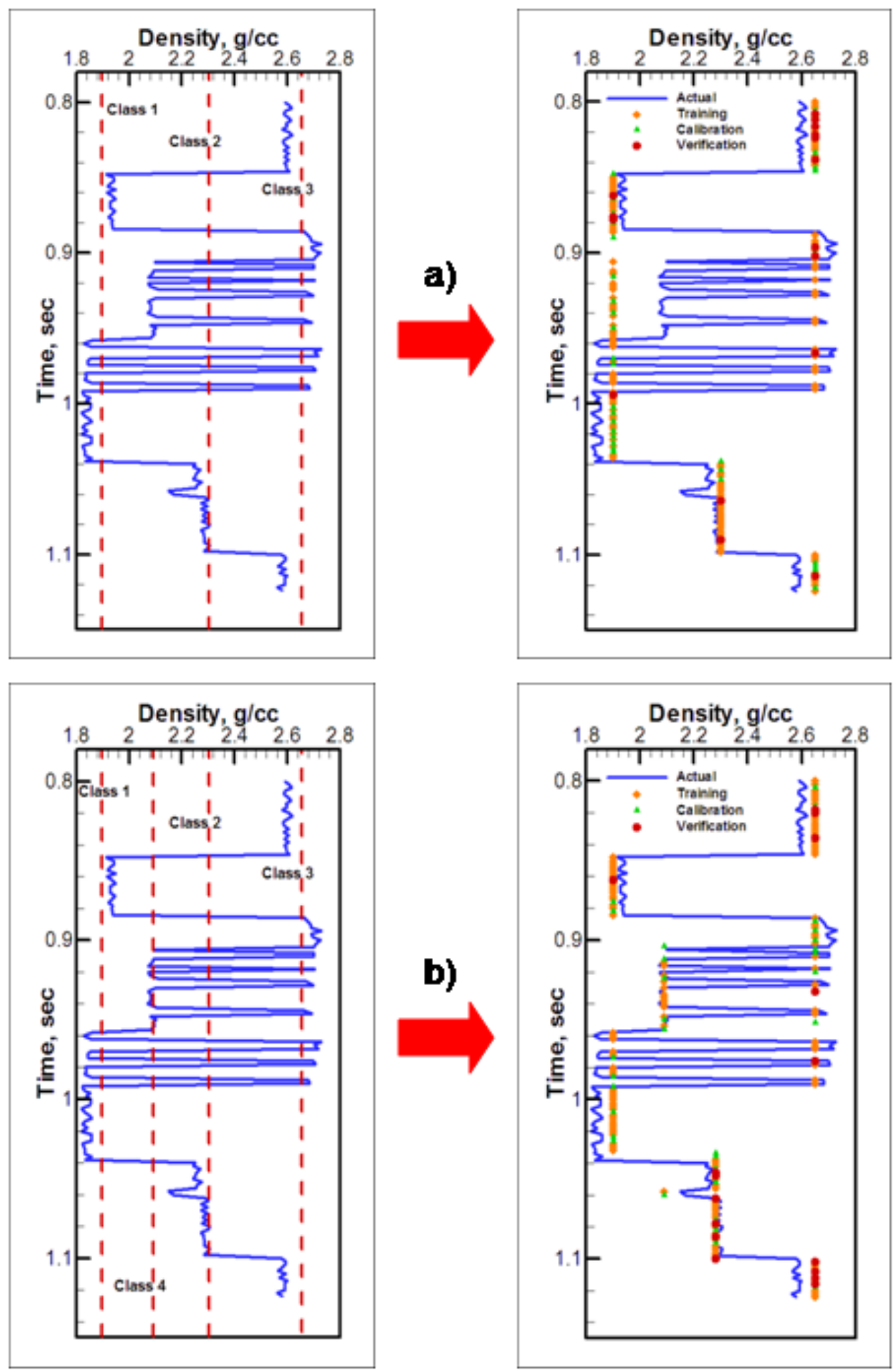

Figure 5-5: Defining density classes, and the corresponding training results. a) Three classes $(1.9,2.3,2.65)$. Training $\left.r^{2}=0.82, \mathrm{~b}\right)$ Four classes $(1.9,2.09,2.3$, 2.65). Training $r^{2}=0.94$ 

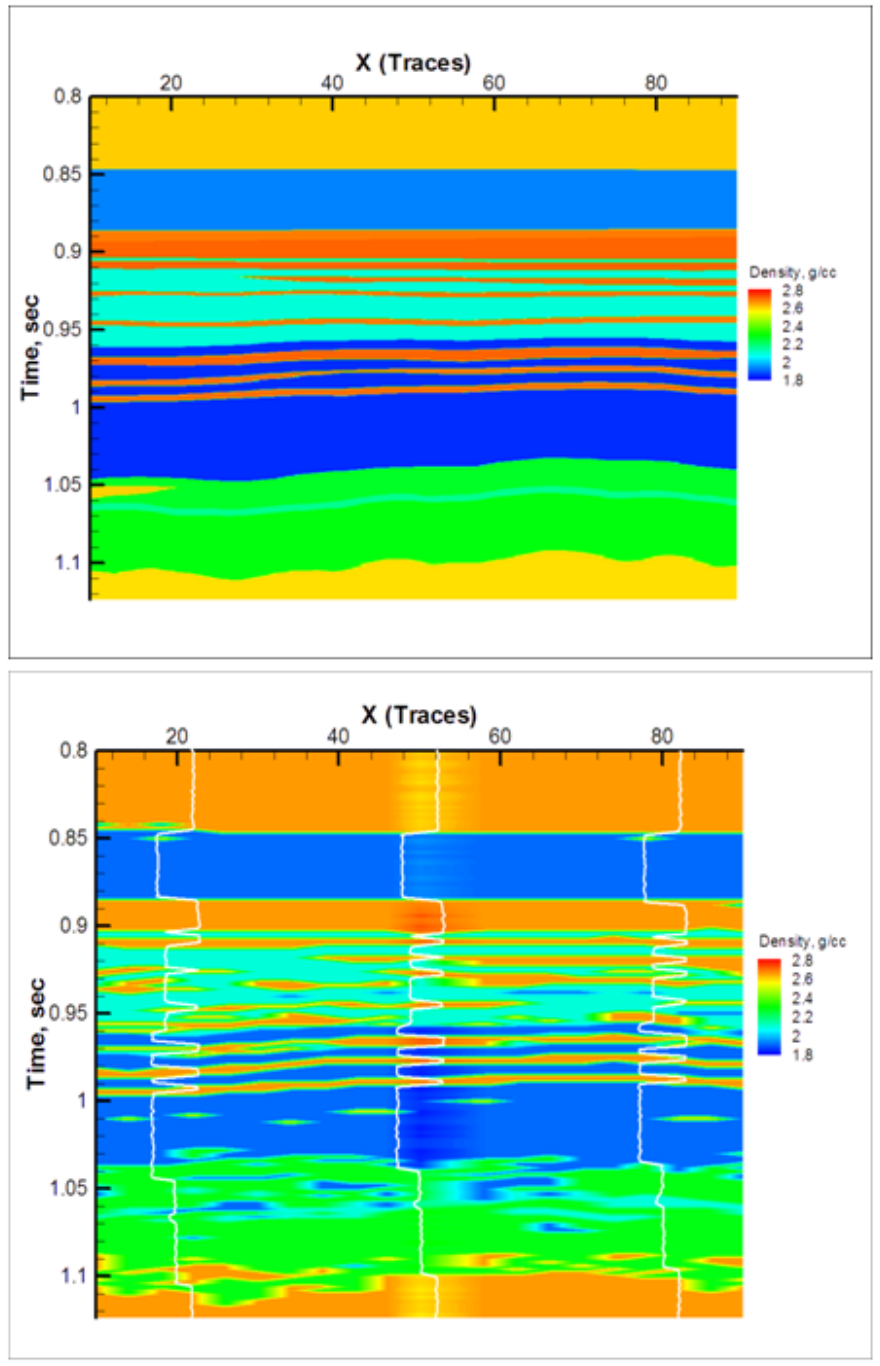

Figure 5-6: Actual (top), and network-predicted (bottom) distributions of density values $(\mathrm{r}=0.81)$. In terms of classes; $87 \%$ of the data points have been predicted correctly. 

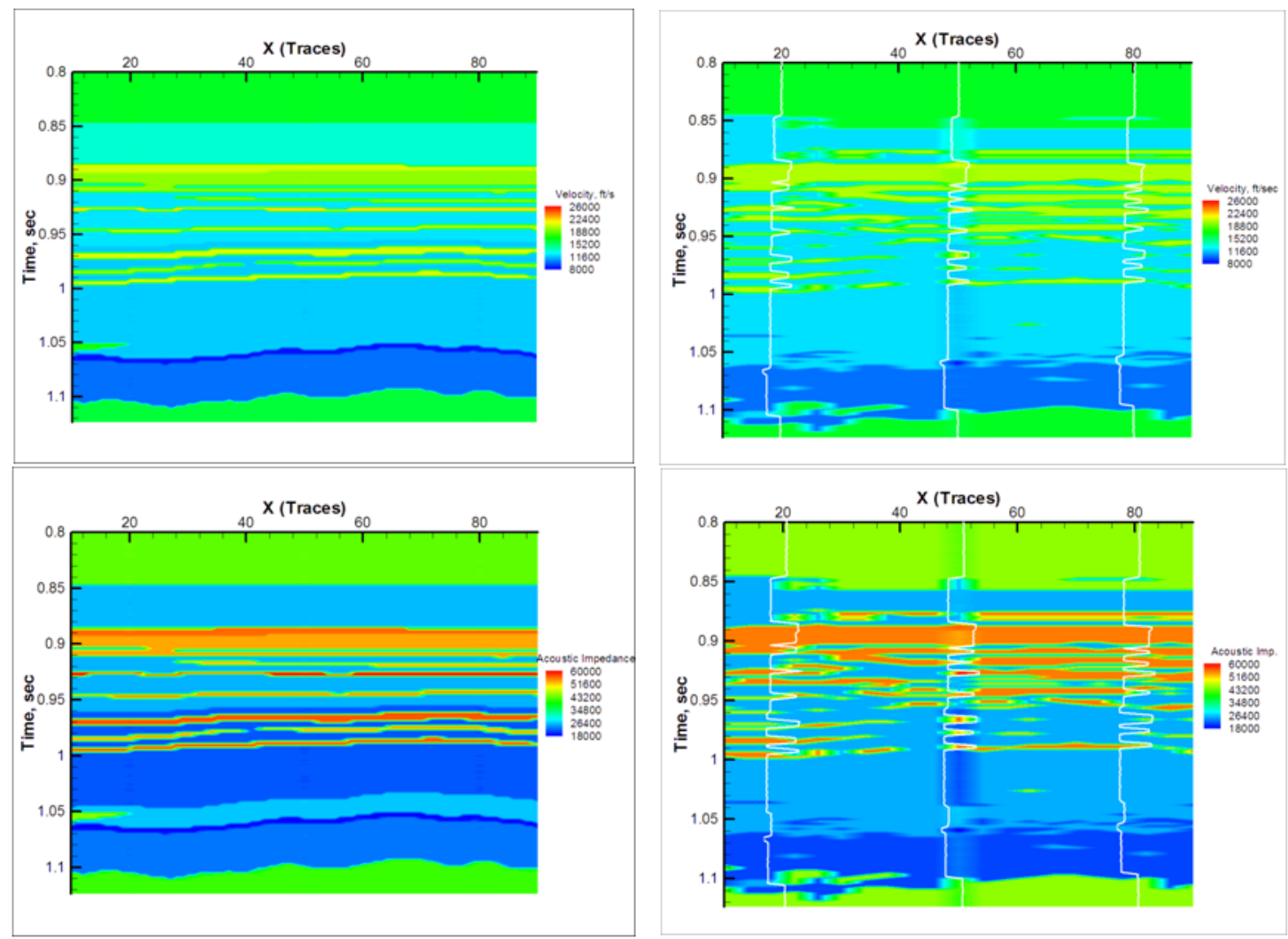

Figure 5-7: Actual (left), and network-predicted (right) distributions of velocity (top), and acoustic impedance (bottom). 


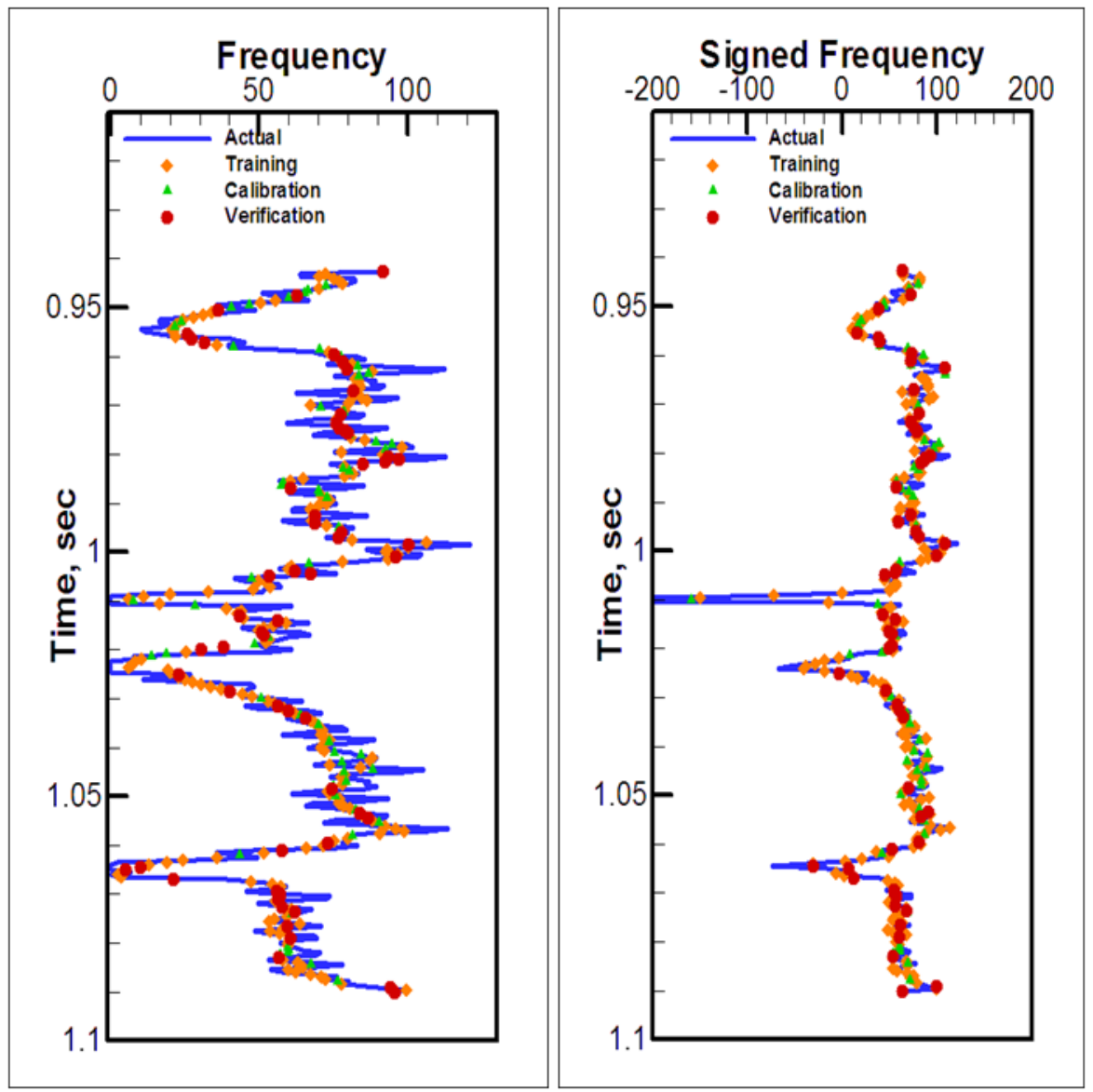

FigURE 5-8: Actual vs. network plots for frequency and signed frequency shown as logs. Although having relatively low correlation coefficient values, visual plots show promise. 

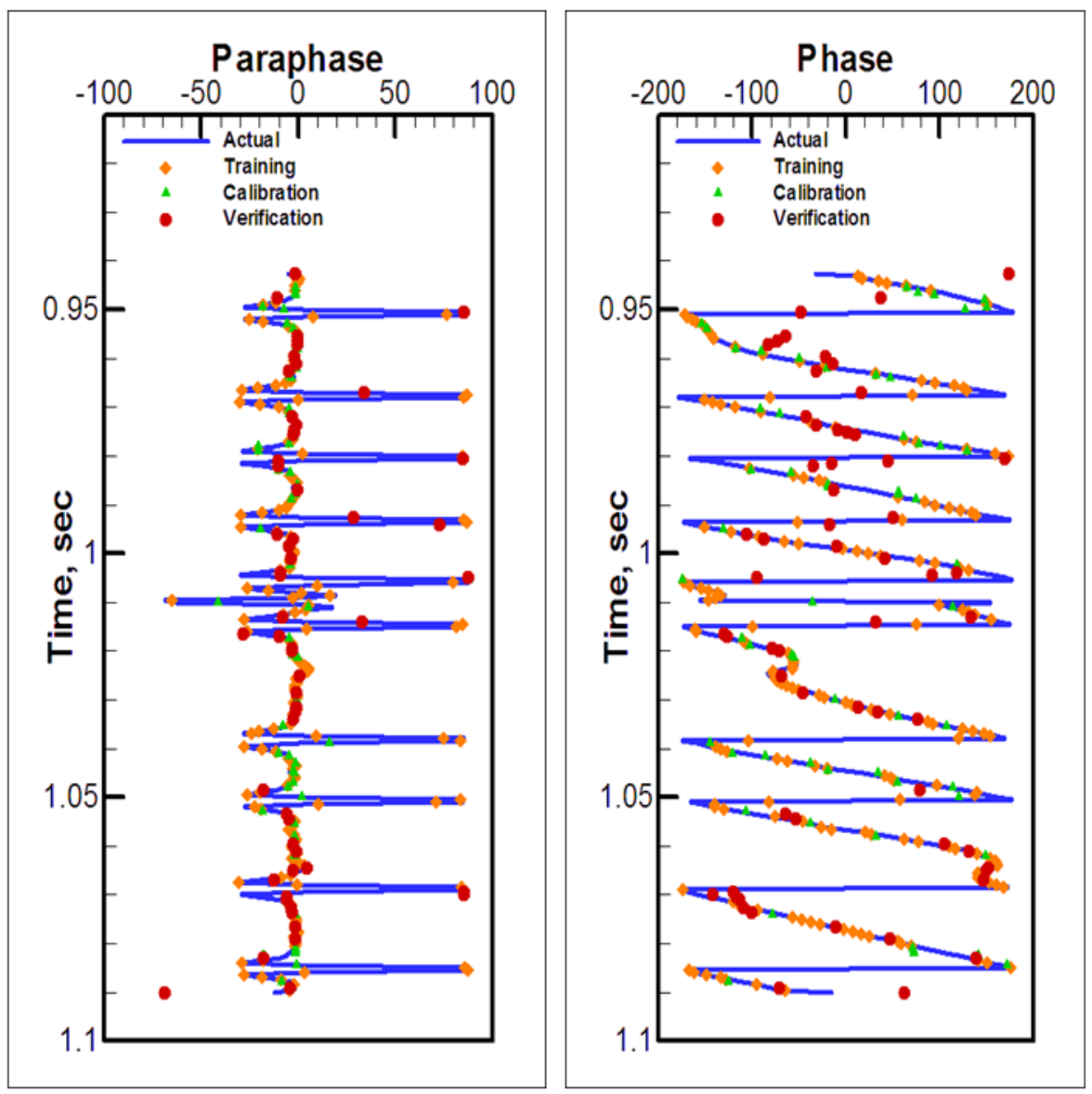

Figure 5-9: Actual vs. network plots for phase and paraphase shown as logs. Although having relatively low correlation coefficient values, visual plots show promise. 

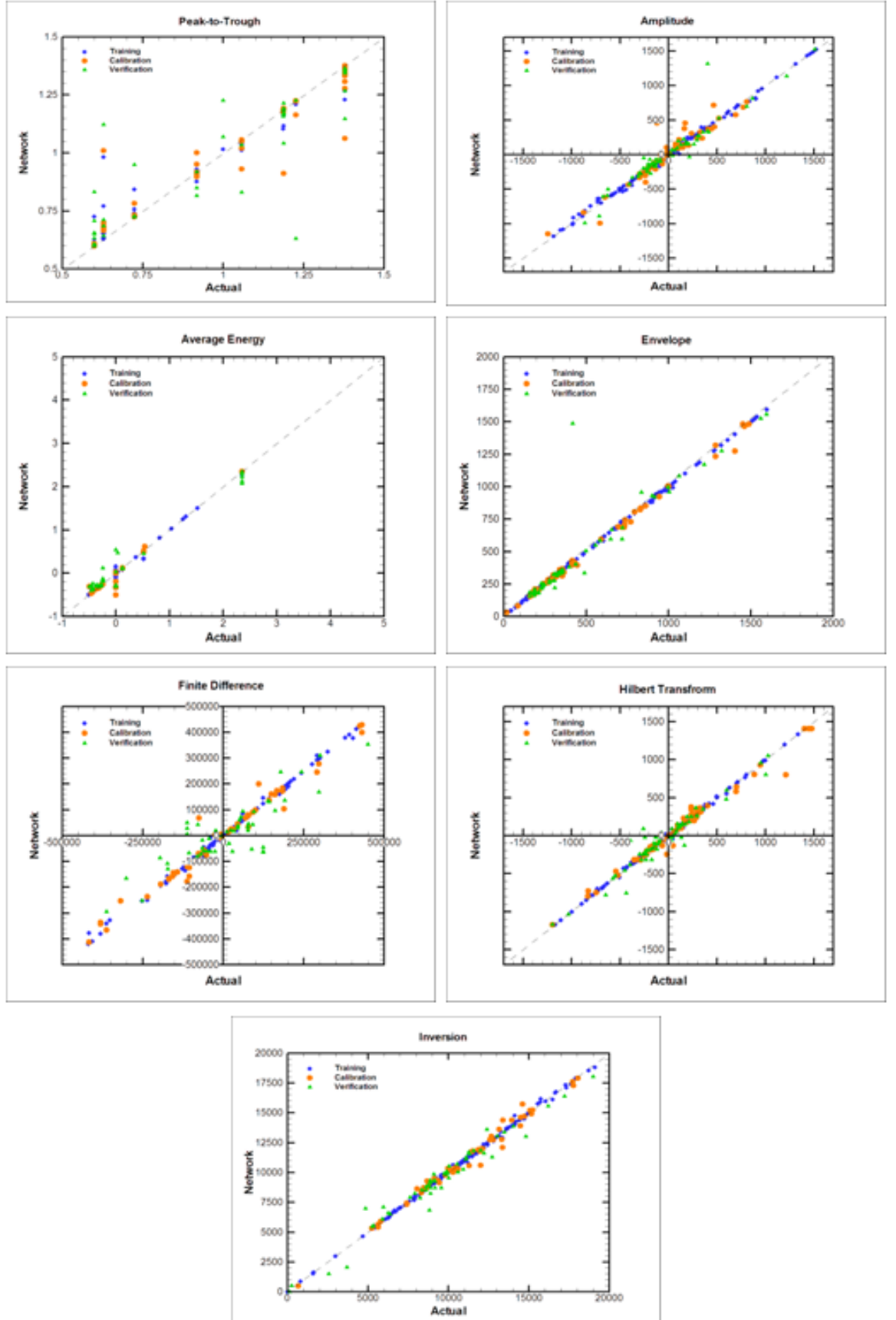

Figure 5-10: Actual vs. network plots for seven of the attributes, that had satisfactory correlation statistics. Training, calibration, and verification sets are included with different symbols and colors. 

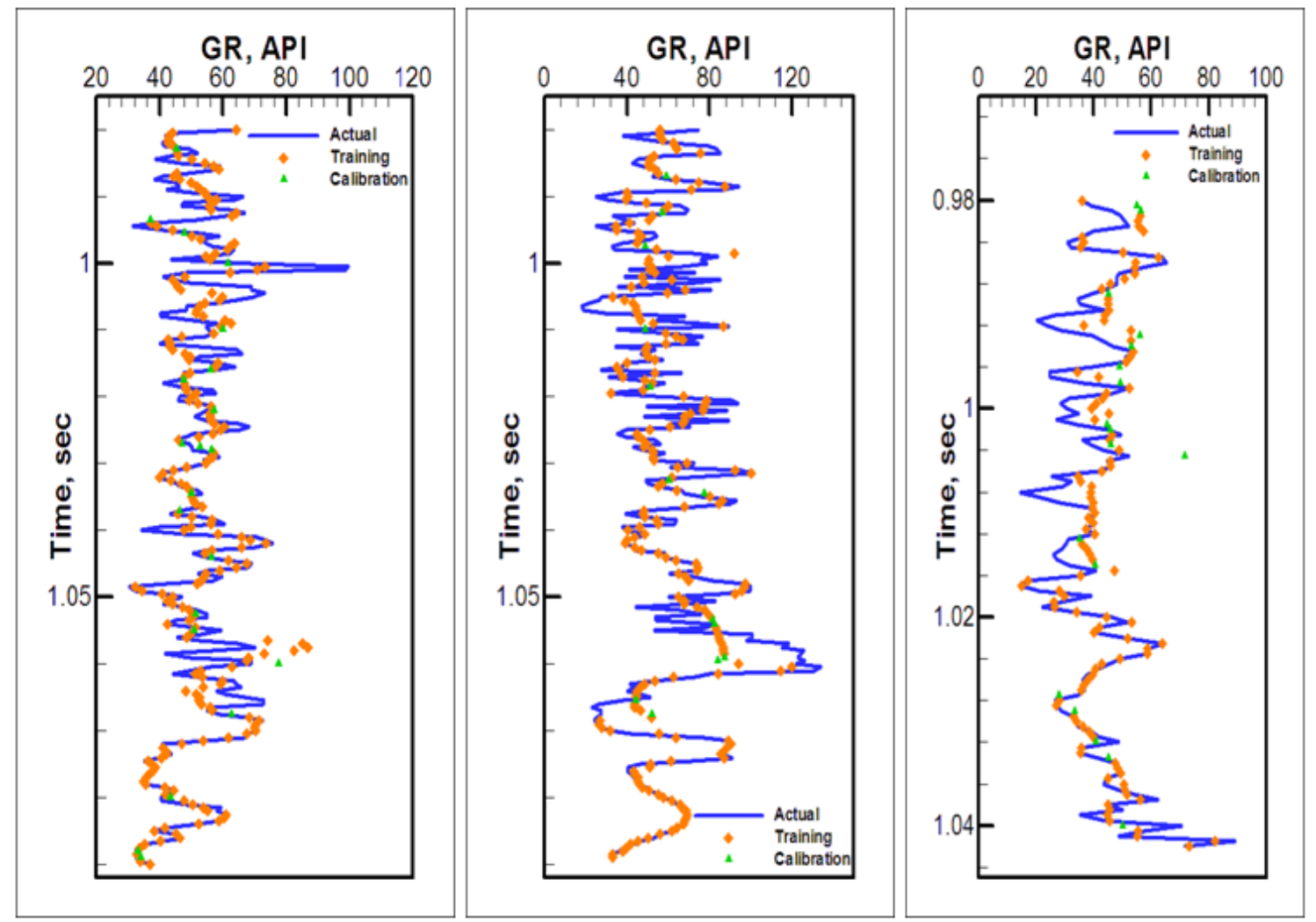

FiguRE 5-11: Actual and network-predicted gamma ray logs for wells 1, 2, and 3. Values for training, and calibration sets are included. VSP attributes were used as inputs. 

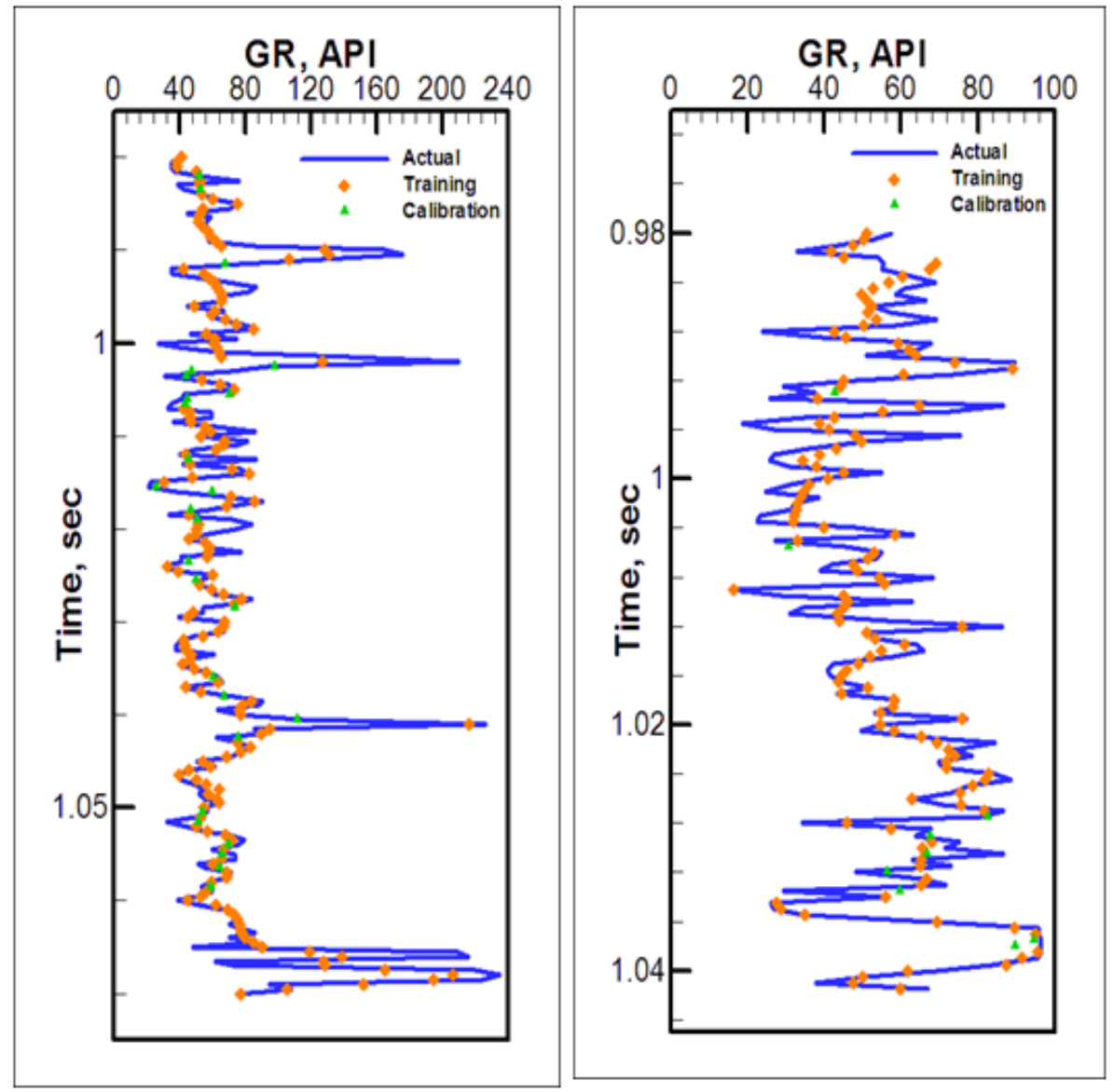

FiguRE 5-12: Actual and network-predicted gamma ray logs for wells 4, and 5. Values for training, and calibration sets are included. VSP attributes were used as inputs. 


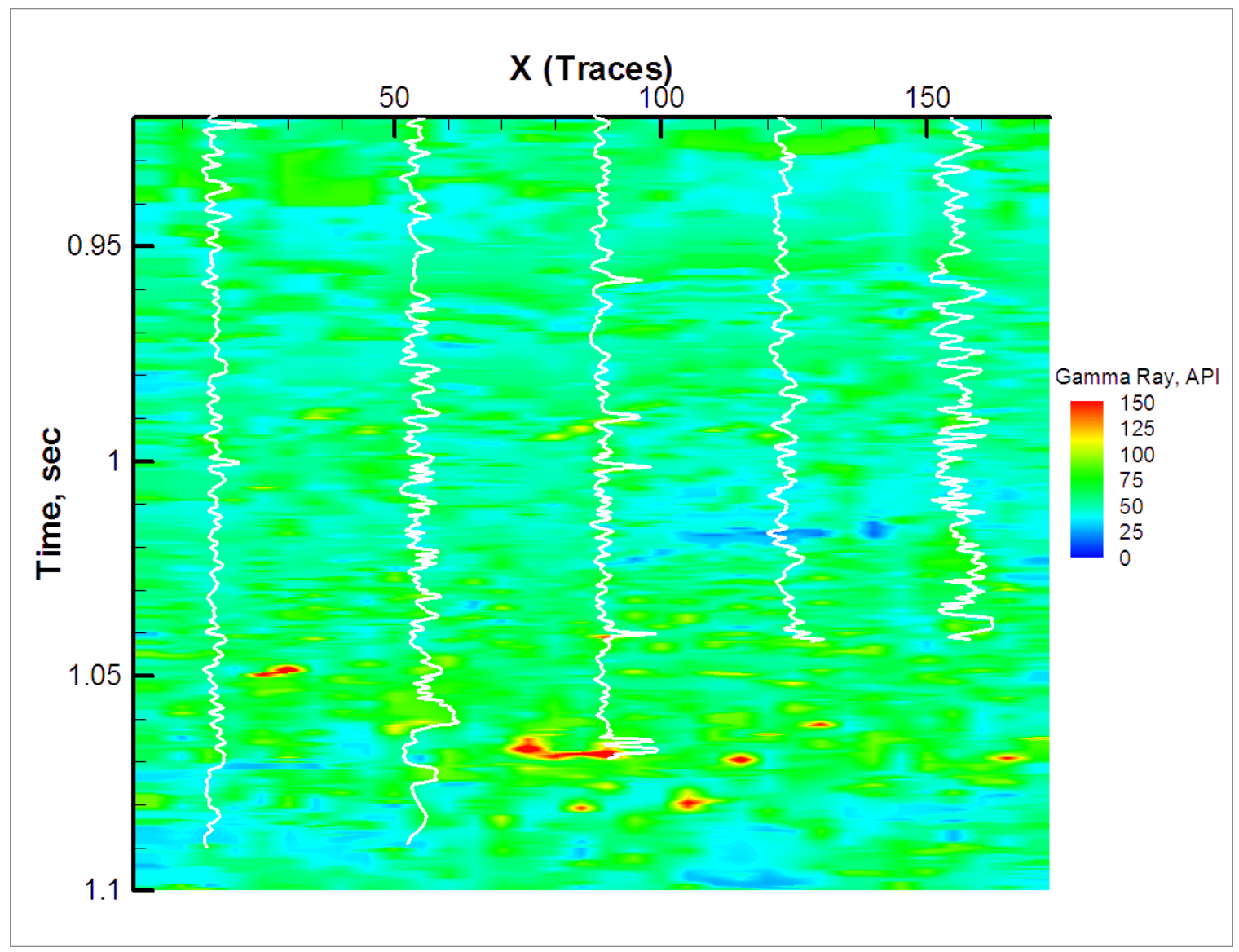

FIGURE 5-13: Network-predicted gamma ray distribution through the seismic line of interest. Actual log lines are also shown for five wells on the line. VSP attributes were used as inputs. 

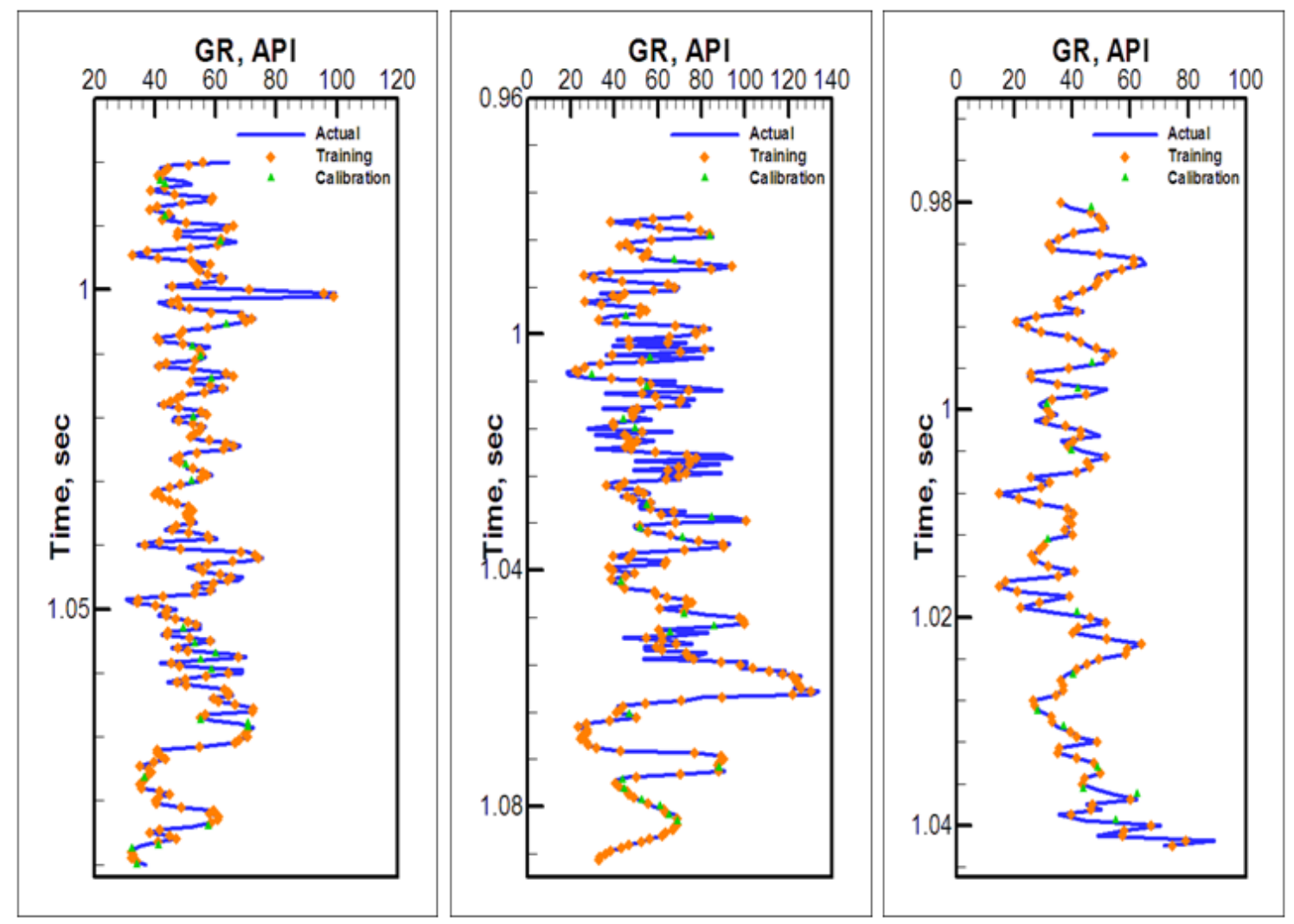

FiguRE 5-14: Actual and network-predicted gamma ray logs for wells 1, 2, and 3. Values for training, and calibration sets are included. Surface seismic attributes were used as inputs. 

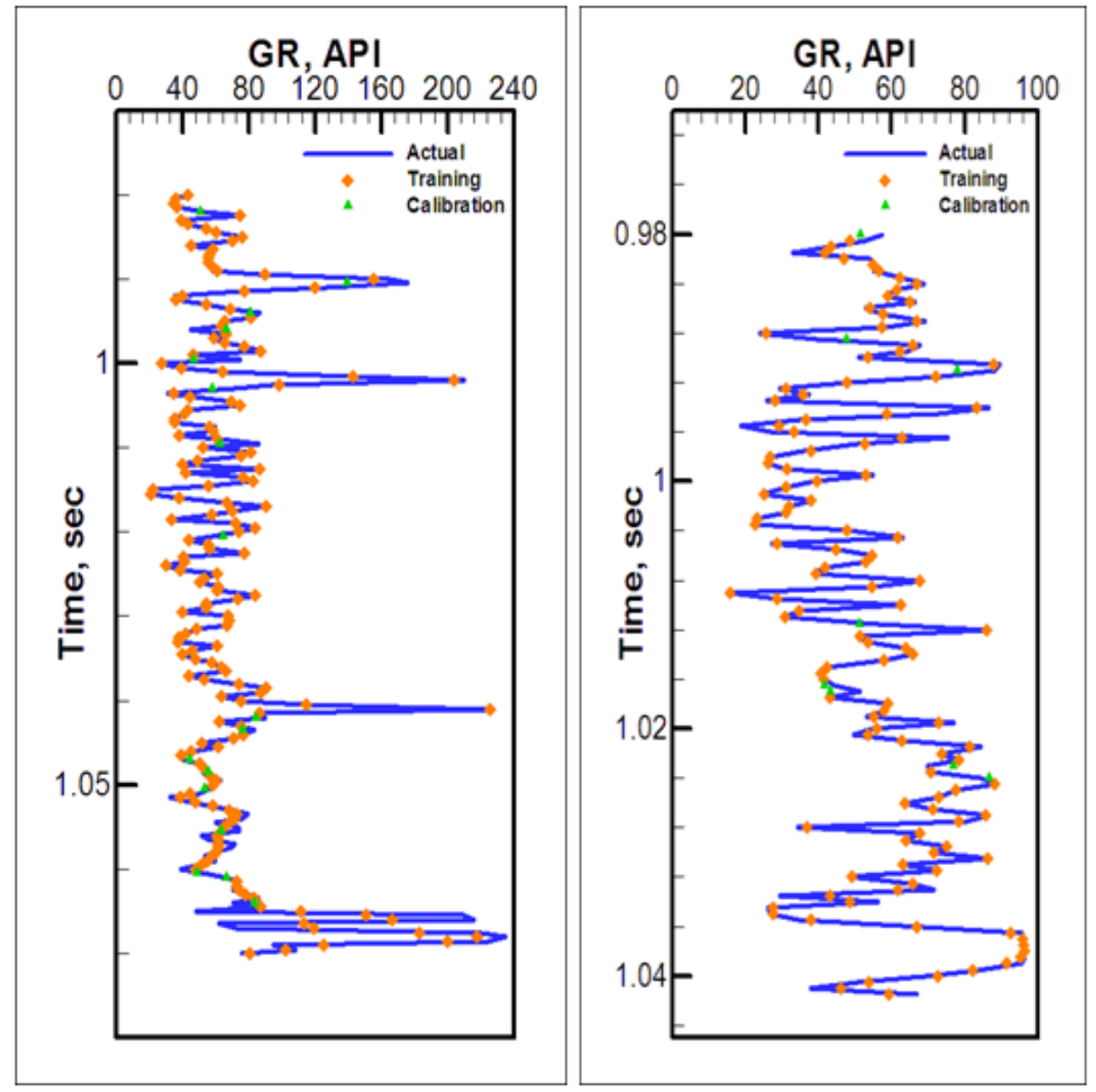

FiguRE 5-15: Actual and network-predicted gamma ray logs for wells 4, and 5. Values for training, and calibration sets are included. Surface seismic attributes were used as inputs. 


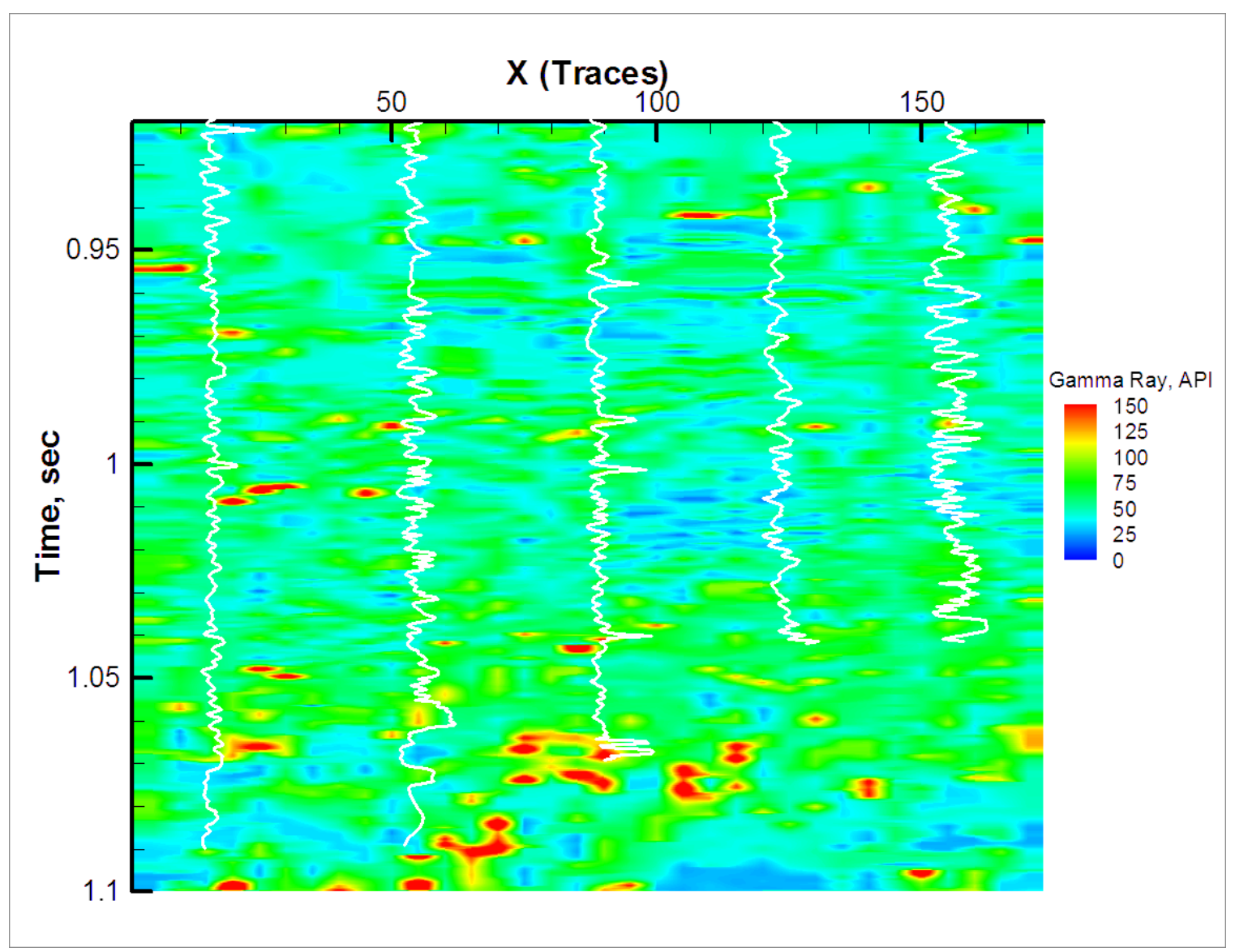

FigURE 5-16: Network-predicted gamma ray distribution through the seismic line of interest. Actual log lines are also shown for five wells on the line. Surface seismic attributes were used as inputs. 
TABLE 5.6: Correlation statistics for the pattern, training, and calibration sets of the training model. VSP attributes were used as inputs to predict the neutron porosity $\log$.

\begin{tabular}{l|cc|cc|cc} 
& \multicolumn{2}{|c|}{ Pattern } & \multicolumn{2}{c|}{ Training } & \multicolumn{2}{c}{ Calibration } \\
\hline Well & $r^{2}$ & $r$ & $r^{2}$ & $r$ & $r^{2}$ & $r$ \\
\hline All & 0.95 & 0.97 & 0.96 & 0.98 & 0.82 & 0.91 \\
Well-1 & 0.95 & 0.98 & 0.97 & 0.98 & 0.77 & 0.88 \\
Well-2 & 0.94 & 0.97 & 0.95 & 0.97 & 0.89 & 0.94 \\
\hline
\end{tabular}

TABLE 5.7: Correlation statistics for the pattern, training, and calibration sets of the training model. Surface seismic attributes were used as inputs to predict the neutron porosity log.

\begin{tabular}{l|cc|cc|cc} 
& \multicolumn{2}{|c|}{ Pattern } & \multicolumn{2}{c|}{ Training } & \multicolumn{2}{c}{ Calibration } \\
\hline Well & $r^{2}$ & $r$ & $r^{2}$ & $r$ & $r^{2}$ & $r$ \\
\hline All & 0.85 & 0.92 & 0.83 & 0.93 & 0.78 & 0.88 \\
Well-1 & 0.88 & 0.94 & 0.89 & 0.94 & 0.81 & 0.90 \\
Well-2 & 0.80 & 0.89 & 0.81 & 0.90 & 0.76 & 0.87 \\
\hline
\end{tabular}

TABLE 5.8: Optimum smoothing factors for GRNN prediction models for the VSP attributes and logs for the synthetic model study.

\begin{tabular}{l|c} 
Attribute / Log & Smoothing factor, $\sigma$ \\
\hline Amplitude & 0.01 \\
Average energy & 0.0411 \\
Envelope & 0.1342 \\
Frequency & 0.2895 \\
Hilbert transform & 0.076 \\
Paraphase & 0.1148 \\
Phase & 0.0411 \\
\hline Density & 0.0255 \\
Velocity & 0.0255 \\
\hline
\end{tabular}




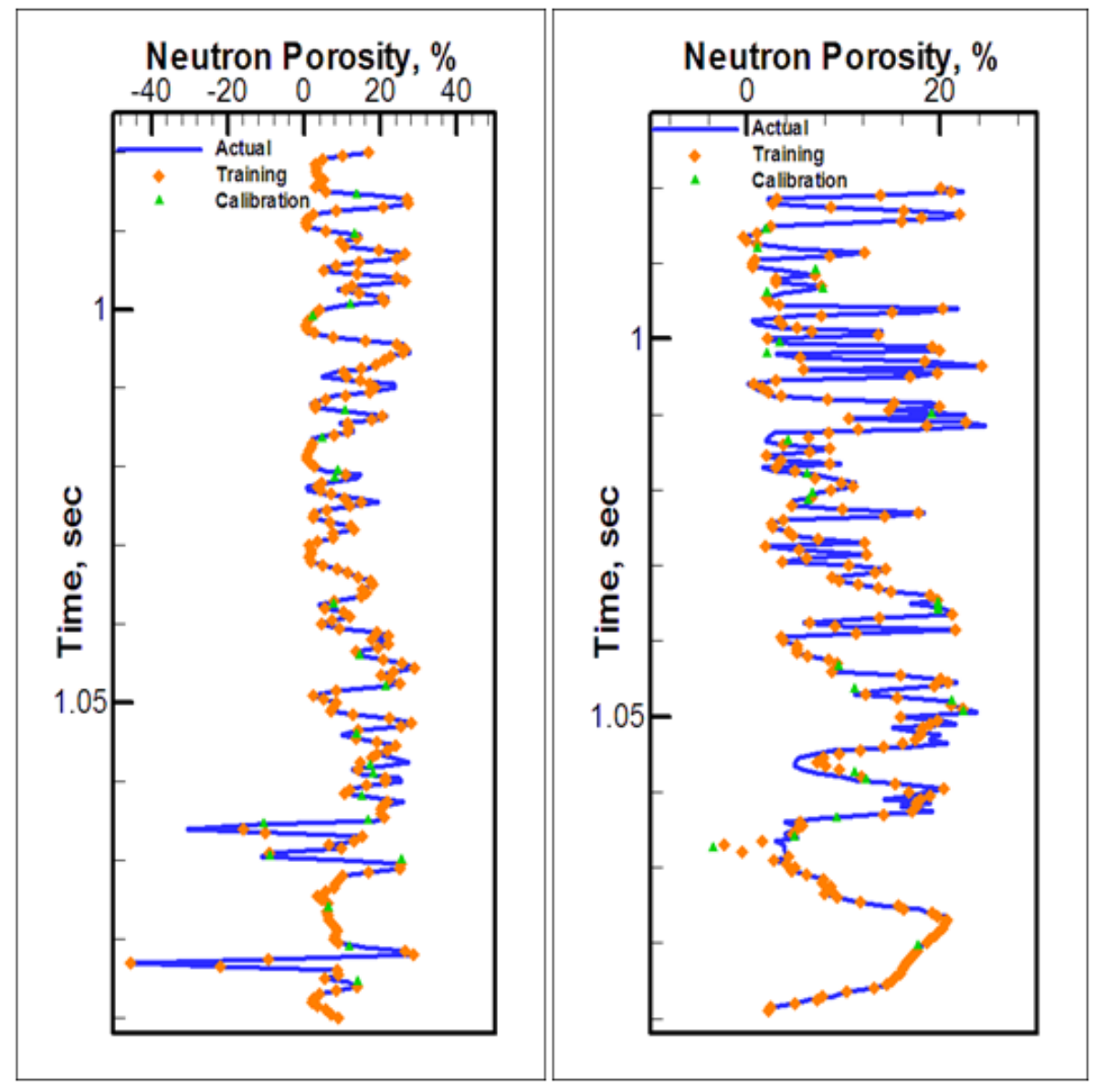

FigURE 5-17: Actual and network-predicted neutron porosity logs for wells 1, and 2. Values for training, and calibration sets are included. VSP attributes were used as inputs. 

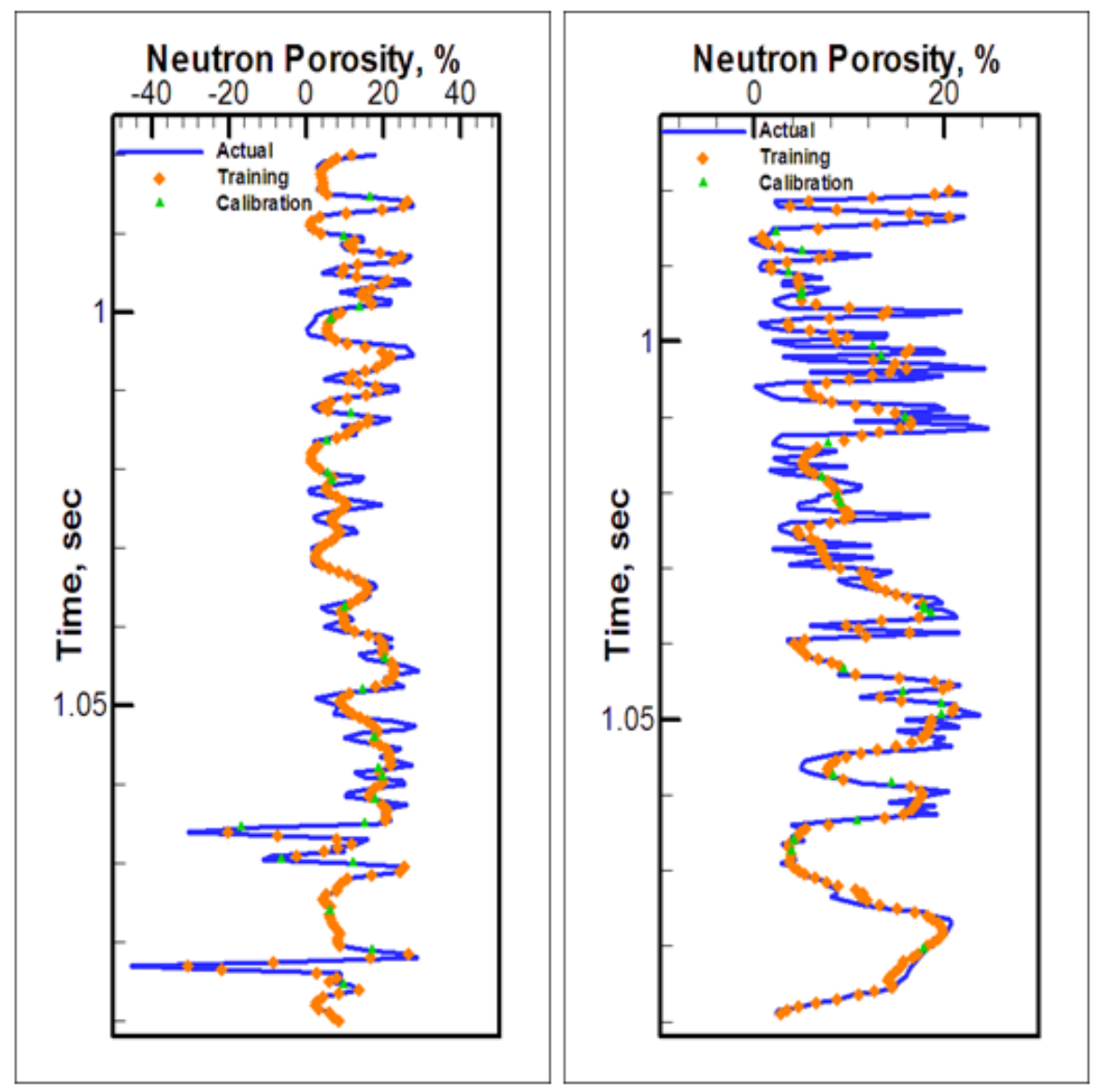

FigURE 5-18: Actual and network-predicted neutron porosity logs for wells 1, and 2. Values for training, and calibration sets are included. Surface seismic attributes were used as inputs. 


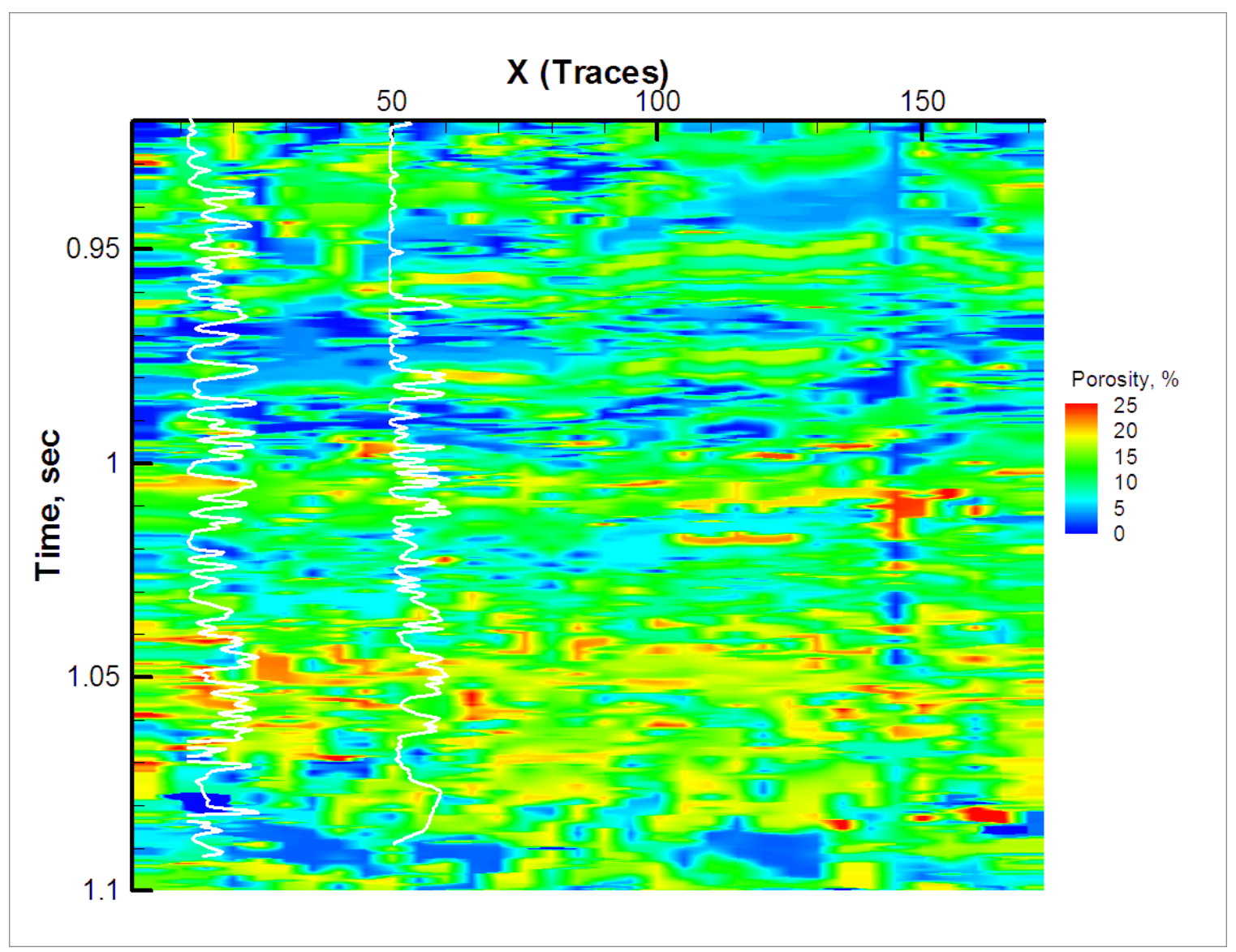

FIGURE 5-19: Network-predicted gamma ray distribution through the seismic line of interest. Actual log lines are also shown for two wells on the line. VSP attributes were used as inputs. 


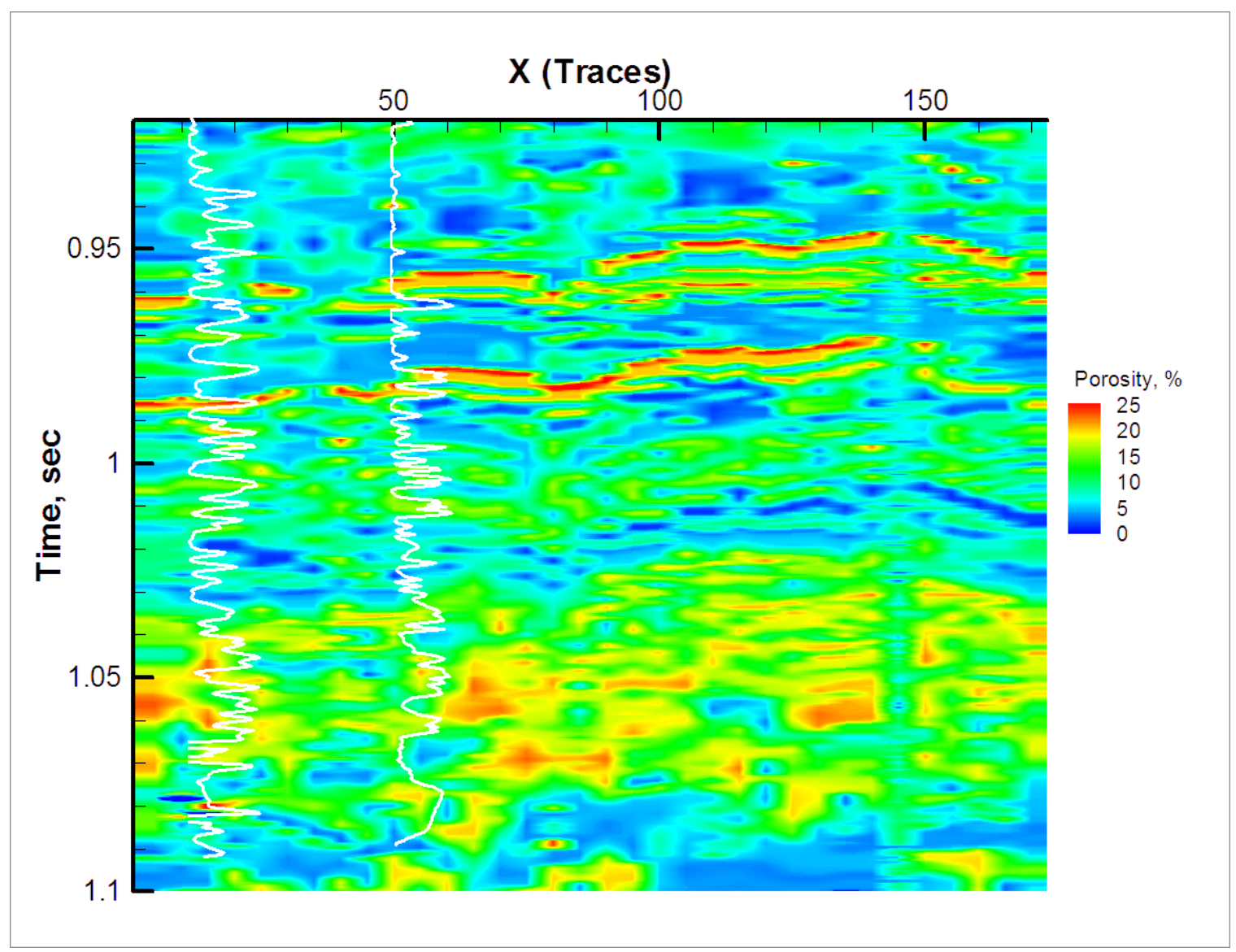

FIGURE 5-20: Network-predicted gamma ray distribution through the seismic line of interest. Actual log lines are also shown for two wells on the line. Surface seismic attributes were used as inputs. 
TABLE 5.9: Optimum smoothing factors for GRNN prediction models for the VSP attributes and logs for the real case study.

\begin{tabular}{l|c} 
Attribute / Log & Smoothing factor, $\sigma$ \\
\hline Amplitude & 0.1148 \\
Average energy & 0.2701 \\
Envelope & 0.0721 \\
Finite difference & 0.0411 \\
Frequency & 0.1304 \\
Hilbert transform & 0.0449 \\
Inversion & 0.0799 \\
Paraphase & 0.0411 \\
Peak-to-trough ratio & 0.2585 \\
Phase & 0.076 \\
Signed Frequency & 0.0411 \\
\hline Gamma ray (from VSP) & 0.2585 \\
Neutron porosity (from VSP) & 0.0294 \\
Gamma ray (from surface seismic) & 0.1537 \\
Neutron porosity (from surface seismic) & 0.1342 \\
\hline
\end{tabular}




\section{Chapter 6}

\section{Concluding Remarks}

The common aim of all geoscientists is to characterize the reservoir spatially, and with highresolution to be input to reservoir simulators to accurately predict the reservoir performance. Data integration has remained as the most challenging issue for reservoir characterization, due to the availability of many different type of multi-scaled data. In this thesis, a novel solution for one of the most important problems in reservoir characterization is presented.

The methodology presented here includes predicting well logs from seismic data through the integration of three types and scales of data: surface seismic, vertical seismic profile (VSP), and well logs. As one of the major tools of soft computing, artificial neural networks have been used to extract the complex and non-linear relationship between these three types of data.

The study is divided into two by a synthetic model study, and a real case study. As a result, different types of logs such as density, gamma ray, and neutron porosity have been produced from seismic data with the proposed methodology. Main conclusions and potential future work for this study are explained in the following sections.

\subsection{Conclusions}

Considering the results presented in Chapter 5, the major findings of this study can be summarized as follows:

1. Even being in a complex and non-linear manner, it was shown that a relationship does exist between various seismic attributes and reservoir properties. Such a relationship can be extracted by using artificial neural networks, as one of the major soft computing 
tools. As an useful algorithm in approximating continuous functions, generalized regression neural network (GRNN) was suggested and applied successfully in this study.

2. Benefits of using a synthetic seismic model were clearly seen in developing the appropriate methodology by identifying the most appropriate neural network algorithm and testing to use other tools. The synthetic model not only made it easy to be familiar with the type of data that is dealt with, but also provided the opportunity of comparing results for a whole seismic section. Although it was not applicable for the field study, the synthetic model was used for a classification (lithology identification) approach.

3. Although there are several examples of using artificial neural networks to correlate seismic attributes to reservoir properties, or well logs, this study is first of its kind because of integrating three types and scales of data. The idea of using an intermediate scale has been introduced by Reeves et al. [14] in 2002, but never has been utilized in the same study. In this study, vertical seismic profile (VSP) has been used as an intermediate scale data. This increases the accuracy and the constraints for the final results. However, in the field study, it was seen that in the case of not having sufficient data, it may be hazardous to develop training models. Seismic data acted better than the predicted VSP data, simply because the training models, which were developed with the data of one well, were not powerful enough for VSP prediction. This brought the importance of the amount of representative data that is used in training.

4. To determine the data that should be used for training, model visualization can be helpful. It was seen in the first correlation step of the synthetic model study that; including unique geological behaviors in the training set can increase the prediction abilities of the neural network models.

\subsection{Future Work}

The methodology presented here can be applied to a 3D seismic block, to obtain 3D distribution of reservoir properties through out the seismic survey area. The power of the methodology can be assessed by doing this on real data taken from a field having highquality well log and seismic data. The final reservoir model can be compared with models 
obtained with other conventional methods such as geostatistical estimation methods. This would give a better understanding of the accuracy of different methods. Reservoir models that are produced with different methods can be simulated and history-matched for a final validation.

The work can be furthered by using a comprehensive synthetic seismic data for network training, and trying to apply that network model to real data that the network has not seen before. This would assess the usefulness of incorporating synthetic models in reservoir characterization. Such kind of a study would be an important achievement, if satisfactory results are obtained.

Moreover, the number of types of data that are used can be increased. Although having a limited availability, one of the major type of data that can be incorporated is the core data, which has a higher resolution than others used in this study. Considering studies that use neural networks to correlate logs with core-permeability data, extending the study to the highest resolution of data available would help to complete the puzzle of intelligent reservoir characterization. 


\section{Bibliography}

[1] Nikravesh, M., Aminzadeh, F. (2001): 'Past, present and future intelligent reservoir characterization trends', Journal of Petroleum Science and Engineering, Vol. 31, pp.6779 .

[2] Hampson, D.P., Schuelke, J.S., and Quirein, J.A. (2001): 'Use of multiattribute transforms to predict log properties from seismic data', Geophysics, Vol. 66, No. 1, pp. 220236.

[3] Mohaghegh, S.D., Richardson, M., Ameri, S. (1998): 'Virtual magnetic imaging logs: generation of synthetic MRI logs from conventional well logs', paper SPE 51075, 1998 SPE Eastern Regional Meeting Proceedings, Nov. 9-11, Pittsburgh, Pennsylvania.

[4] Mohaghegh, S.D., Goddard, C.,Popa, A., Ameri, S., and Bhuiyan, M. (2000): 'Reservoir characterization through synthetic logs', paper SPE 65675, 2000 SPE Eastern Regional Meeting Proceedings, Oct. 17-19, Morgantown, West Virginia.

[5] Rolon, L. (2004): 'Developing intelligent synthetic logs: Application to Upper Devonian Units in PA', M.Sc. thesis, West Virginia University, Morgantown, West Virginia.

[6] Mohaghegh, S.D., Arefi, R., Ameri, S., and Rose, D. (1994): 'Design and development of an artificial neural network for estimation of formation permeability', SPE 28237, 1994 SPE Petroleum Computer Conference Proceedings, Jul. 31 - Aug. 3, Dallas, Texas.

[7] Arpat, G.B., Gumrah, F., Yeten, B. (1998): 'The neighborhood approach to prediction of permeability from wireline logs and limited core plug analysis data using backpropagation artificial neural networks', Journal of Petroleum Science and Engineering, Vol. 20 , pp. $1-8$.

[8] Weiss, W.W., Balch, R.S., Stubbs, B.S. (2002): 'How artificial intelligence methods can forecast oil production', paper SPE 75143, 2002 SPE/DOE Improved Oil Recovery Symposium Proceedings, April 13-17, Tulsa, Oklahoma.

[9] Barnes, A.E. (2001): 'Seismic attributes in your facies', CSEG Recorder, pp. 41-47, September, 2001.

[10] Leiphart, D.J., Hart, B.S. (2001): 'Comparison of linear regression and a probabilistic neural network to predict porosity from 3D seismic attributes in Lower Brushy Canyon channeled sansstones, southeast New Mexico', Geophysics, Vol. 66, No. 5, pp. 1349-1358. 
[11] Balch, R.S., Stubbs, B.S., Weiss, W.W., Wo, S. (1999): 'Using artificial intelligence to correlate multiple seismic attributes to reservoir properties', paper SPE 56733, 1999 SPE Annual Technical Conference and Exhibition Proceedings, Oct. 3-6, Houston, Texas.

[12] Chawathe, A., Ouenes, A., Weiss, W.W. (1997): 'Interwell property mapping using crosswell seismic attributes', paper SPE 38747, 1997 SPE Annual Technical Conference and Exhibition Proceedings, Oct. 5-8, San Antonio, Texas.

[13] Soto, B.R., Holditch, S.A. (1999): 'Development of reservoir characterization models using core, well log, and 3D seismic data and intelligent software', paper SPE 57457, 1999 SPE Eastern Regional Conference and Exhibition Proceedings, Oct. 21-22, Charleston, West Virginia.

[14] Reeves, S., Mohaghegh, S.D., Fairborn, J., and Luca, G. (2002): 'Feasibility assessment of a new approach for integrating multi-scale data for high-resolution reservoir characterization', paper SPE 77759, 2002 SPE Annual Technical Conference and Exhibition Proceedings, Sep. 29 - Oct. 2, San Antonio, Texas.

[15] Gadallah, M.R. (1994): 'Reservoir Seismology: Geophysics in Non-technical Language', PennWell Books, Tulsa, Oklahoma.

[16] Chen, Q., Sidney, S. (1997): 'Seismic attribute technology for reservoir forecasting and monitoring', The Leading Edge, Vol. 16, No. 5, pp. 445-448.

[17] Taner, M.T. (2001): 'Seismic Attributes', CSEG Recorder, pp. 48-56, September, 2001.

[18] Kingdom Suite software tutorial, Seismic Micro-Technology, Inc., Houston, Texas.

[19] Fausett, L. (1994): 'Fundamentals of Neural Networks: Architectures, Algorithms, and Applications', Prentice-Hall, Englewood Cliffs, New Jersey.

[20] Mohaghegh, S.D. (2000): 'Virtual intelligence applications in petroleum engineering - Part 1: Artificial neural networks', Journal of Petroleum Technology, Distinguished Author Series September 2000, pp 64-73.

[21] Specht, D. (1991): 'A general regression neural network', Vol. 2, No. 6, IEEE Transactions on Neural Networks, November, 1991.

[22] NeuroShell 2, Release 4.0 Tutorial, Ward Systems Group, Inc., Frederick, Maryland, 1993-1998.

[23] Microsoft Excel 2002 Help, Microsoft Corporation, 1985-2001.

[24] Sanchez, A.A. (2004): '3D seismic interpretation and synthetic modeling of the Atoka and Morrow formations, in the Buffalo Valley Field (Delaware Basin, New Mexico, Chaves County) for reservoir characterization using neural networks', M.Sc. thesis, West Virginia University, Morgantown, West Virginia. 
[25] Huang, Z., Williamson, M.A. (1994): 'Geological pattern recognition and modeling with a General Regression Neural Network', Canadian Journal of Exploration Geophysics, Vol. 30, No. 1, pp. 60-66.

[26] Luca, G. (2001); 'Towards high resolution reservoir characterization', M.Sc. Thesis, West Virginia University, Morgantown, West Virginia.

[27] Official web site of New Mexico Bureau of Geology and Mineral Resources; http://geoinfo.nmt.edu/resources/petroleum/poolmaps.html.

[28] Official web site of New Mexico Energy, Mineral and Natural Resources Department Oil Conservation Division; http://ocdimage.emnrd.state.nm.us/.

[29] Official web site of the New Mexico Tech Go-Tech; http://octane.nmt.edu/data/ongard/.

[30] Key Performance Indicators (KPI) module of Intelligent Reservoir Characterization $\&$ Analysis, IRCA. http://www.intelligentsolutionsinc.com/irca.htm. 